\title{
Conceptually Ambitious, Hardly Novel, and Currently Failing: The Irish Army Reserve in the Single Force Concept.
}

\section{Jonathan Carroll}

\begin{abstract}
In 2013 the Irish Defence Forces went under significant reorganisation. Part of this organisation entailed integrating the Irish Army Reserve into the Defence Forces, as part of the 'Single Force Concept'. Ostensibly, the Single Force Concept sought to provide a more reliable, fit for purpose, reserve force. However, this article argues that the concept has failed and that the Army Reserve is almost unusable. The article evaluates each service corps and provides an analysis of Reserve capabilities. This shows that the training of the force is suboptimal for augmenting the regular army in an emergency, and that a gap exists between what government policy wants the Reserve to do, and what it is actually capable of doing. This has resulted in an unusable reserve force with questionable utility. This article also highlights the difficulty of establishing the qualitative strength of the Army Reserve in the absence of appropriate means of defining what is meant by an 'effective' reservist, and explores the detrimental consequences of paltry financial investment in sustaining, developing, or enabling the Reserve as an effective force. It argues that the Single Force Concept has failed because it did not remedy the fundamental pre-existing flaws that plagued the various iterations of the Irish reserve land component prior to 2013, nor did it attempt to bring the Army Reserve into line with international best practice regarding reserve forces. The article concludes by arguing that the current Irish reserve model is unsustainable, and that fundamental changes are required in order to make the force usable to the State, and to prevent it from collapsing altogether.
\end{abstract}

The Single Force Concept, introduced by the Irish Defence Forces in 2013, is failing. ${ }^{1}$ The concept resulted in the integration of the Army Reserve into the force structure of the regular army, with the aim of providing a "reliable, fit for purpose" Reserve. ${ }^{2}$ Six years on, the Army Reserve in the Single Force Concept is at a record low; numerically and proportionally. This paper contends that the Single Force Concept was flawed conceptually, and that it has failed. Furthermore, it argues that the current Army Reserve model is unsustainable, with the force on the brink of collapse. The Concept failed to bring about positive and meaningful change because it failed to address the historical issues confronting the Army Reserve directly relating to reliability, and viability, making a "fit for purpose" reserve force inherently problematic. The initiative itself was ambitious in its assignment of ends, but fundamentally ignored the provision of ways and means. The Single Force Concept was also hardly novel, as a similar initiative had previously been attempted. This also resulted in failure. This article examines the Single Force Concept and argues the reasons for its failure. It will briefly address the history of the Army Reserve and its evolution prior to the introduction of the Single Force Concept. It will then examine the role, structure and employment of 
the Army Reserve, and the legislative framework within which the Reserve operates, to identify key challenges today and to analyse and explain the shortcomings of the Single Force Concept. This article will demonstrate that the Concept failed, because it failed to meaningfully change a model for the Army Reserve that was categorically unsuited to the needs of the Defence Forces or of the state, and that sees the Reserve in apparently inexorable decline in terms of size, relevance, and utility.

\section{The FCA, 1946-2005.}

In 1946, An Forsa Cosanta Aitiul, the FCA, was created as an independent, reserve volunteer local defence force of 60,000 personnel. $^{3}$ In the 1950 s, the Irish Permanent Defence Forces (PDF) was suffering a personnel shortage due to poor pay and was seemingly unable to maintain its full-strength establishment. ${ }^{4}$ This, combined with a resurgence of Irish Republican Army (IRA) activity along the border with Northern Ireland, forced a reorganisation of the Defence Forces. To create a credible military force, and to shore up the shorthanded PDF, the then 25,000 strong volunteer FCA was integrated into the PDF in $1959 . .^{5}$ This allowed the Irish Army to boast six "integrated" brigades made up of part-time FCA and full-time PDF personnel. Integration transformed the operation of FCA units, placing them under the command of PDF officers, with attached training cadres. ${ }^{6}$ Integration was not uniformly implemented across the spectrum. In all cases FCA and PDF infantry did not serve in mixed units. Infantry battalions remained segregated. Artillery units were integrated, with artillery regiments made up of FCA and PDF batteries. Interestingly, in three of the six brigades, support and logistics units were entirely staffed by FCA personnel. ${ }^{7}$ Beginning in 1969, the FCA provided garrison duties for the PDF, while three new infantry battalions were established to secure the border with Northern Ireland due to the increasing violence of the Troubles (1969-1998). This resulted in the formation of the $27^{\text {th }}, 28^{\text {th }}$ and $29^{\text {th }}$ PDF Infantry Battalions. ${ }^{8}$ However, integration put severe stress on FCA personnel. The expectation of measuring up to the PDF meant that reservists were parading three times a week, and attrition was high. ${ }^{9}$ By 1978, the FCA effective strength was 15,000, out of an establishment of 22,000. In this condition it was argued that the FCA was unable to support the PDF. Also, it was estimated that the security environment with Northern Ireland had stabilized sufficiently for the PDF to handle alone, making continued integration with the FCA unnecessary. With PDF units up to strength and modernized out of necessity for United Nations peace support missions, FCA integration ended in $1979 .{ }^{10}$

After separation in 1979, the FCA had a revised organisational establishment of 22,110 . Though a large force (by Irish standards) on paper, this belied the actual number of active reservists. Quantifying the actual strength of the FCA was problematic due to the nature of reserve service in Ireland. FCA members were parttime volunteers, attending unpaid training one evening a week, occasional weekends, and periods of paid full-time training for one to two weeks during the summer months. ${ }^{11}$ No legislative framework existed to protect reservists' civilian employment while training. ${ }^{12}$ Consequently, FCA personnel were more beholden to their employer than the Defence Forces. Just as the force dwindled from 60,000 in 1946 to 15,000 in 
1978, the decline continued until 2005, when the effective strength of the FCA was recorded as $12,652 .{ }^{13}$ Reform was needed.

\section{The Army Reserve, 2005-2013.}

In 1999, just prior to Ireland's first White Paper on Defence, a governmental study analysed the strengths and weaknesses of the FCA. The Report of the Steering Group on the special study of the Reserve Defence Force made several sweeping recommendations argued as being critical to the successful retention and development of an effective reserve force ${ }^{14}$ Firstly, the FCA needed to be reorganised, and given a clear role to provide direction, and a rationale, for training. Interoperability between reserve and regular forces needed to improve through better equipment, training and financial investment. The report also advocated for the future deployment of reservists on overseas missions. ${ }^{15}$

Instead of the 22,110 strong FCA, a reduced organisation of 11,948 was proposed, encompassing two elements. ${ }^{16}$ The main element, 9,292 strong, would comprise traditional reserve units, like those of the FCA, although renumbered and redesignated. It was proposed that another 2,656 reservists should be integrated directly into PDF units. ${ }^{17}$ To combat the issue of personnel retention, the report recommended the annual gratuity, paid to reservists who achieved annual training benchmarks, be increased significantly, and formal engagement with employers should commence to facilitate reservists being released for training. ${ }^{18}$ The Department of Defence adopted many, but not all, of the recommendations. Financial incentives were increased, and the proposed main reserve element of 9,292 personnel was authorised. However, the key legislative framework facilitating reserve service, employment protection, was not addressed, nor were there any meaningful attempts at employer engagement. Thus, the organisation changed cosmetically, but the underlying problems of personnel retention remained

The reorganised, and renamed, Army Reserve was launched in 2005. FCA units were disbanded, and their personnel amalgamated into new Army Reserve units. Each reserve unit was twinned with a sister PDF unit (See Annex B) to facilitate improved training and interoperability in a force structure mirroring that of the PDF. ${ }^{19}$ At its launch, then Minister for Defence Willie O'Dea stated that "we will ensure that the new Reserve will be as good as - if not better than - other Reserve Forces throughout the world. It is true to say that the Permanent Defence Force is a world-class organisation and I can see no reason why the same will not apply to the Reserve." 20 Nonetheless, from its inception, the Army Reserve suffered the same strength issues of the FCA, with personnel numbers continually declining from year to year.

While not being formally adopted in the 2005 reorganisation, some attempts were made to give life to the concept of the integrated force of 2,656 reservists. Despite enthusiastic efforts, this integrated force was unsuccessful. A pilot integration program was run from 2007 to 2008 whereby serving reservists were attached to, and 
trained by, PDF units. Integration was not adopted by every unit, and, as a concept, differed from unit to unit. Integration training required reservists to commit to three years of an increased training schedule to raise the standards of training, interoperability and reserve capabilities. The response to the extra time obligations and the inherent difficulties of a three-year consecutive commitment was poor. For example, the $2^{\text {nd }}$ Artillery Regiment had just two volunteers for the program, the $4^{\text {th }}$ Artillery Regiment lost most of its integrated personnel after one year as reservists could not maintain the consecutive annual commitment, and the $4^{\text {th }}$ and $5^{\text {th }}$ Infantry Battalions received low numbers of volunteers. ${ }^{21}$

\section{The Single Force Concept, 2013-Present.}

Like many militaries in the European Union, the Irish Defence Forces suffered in the economic crisis that began in 2008. A moratorium on reserve recruitment was enforced. When lifted, recruitment was strictly curtailed. By 2012, the Army Reserve had just 4,300 personnel. None of the nine reserve infantry battalions mustered above 50 percent strength. ${ }^{22}$ Another government review was commissioned. The 2012 Value for Money Review of the Reserve Defence Forces (VFM) recommended that the Army Reserve be reorganised downwards to just 3,869 personnel, and that the annual gratuity for training achievement be removed, as a cost-saving measure. In 2013, the VFM recommendations were included in a major reorganisation of the Irish Defence Forces. While the Naval Service and the Air Corps were affected, the Army underwent significant change. Reduced from three brigades to two, with barrack closures and the amalgamation of units, the Army had an additional challenge to surmount, the absorption of reservists into regular units. Unlike the 2005 twinned unit reorganisation, while the force was reduced in line with the VFM, the Army Reserve was also integrated directly into the PDF force structure. This amalgamation was called the "Single Force Concept" (see Annex C). Army Reserve units were disbanded in 2013 and reserve personnel were integrated into PDF units depending on service corps. Each PDF infantry battalion absorbed three to four companies of reservists, and artillery regiments added two reserve batteries to their establishment. Company sized PDF units, such as transport, cavalry or engineers, integrated reservists in platoon strength. Reservists now served under the command of a PDF unit commander, as part of a PDF unit; albeit on a part-time basis. The objective of the Single Force Concept was, and ostensibly still is, to provide a "reliable, fit for purpose" Army Reserve. ${ }^{23}$ However, in the spirit of the old adage of "the more things change," the Single Force Concept failed to tackle any of the real issues that directly effecting the utilisation of the Army Reserve as a viable reserve force.

\section{The Law and Deployability.}

Legislatively speaking, the Army Reserve is in a twilight zone; it exists, but its utilisation is not legally supported. The existing legislative framework does not enable deployment of the Army Reserve in the case of an emergency, for overseas service or even for individual reservists. For some, this represents the greatest strategic 
weakness of the Reserve. ${ }^{24}$ After all, for many Western nations, large standing armies are a distant memory. Many militaries prefer having a dependable reserve component that caters to supplying critical skills, and to providing a short-notice surge of personnel. For the Irish Army Reserve the principle legislation is the Defence Act 1954. It states that reservists can be called up by the Minister of Defence in a "state of emergency," or for the "restoration of the public peace." 25 Therefore, there is a legislative mechanism justifying the deployment of the Reserve for large-scale emergencies, but there are several problems with it, unresolved by the Single Force Concept.

The 1954 Act does not facilitate scenarios where skilled individual reservists are required instead of a full-force deployment. More of an issue is the lack of either coercive or incentivising measures to ensure that reservists report for duty if called up. There is no realistic punishment for not reporting for duty. Section 118 of 1954 Act states that reservists, unlike members of the PDF, are only under military law whilst in uniform. Moreover, section 243 states that if a reservist fails to report for duty they can be charged with desertion or being absent without leave. This only incurs a modest monetary fine, not custodial punishment. But, even if a reservist commits this offence, they must present themselves, in uniform, to be charged. Therefore, theoretically, if an individual simply does not present themselves they will not be punished. ${ }^{26}$

Another legal problem is that there is no employment protection legislation, guaranteeing a reservists' civilian employment while called up for military service, nor is a reservists' civilian employer legally obligated to release them for military service. Resultantly, while the Defence Act 1954 lays out the circumstances for the deployment of the Reserve, the actual practicalities of making this happen are absent. This means that the Defence Forces depends entirely on the goodwill of the individual reservist and their employer for the provision of reserve capabilities. Consider this hypothetical example; a weather-related contingency in Donegal requires the timely deployment of reserve personnel to assist relief efforts. Reservists in Cork cannot obtain leave from their employers due to the lack of geographical proximity to the emergency. A conflict of interest is now created between a reservists' military obligations and their civilian employment. What will the reservist choose to do? Obey their employer, who pays their salary and influences their career prospects, or the Defence Forces which provides neither adequate financial remuneration, nor job protection? While the gravity of an emergency may influence some to dutifully don the uniform, realistically, many reservists, while loyal to their oaths of enlistment and undoubtedly willing to serve, will make the pragmatic choice of not risking their livelihoods. This is not a new development, it has been like this since the creation of the FCA, and the enactment of the Defence Act 1954, 66 years ago. Yet, the Single Force Concept in no way addressed the glaringly obvious problem. 


\section{Employer Engagement.}

Where operations in the domestic setting are concerned, employer engagement could potentially make a difference for the better. Moves in this direction have been put forward since 1999 with calls for the engagement of reservists' employers to facilitate their release from work commitments to attend military training. ${ }^{27}$ However, legislating such an arrangement, to guarantee cooperation, has not been suggested. The only output of employer engagement thus far is the Reserve Defence Forces Employer Information Booklet, published in 2016. This merely encourages employers to look kindly on reservists by granting annual or unpaid leave to attend training. Without legislation though, this amounts to no more than a suboptimal plea for cooperation, which remains entirely at the discretion of the employer. A serious omission in the booklet is that no mention is made of the possibility of reservists being called up in an emergency, or that a uniquely skilled reservist might be required by the Defence Forces for an extended period due to their expertise. ${ }^{28}$

Employment protection legislation would clearly be a force enabler for the Army Reserve. However, some argue that such legislation is a "double edged sword" as employers may choose not to hire reservists due to their potential military obligations. ${ }^{29}$ Supporting this view is the fact that, despite Ireland's anti-discrimination laws, workplace discrimination, based on gender for example, still occurs. ${ }^{30}$ However, while discrimination does still occur, employment protection legislation would only cater to the miniscule figure of 3,869 personnel in the Army Reserve. Given this small number, cases of reservist employment discrimination are either unlikely or limited to a very few personnel. On balance, the decision comes down to choosing between having a deployable Reserve with the risk of a few instances of discrimination - which can be dealt with legally - or having an undeployable Reserve in favour of avoiding workplace discrimination altogether.

It has been argued that there is no need to amend legislation because there has never been the need to deploy the Reserve. ${ }^{31}$ This justification is not grounded in fact. There were large FCA deployments for garrison duties across the country, and to the border with Northern Ireland during the Troubles in the 1960s, and smaller regional deployments also occurred during the 2015 Shannon flooding, not to mention future unknown contingencies arising from Brexit. ${ }^{32}$ The double-edged sword cuts both ways, as the government and Defence Forces are deterred from using the Reserve because reservists can simply choose not to report for duty. ${ }^{33}$

\section{Overseas Deployment.}

The most practical application of specialist reserve skills in modern militaries is overseas deployments. The suggestion of sending suitably qualified individual reservists overseas has been made repeatedly in policy documents and reports over the past two decades. ${ }^{34}$ However, the deployment of reservists overseas is currently illegal. All legislation pertaining to overseas service specifically states it is for members of the "Permanent Defence Forces." 35 Internationally, the benefit of using reserve 
forces overseas has been clearly demonstrated by their extensive use by British and American forces in Iraq and Afghanistan. For the Defence Forces, PDF personnel serving in Lebanon have also been exposed for many years to working alongside Finnish reservists. As such, the Defence Forces is operating in an environment where the utility of reservists overseas has been clearly established.

In 2009, a training syllabus was developed for reservists to deploy to Kosovo with the NATO KFOR mission, the two-month upskilling RDF Overseas Integration Course. The Defence Forces sought reservists with civilian specialisations such as doctors, engineers, medics, drivers, tradesmen and radio operators. As mentioned, the first obstacle to reservists deploying overseas is legislative. To circumvent this, reservists were to be enlisted into the PDF on a short one-year contract, thus legalising their deployment. Problematically, this contract hoped to obtain the services of professional specialists for the lowest cost possible. Suitable reservists who applied, regardless of their Reserve rank, were to be enlisted into the PDF at the rank of 2-Star Private and paid the equivalent wage. Perhaps unsurprisingly, offering doctors and engineers a salary slightly above that of a recruit yielded few volunteers. Compounding the problem, no mention or facility was made for employment protection. ${ }^{36}$ This meant that reservists in this overseas initiative would have had no jobs waiting for them after their enlistment term ended. Ultimately, this failed initiative was overtaken by events, and plans to send reservists overseas were shelved due to the financial crisis. Some senior officers within the Defence Forces have criticized this legal twilight zone, calling it "completely outdated" and "farcical" compared to international best practice. ${ }^{37}$

\begin{tabular}{|l|l|l|l|l|l|l|}
\hline & Ireland & $\begin{array}{l}\text { New } \\
\text { Zealand }\end{array}$ & Australia & Canada & UK & $\begin{array}{l}\text { United } \\
\text { States }^{38}\end{array}$ \\
\hline Defence Acts & Yes & Yes & Yes & Yes & Yes & Yes \\
\hline $\begin{array}{l}\text { Legislative Enablers for } \\
\text { Reserve Forces }\end{array}$ & No & Yes & Yes & Yes & Yes & Yes \\
\hline $\begin{array}{l}\text { Integration with } \\
\text { Regular Forces }\end{array}$ & Yes & Yes & Yes & Yes & Yes & No \\
\hline Employment Protection & No & Yes & Yes & Yes & Yes & Yes \\
\hline $\begin{array}{l}\text { Voluntary “Unpaid” } \\
\text { Service }\end{array}$ & Yes & No & No & No & No & No \\
\hline Deployment Overseas & No & Yes & Yes & Yes & Yes & Yes \\
\hline
\end{tabular}

The legal framework for the Irish Army Reserve, as mentioned, has neither a coercive, nor an incentivising effect on reservist commitment. This is an anomaly compared to other armed forces' reserve components. Legislation in New Zealand, Canada, Australia, the United Kingdom and the United States guarantees a reservists' 
employment if deployed. ${ }^{39}$ Resultantly, the crisis of decision between choosing duty, and one's career is removed. Failure to report for duty can also result in imprisonment. ${ }^{40}$ There is no "voluntary unpaid training," as all reserve service is paid, and in some cases pensionable. ${ }^{41}$ The Irish Army Reserve, by comparison, has none of these enablers. The Irish Army Reserve is legislatively out of step with international best practice where many other nations have a usable and reliable reserve component to call upon. The Single Force Concept sought to create a reliable, fit for purpose Army Reserve. With no legislative reform, the Army Reserve is still not reliable, and existing legislation is clearly not fit for purpose.

\section{The Role of the Army Reserve in the Single Force Concept.}

The 2015 White Paper set out the primary task of the Army Reserve as augmenting the PDF in a crisis, contributing to conventional defence, garrison duties and to carry out state ceremonial tasks. ${ }^{42}$ Providing support for Aid to Civil Authority (ATCA) and Aid to Civil Power (ATCP) operations are secondary roles. ${ }^{43}$ ATCA involves providing personnel for relief operations during emergencies such as flooding, forest fires, tasks not requiring personnel to be armed. ${ }^{44}$ ATCP is defined as providing armed support to the Irish Government for cash, ordnance, and prisoner escorts and Explosive Ordnance Disposal teams (EOD), or any task short of conventional warfare to ensure the internal security of the state. ${ }^{45}$ This role was defined during the White Paper preparation process, after an examination of what capabilities the Defence Forces required up to $2025 .{ }^{46}$ It was found that the Reserve could contribute to ATCA tasks, but required additional area specific training to be competent in ATCP operations. ${ }^{47}$ This examination also concluded that limited conventional warfighting, or overseas service on peace support operations (PSO) was beyond the capabilities of the Reserve. ${ }^{48}$ This, seemingly unambiguous, role of Reserve in the Single Force Concept, is ambiguous and problematic for several reasons. The suggestion that in a crisis the Army Reserve could be used for ATCP tasks or conventional defence is undermined considering this examination of Reserve capabilities concluded that ATCP operations, and conventional military tasks, were beyond the Army Reserve. This raises the question, why, after this examination, was the stated role defined as it was?

In the case of ATCP operations, the issue is that Army Reserve training syllabi do not include any instruction in ATCP operations. ${ }^{49}$ Instead, these syllabi focus on conventional warfighting, a task stated to be beyond the Reserve. Reserve personnel are not utilised in ATCP tasks as they are not considered interoperable with their PDF counterparts, and no experience in these tasks is gained. As for the ATCA role, it was envisaged, at the outset of the Single Force Concept, that the Army Reserve would not be needed for ATCA tasks for two reasons. Firstly, the White Paper suggested that the Civil Defence, the volunteer organisation augmenting Ireland's emergency services, could provide ATCA support when needed, with the added benefit of being no cost to the State. Hence, why the Reserve had not been called upon previously. The second reason was a belief that local authorities would have the organic capacity to deal with 
any incidents that arose, without needing the support of the Defence Forces, let alone the Army Reserve. ${ }^{50}$

These assertions, that the Civil Defence could handle any ATCA requirement, and that local authorities would have organic capacity were proven false when the River Shannon burst its banks in 2015. Local authorities, under strain, called the Civil Defence. The cost neutrality of the Civil Defence, seen as a benefit by the government, was its Achilles heel. Very quickly after being deployed, the unpaid Civil Defence volunteers had to return to their civilian employments for financial reasons. The next call went to the PDF. Sufficient numbers of personnel were unavailable due to operational commitments. The Defence Forces then called upon the Reserve. ${ }^{51}$ In the context of the Army Reserve, the White Paper was undone by a river. Reservists from several units deployed in the flood relief efforts. ${ }^{52}$ While paid for their service, only reservists whose personal circumstances allowed their deployment were involved, again highlighting the inadequate legislative support. ${ }^{53}$ Considering that the local authorities, the Civil Defence and the PDF could only provide a limited response before calling the Reserve, with participation limited to reservists whose employment circumstances allowed them to do so, a relatively benign incident could have been a lot worse.

Debate surrounds the stated role of the Army Reserve. Some quarters claim it is ambiguous, that clarity is needed, especially relating to what constitutes a "crisis." Others argue that the White Paper clearly states the role, thus it is unambiguous. ${ }^{54}$ While elaboration on the meaning of "crisis" is perhaps unnecessary, there is clearly a disconnect between what Irish defence policy wants the Reserve to do, and what the Reserve is capable of realistically delivering, either because of opinion or design. Thus far, the Reserve has proven it can contribute in an ATCA role, albeit in limited numbers. However, with ATCP tasks and conventional defence off the table, the result is that the Army Reserve, trained overwhelmingly for conventional military operations as will be shown subsequently, can only handle weather related emergencies and state ceremonial taskings from its defined roles.

In 1999 it was argued that a clearer role, defining the raison d'etre of the Reserve was needed. ${ }^{55}$ The 2000 White Paper reiterated this suggestion, whilst failing to deliver on it. ${ }^{56}$ The 2015 White Paper compounded the problem in its ascribing of roles for which policy clearly does not reflect reality. This is a glaring omission given the advent of the Single Force Concept, where the goal is a reliable, fit for purpose Reserve, where reservists have the potential to gain experience, imparted from PDF personnel they serve alongside. The problem is, what purpose is the Reserve supposed to be fit for? The participation of the Army Reserve in the 2015 Shannon flooding disproved statements in the White Paper and the VFM Review which argued no operational requirement existed to expand the defined role of the Reserve, as all needs were being met by the PDF ${ }^{57}$ If ATCA support, the Army Reserve's only realistic operational output, apart from possible garrison duties or military ceremonies, can be met by the Civil Defence, duration dependent, there are some serious issues. 
The goal of reserve training is to provide the Army Reserve with a foundation that can be built upon in an emergency. ${ }^{58}$ ATCP training has been described as another module that can be acquired relatively quickly. ${ }^{59}$ In the case of an emergency however, the PDF would have to provide this additional training and there is the question of whether the PDF would have the resources to do this, or the time. ${ }^{60}$ The current personnel retention crisis in the wider Defence Forces exacerbates this problem. If ATCP proficiency can be acquired relatively quickly, it would be more logical to instead focus Reserve training on ATCP, not conventional warfare, especially as the latter is beyond the Reserve's capabilities and overseas service is legally prohibited. The Single Force Concept is an ideal environment for the PDF to impart, and for reservists to develop, such skills. This would allow for the broadest possible utilisation of reserve personnel in whatever contingency that arises, and to allow the Reserve to fulfil a stated role.

Consider another hypothetical example; there are at least 208 border crossings between Northern Ireland and the Republic of Ireland. ${ }^{61}$ There is now a possibility that some form of border with Northern Ireland may be re-established due to Brexit. Securing it would fall under the category of an ATCP operation, yet the Army Reserve, in the main is not trained for or utilised in ATCP operations. ${ }^{62}$ If each of these crossings was manned by four personnel for a 24-hour duty, at least 832 personnel are needed. If they are manned in two twelve-hour shifts, or three eight-hour this requires, 1,664 or 2,496 personnel respectively. This is roughly equivalent to a quarter, or a third of the PDF, not counting the personnel required to support such an operation. Factoring in overseas deployments, recruits in training, and those who manage the administration of the Defence Forces itself, securing the border would cause severe personnel attrition to the PDF. The Army Reserve would be needed to make up the numbers, and the training and role of the Reserve in the Single Force Concept should reflect this reality. There is a precedent supporting this. When the Troubles in Northern Ireland began in 1969 the PDF was twice its current size and facing a retention crisis; many battalions had only 100 personnel. ${ }^{63}$ The FCA was deployed not only for garrison duties but for border security while the PDF established three infantry battalions to adequately secure the border with Northern Ireland. ${ }^{64}$

When theorising about deployment, the usual response put forward is that the Army Reserve is in fact the "second line reserve" and that, in an emergency, the First Line Reserve (FLR) made up of retired PDF personnel would be called upon first. ${ }^{65}$ However, the FLR has not trained meaningfully since $1987 .{ }^{66}$ At that time the FLR had 856 personnel. ${ }^{67}$ In 2015, there was just 240 personnel, a record low. ${ }^{68}$ And in 2019, it was acknowledged that the FLR was limited to providing specialists to fill gaps in the Naval Service and the Air Corps, not the Army. ${ }^{69}$ This makes the Army Reserve the de facto First Line Reserve simply due to numbers and regular training. As such, the role of the Reserve needs to reflect the reality of what it can deliver, with training to match. That is, in the context of the current lack of legislative support the Reserve exists within. This raises the next question, what can reservists do? 


\section{Operational Viability and Interoperability.}

The legislative situation surrounding the Reserve is certainly its greatest strategic weakness, unchanged in the Single Force Concept. The stated role is also, problematic. But how do reservists in the various service corps of the Army match up against their regular counterparts? This would indicate whether the "fit for purpose" goal of the Single Force Concept has been achieved in terms of interoperability and operational viability. Given the Reserves' lack of deployment it is hard to qualify capability in an operational setting. However, much can be inferred from the opinions of PDF unit commanders across the corps spectrum in terms of skill attainment and the exercise performance of reservists. The central issue at hand here is whether, in the single Force Concept, the reserve contingents of the various service corps can support their PDF counterparts in an emergency. The Single Force Concept was enacted to improve interoperability between the PDF and Army Reserve..$^{70}$ In some areas this appears to be working, in others it is not. In some corps, the Reserve is focused on conventional warfare, to the detriment of interoperability. In the specialised corps the utilisation of reserve skills has resulted in increased interoperability and operational viability and showcases the tangible potential of elements of the Army Reserve.

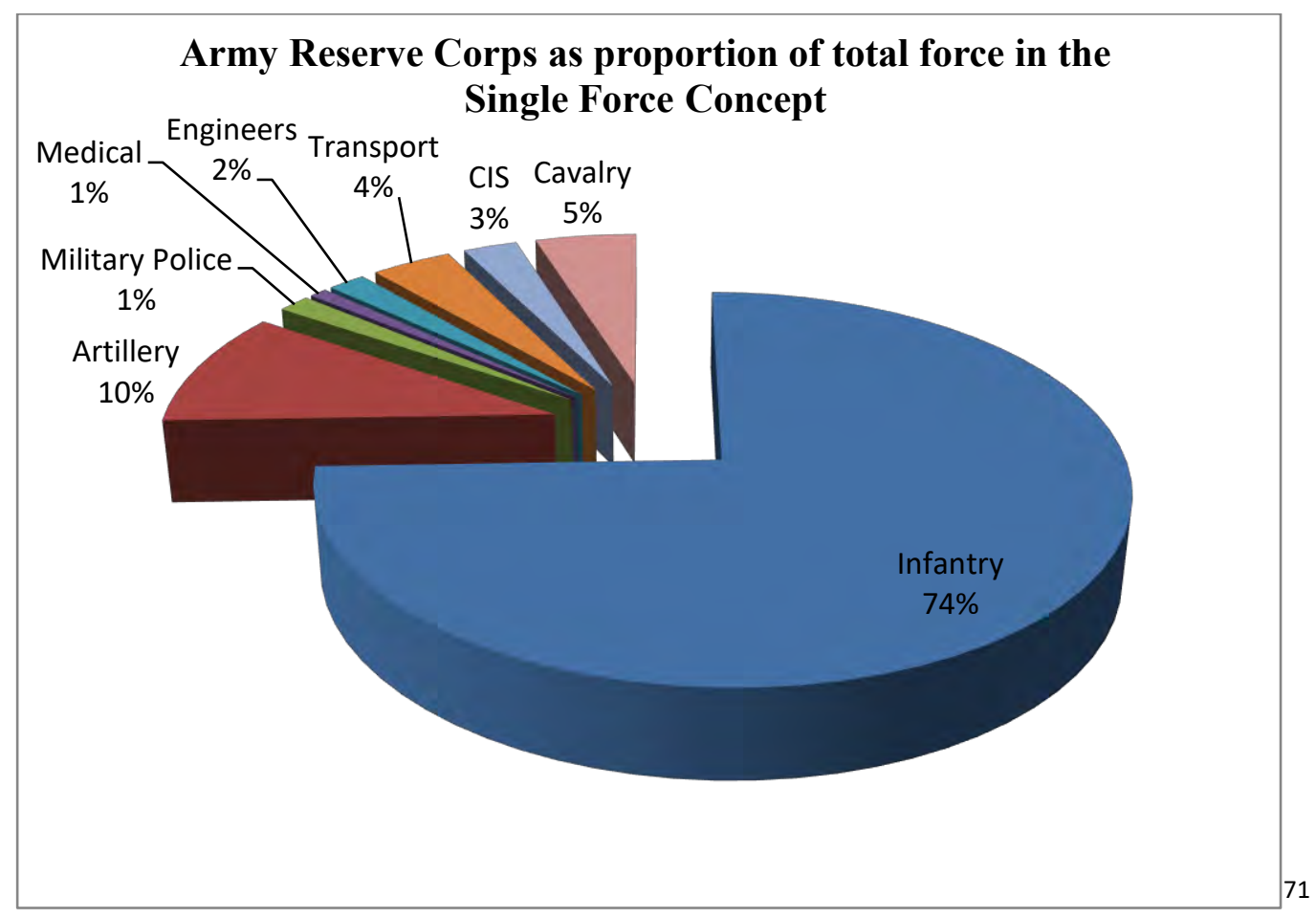

\section{The Infantry Corps.}

74 percent of the Army Reserve is in the Infantry Corps, 2,804 personnel if at full establishment. ${ }^{72}$ In the Single Force Concept, each PDF infantry battalion includes 
three or four reserve companies. All reservists, on enlisting, complete infantry recruit induction, followed by a 2-3 Star Private course. ${ }^{73}$ Therefore, all reserve personnel have a foundation in infantry training regardless of their specific service corps. The VFM Review argued that a PDF and Reserve 3-Star Private are not equal for several reasons, including disparities in experience, training courses undertaken, and time served. ${ }^{74}$ A PDF Private will be trained in chemical, biological, radiation and nuclear (CBRN) drills, helicopter operations, internal security, un-armed combat and communications systems as standard. ${ }^{75}$ PDF infantry are utilised in a variety of tasks both in Ireland and overseas. They provide ATCA support in weather related contingencies. ${ }^{76}$ In an ATCP role they provide armed support to An Garda Siochana, security for ordnance and cash escorts, and accompany Explosive Ordnance Disposal (EOD) teams. ${ }^{77}$ PDF personnel also train to take over Irish prisons in the event of a strike, provide crowd riot control (CRC) in support of the Gardaí and provide armed security at Portlaoise Prison. ${ }^{78}$

None of these areas are covered in reserve training syllabi for recruits and privates due to the required time commitment for training. There are other infantry training courses open to reservists, but many are scaled down PDF courses allowing delivery in a timeframe feasible for a reservist who can commit, on average, two full time weeks per year and several weekends. ${ }^{79}$ This creates a clear disparity in capability, effecting the utility of reserve infantry. While some reservists have been trained in CRC, a scenario where they would be needed has not been envisaged. ${ }^{80}$ Such a scenario would require timely mustering and deployment of reservists in large numbers. As mentioned, the mechanism exists, but is unworkable practically.

It is acknowledged that reservists are capable and interoperable with PDF personnel in tactical exercises. And, while heavy weapons training courses for reservists are of a shorter duration this, in the opinion of some officers, qualifies reservists to the same standards to use such weaponry. ${ }^{81}$ This does not mean that PDF and reserve personnel are equally qualified, as there is the obvious significant experiential disparity. This suggests reserve infantry units do have some tactical utility in addition to contributing to ATCA tasks in weather related contingencies such as the 2015 Shannon flooding, but remain unable to support the large amount of practical ATCP tasks which primarily occupy their PDF counterparts.

\section{The Artillery Corps.}

In their specialist role, the Artillery Corps provides indirect fire support and air defence assets to the Irish Army in the form of anti-aircraft weapons, ground radar, heavy mortars and light artillery with $105 \mathrm{~mm}$ light howitzers. ${ }^{82}$ Artillery regiments also provide PDF personnel to ATCP tasks and ATCA operations. ${ }^{83}$ In the Single Force Concept each PDF artillery regiment includes two reserve batteries. In contrast to the infantry, the reserve artillery component has been described by many PDF officers as the only element of the Reserve to come close to meeting, or exceeding, the professional standard of the PDF in its conventional military role. ${ }^{84}$ The practical utilisation of artillery pieces is a technical process coupled with a high risk of death or 
injury in the event of malpractice whilst firing high explosive shells. ${ }^{85}$ Artillery training courses for reservists are PDF courses run over a longer period instead of being dumbed down, thus they are equally qualified. ${ }^{86}$

It has been remarked that since the FCA, the reserve and regular artillery regiments have had a continuing close working relationship that stems from a skill set that is a tangible universal metric, attainable by reservists. ${ }^{87}$ In many firing exercises, past and present, gun crews are a mix of PDF and reserve personnel, a practice that seems to pay off in terms of interoperability. ${ }^{88}$ Furthermore, reservists with civilian skills such as surveying are used to carry out regimental surveys for artillery batteries in exercises, and reservists are used extensively as instructors on artillery courses for regular and reserve personnel. ${ }^{89}$ And, in contrast with other corps, where there are areas that reserve personnel are deemed unsuitable for, the belief exists that reserve personnel are capable of operating proficiently in any area of the Artillery Corps. ${ }^{90}$

\section{The Cavalry Corps.}

The Cavalry Corps is the mechanised arm of the Irish Army, organised into three cavalry squadrons, with each having two troops of reservists. ${ }^{91}$ Cavalry units also provide personnel for ATCA and ATCP tasks. ${ }^{92}$ Cavalry units specialise in dismounted reconnaissance, and utilising armoured vehicles such as the Mowag Piranha and the Scorpion. ${ }^{93}$ PDF personnel train in driving, commanding and deploying from the armoured vehicles, combat tracking, vehicle gunnery, and reconnaissance techniques. ${ }^{94}$ Reserve cavalry personnel receive a mix of modularised PDF training courses and some shortened courses tailored for reservists. ${ }^{95}$ Consequently, reserve personnel are considered by some unit commanders as interoperable with the PDF in terms of basic reconnaissance, and have been used successfully in integrated exercises. ${ }^{96}$ Reserve cavalry personnel are trained as light reconnaissance troops. The main difference is that reserve personnel, in the main, are not trained in armoured vehicle driving or vehicle gunnery. ${ }^{97}$ Reservists are not disqualified from doing a Mowag Crewman's Course per se, but the length of the course, and the prerequisite of a truck driving licence limits eligible reserve candidates. ${ }^{98}$ Furthermore, PDF personnel are prioritised on training courses as they are required for service overseas. As such there are rarely spaces on the courses for reserve personnel, even if they could meet the significant time commitment. ${ }^{99}$ Therefore, it is suggested that reserve cavalry personnel are tactically interoperable and operationally viable in terms of a light, dismounted, reconnaissance role with the future potential capability of vehicle gunnery skills.

\section{The Transport Corps.}

The reserve transport element can carry out most tasks the PDF Transport Corps engages in. The Defence Forces Driver Training Policy sets out that the driving standard, for both RDF and PDF personnel, is the same. ${ }^{100}$ Also, unlike the shortened reserve courses in other corps, the Transport Corps driving courses are identical for both reservists and regular personnel, making them interchangeable in terms of 
vehicular competency. ${ }^{101}$ There are caveats though. Reservists cannot carry out mechanical vehicle maintenance, despite a shortage of qualified mechanics in the PDF, and the likelihood that qualified mechanics serve within the ranks of the Reserve. ${ }^{102}$ Operationally, transport reservists are utilised in heavy lift platoons, VIP transport and in an ATCA role providing transport capability, such as during the 2015 Shannon floods. ${ }^{103}$ Furthermore, reservists are used as instructors on all vehicles, instructing both reserve and PDF personnel. ${ }^{104}$ That the key skill in the Transport Corps is of a universal standard for both reserve and regular personnel means that for a majority of transport related tasks reserve personnel are operationally viable and interoperable with the PDF.

\section{The Military Police Corps.}

The reserve military police (MP) element is made up of a provost platoon in each military police company, enjoying a level of limited operational viability and interoperability. The Military Police Corps is responsible for the investigation of crime within the Defence Forces, the enforcement of military law, traffic control and state ceremonial events. ${ }^{105}$ Military police provide security to Government Buildings and the Central Bank of Ireland on an ongoing basis. ${ }^{106}$ Reserve personnel are not utilised in this role, nor are they qualified military investigators due to the length of the qualifying course and the need for continuous application of investigative skills and experience that the part-time nature of reserve service makes unachievable. ${ }^{107}$ For other tasks such as traffic control, the 24-hour brigade mobile patrol, the enforcement of military law and ceremonial events reserve personnel are used effectively. ${ }^{108}$ Reserve military police have the power of arrest over PDF personnel, and with the exception of investigative skills, are considered by some as equally capable of enforcing military law, albeit on a part-time basis. ${ }^{109}$

\section{The Communications, Information Systems (CIS) Corps.}

The PDF Communications, Information Systems Corps (CIS), maintains the communications and IT equipment of the Defence Forces. ${ }^{110}$ PDF personnel staff the communications centre (COMCEN) in each military facility. ${ }^{111}$ Operationally, or during an emergency, the CIS Corps manages and maintains the communications network between Defence Forces Headquarters and units through the use of field deployable C1 (Communications) and C2 (Command and Control) containers. ${ }^{112}$ Reserve personnel cannot man the COMCEN as they lack the requisite security clearance. They are also precluded from qualifying as an equipment technician, despite a shortage of PDF technicians due to the high demand for skilled technicians outside the Defence Forces. ${ }^{113}$ The basic level CIS course for both reservists and regulars, the Communications Operators Course, is the same. For the PDF it is a six-month course, for reservists it is modularised and can be completed over several years. ${ }^{114}$ As such reserve personnel are qualified as C1 and C2 operators, and in various other CIS equipment to an equivalent level as the PDF. This was demonstrated in 2015 during Exercise Dark Nights, an all arms brigade level exercise where the CIS element was a 
mix of PDF and reservists. ${ }^{115}$ In an emergency, the reserve CIS Corps is, to a certain practical extent, operationally viable and interoperable with the PDF.

The CIS Corps, though, showcases the real potential and utility of the Army Reserve as an asset of the Defence Forces. ${ }^{116}$ This is due to the application of reservists' specialized professional skills gained from their civilian careers, in a military context. In many cases, these skills were not organic to the PDF. In 2014, reservists in the CIS Corps developed a system of transmitting encrypted video and audio data via mobile phone signals. ${ }^{117}$ The system was tested for operational viability with the Nordic EU Battlegroup, and was due to be used by the Irish contingent of the GermanAustrian Battlegroup in 2016. ${ }^{118}$ However, the reservists who designed this system were legally prevented from attending field testing exercises in Sweden as it equated to overseas service for reservists. This is a clear example of reservists fostering technological innovation and development and being "fit for purpose," yet a lack of corresponding legislative reform accompanying the Single Force Concept highlights a lack of strategic thinking. This oversight could perhaps be forgiven if this CIS contribution had been isolated. However, reservists in the CIS Corps have contributed their professional skills to the Defence Forces since at least 2007 "in some shape or form...[contributing] civilian skillsets from industry best-practice and implementation...in innovation, research and development, proof of concept, project management, and troubleshooting." ${ }^{119}$ Consequently, CIS reservists have been central to Irish participation in NATO Exercise Combined Endeavour 2008 and 2009, the development of "network enabled operations" in several EU Battlegroups and participation in NATO Exercise Cyber Coalition in 2013 and 2015. ${ }^{120}$ That CIS reservists were legally barred from participation in the Swedish exercise in 2015 is curious, given that reservists had previously travelled to Germany for Combined Endeavour in 2008. ${ }^{121}$

Prior to 2013, there were three Army Reserve CIS companies totalling 210 personnel. In the Single Force Concept these were reduced to two platoons amounting to 98 personnel, an illogical reduction given the significant contributions made by reserve CIS personnel. Curiously, a critique of reserve forces by regular forces, particularly in the combat arms, is a perceived lack of experience. This skill imbalance reverses in favour of reservists in the areas of the CIS and Medical Corps. This is proven by the innovation shown by CIS reservists. In the case of the Medical Corps, any benefit that could be derived from reservists' civilian experience is undermined by the Single Force Concept.

\section{The Medical Corps.}

The reserve element of the Medical Corps is just 32 personnel, the smallest contingent in the Reserve. ${ }^{122}$ Unlike other service corps, to shorten or modularise regular training courses for reservists is not an option, as the standard of medical training must be universal to deliver competent medical care. ${ }^{123}$ PDF and reserve medical officers are already qualified doctors prior to joining the Defence Forces and are equally 
interoperable in medical terms. ${ }^{124}$ But no mechanism exists for training reserve personnel without medical skills, or for converting existing skills. ${ }^{125}$ The Medical Corps utilises enlisted personnel as medics. PDF medics complete a one-year Diploma in Military Medical Care in University College Cork to qualify as an Emergency Medical Technician (EMT). ${ }^{126}$ This course also teaches military medical administration but is not feasible for reservists to complete due to its length. Moreover, PDF medics accompany National Ambulance Service ambulances for experiential purposes. ${ }^{127}$ Problematically, the Medical Corps is under significant pressure as members of the PDF, and all reservists, require annual medical examinations. There are not enough PDF medical officers to meet this obligation. Reservists cannot alleviate the situation as they cannot complete the PDF medics course. The result is that reservists with existing civilian qualifications as paramedics or EMT's cannot use their skills in a military capacity. Thus, the reserve contingent of the Medical Corps is not operationally viable, nor the personnel interoperable.

\section{The Engineering Corps.}

The PDF Engineering Corps carries out specialist ATCA and ATCP operations. In an ATCP role, PDF engineers carry out Engineer Special Search and Clearance (ESSC) operations, aiding criminal investigations or searching areas for dangerous ordnance. ${ }^{128}$ In an ATCA role engineering units provide specialist personnel to operate boats and plant machinery. ${ }^{129}$ However, there is a pronounced juxtaposition between the capabilities of the reserve engineering component and the PDF, as reserve training focuses on conventional aspects of combat engineering. PDF personnel are trained by civilian companies to operate plant machinery and as coxswains for boats; reserve personnel are not and cannot carry out such tasks unless they happen to hold the requisite civilian qualifications. ${ }^{130}$ Reservists are not trained in ESSC operations either. This precludes their utilisation in the specialist ATCP and ATCA tasks of the Engineering Corps.

Reserve engineers are trained in the PDF Combat Engineering Course, broken down into modules for delivery on a part time basis. ${ }^{131}$ This course covers areas such as bridging, heavy demolitions, water purification, and mine warfare, and reservists have been used successfully in integrated exercises with the PDF. ${ }^{132}$ For conventional military tasks, reservists are interoperable with PDF personnel, with only an experiential disparity. ${ }^{133}$ PDF engineering personnel are, at a minimum, tradesmen and plant operators. The reserve engineering contingent does not have such personnel, despite the laws of probability arguing that there are probably civilian tradesmen or plant operators amongst the ranks of the Reserve. ${ }^{134}$ Therefore, reserve engineers are interoperable for basic conventional military engineering tasks but are not operationally viable for ATCA or ATCP tasks within the state in an emergency. 


\section{Could Reservists Serve Overseas?}

Hypothetically, if the legislative barrier to reservists deploying overseas were lifted, and employment protection existed, do reservists in the Single Force Concept have the foundational skills for overseas deployments? This is difficult to ascertain. In terms of training, the suitability of reservists to serve overseas depends on their completion of pre-deployment training, as well as passing an annual personal weapons test (APWT), medical and fitness test. The latter three are completed by many, but not all, reservists annually. The hurdle is pre-deployment training, requiring significant training up time. There are corps-specific requirements for deploying overseas that also must be attained. Military police must be investigation qualified and complete a baton and restraint course. Reservists cannot currently attain the former, though the latter is an achievable one-day course. ${ }^{135}$ Infantry deploying overseas must be trained to use the Mowag Piranha APC's and their heavy weapons, training which reserve infantry for practical reasons are largely unable to achieve. ${ }^{136}$ Cavalry personnel share these requirements, in addition to being reconnaissance qualified, which some reservists have achieved. ${ }^{137}$ Whilst the reserve engineering component is trained predominantly for conventional military tasks that would be applicable overseas, there is the requirement for deploying engineers to be plant operators and tradesmen and be trained for ESSC operations. ${ }^{138}$ Despite the conventional focus of reserve training, the shortfall in these requirements would also preclude them from deployment overseas. For the Medical Corps, reservists would have to complete the Diploma in Military Medical Care, which is not open to reservists, nor feasible due to its duration.

Artillery personnel deploy overseas, providing mortar detachments. ${ }^{139}$ Due to reservists receiving the same level of artillery training, and involvement in integrated shooting exercises it is feasible that reservists could deploy in such a role. Also, the equality in vehicular competency of the PDF and reservists in the Transport Corps could potentially make such reservists eligible for overseas deployment. The key corps requirement for overseas service with the CIS Corps is completion of the Communications Operators Course. ${ }^{140}$ As this course is modularised for reservists there is the potential for such qualified personnel to serve overseas. In some service corps there are clear competency gaps that need to be filled before reservists could deploy overseas, in other corps the gaps are less insurmountable. However, this hypothetical is predicated on employment protection legislation to facilitate the completion of pre-deployment training, and the deployment itself, to prevent overseas service being detrimental to reservists' employment.

The 2015 White Paper on Defence suggested sending small numbers of suitably qualified reservists overseas. ${ }^{141} \mathrm{~A}$ mechanism for overseas reserve service was slated for development by Defence Forces Strategic Planning Branch under the White Paper implementation plan. ${ }^{142}$ However, as of December 2019, work on "project no.72" has "not yet commenced." 143 Consequently, what form this mechanism will take is unknown. Currently, members of the PDF are contractually obligated to serve overseas. ${ }^{144}$ This, coupled with the legislative cap of 850 personnel serving overseas at 
any one time means that the deployment of reservists could result in PDF personnel not meeting their contractual obligations. ${ }^{145}$

There are arguments for and against reservists serving overseas. It is accepted by some PDF unit commanders that, if reservist's complete pre-deployment training, they are qualified and capable to serve overseas. The major impediment though, is employment protection legislation. In the opinion of several officers there is certainly scope for reservists with specialist skills to serve overseas. Although, given the lack of kinetic operations abroad, and the ease with which the PDF can currently supply suitable personnel, reservists in the infantry, cavalry and artillery corps would probably not be needed. ${ }^{146}$ In contrast, some officers have stated that reservists, even specialists, are not needed overseas as the PDF has fulfilled all personnel requirements to date. ${ }^{147}$ Curiously, it was suggested that when a member of the PDF serves overseas, their experience benefits the Defence Forces as a whole, whereas a reservist could simply resign after their tour. ${ }^{148}$ But, members of the PDF can leave after their overseas tour just as easily as reservists, and given the personnel retention crisis in the PDF such an argument is moot.

There is also the belief that overseas service for the Army Reserve would encourage further budget cuts to the PDF. ${ }^{149}$ Such a belief implies that avenues for reservists' contribution overseas may not be made available to avoid promoting the financial appeal of utilising reservists instead of PDF personnel. If this institutional belief is widespread, countering it, to bring about practical reform will certainly be difficult. More importantly though, that such attitudes exist, suggests that in some quarters a competitive mentality reigns, instead of a Single Force Concept. Regardless of the differing viewpoints, the practical and potential benefits of such utilisation have been consistently displayed by reservists in the CIS Corps. This clearly indicates the practical contribution that such specialists can give to the Defence Forces, but also the lack of a proper mechanism to utilise or capitalise on it. Government policy is working ahead of legislative enablement.

In the final analysis, examining the interoperability and operational viability of the various service corps within the Army Reserve in the Single Force Concept yields mixed results. In the Single Force Concept, the Medical and Engineering elements are seemingly unusable through design. The Infantry, Artillery and Cavalry Corps, making up 89 percent of the Reserve are only suited for ATCA tasks due to a focus on training for war, instead of training for ATCP tasks where experience, and competence, could be developed to deliver tangible outputs. This is not to suggest that training for conventional warfare should be abandoned, but it should no longer dominate proceedings if the legislative situation and stated role remain as they are. For the CIS and Transport Corps, however, this analysis does show real potential in the use of specialist skills in the Army Reserve. If "fit for purpose" is the goal of the Single Force Concept, then these corps are positioned to deliver across the board. 


\begin{tabular}{l|l|l|l|}
\hline Reserve Service Corps & ATCA Capable? & ATCP Capable? & Overseas Capable? \\
\hline Infantry & YES & NO & NO \\
\hline Artillery & YES & NO & THEORETICALLY \\
\hline Cavalry & YES & NO & NO \\
\hline CIS & YES & YES & YES \\
\hline Military Police & YES & YES & NO \\
\hline Medical & NO & NO & NO \\
\hline Transport & YES & YES & YES \\
\hline Engineer & NO & NO & NO
\end{tabular}

\section{The Issue of "Effective" Strength.}

Historically, the FCA, and subsequently, the Army Reserve has had a major issue with personnel retention, and with gauging the qualitative strength of the force. The FCA, with an establishment of 22,110, struggled continually with personnel retention. ${ }^{150}$ Despite several reorganisations, the central issue of personnel retention has remained unresolved, and has been exacerbated by the Single Force Concept. According to Defence Forces Regulation $R 5$, a reservist has only to attend a minimum of 24 two-hour unpaid training nights, or 48 cumulative training hours, made up of training nights and training weekends, annually to be classed as "effective." 151 Personnel failing to achieve this are classed as "non-effective," and ultimately discharged, but only after two years of non-effective status. Attending paid training is not required to be effective. ${ }^{152}$

Undoubtedly, a reservist who has attended paid, full-time training periods, in conjunction with the obligatory 48 hours is a higher trained soldier, qualitatively, than one who has only met the 48-hour minimum requirement. Therefore, effective strength is indicative of the quantitative, not qualitative strength of the force. Despite this obviously defective metric, neither the 2005 reorganisation of the FCA into the Army Reserve, or the 2013 Single Force Concept resulted in an amendment to the criteria for being categorised as effective. The graph below shows the effective strength versus the establishment of the Army Reserve from 2005-2012. 


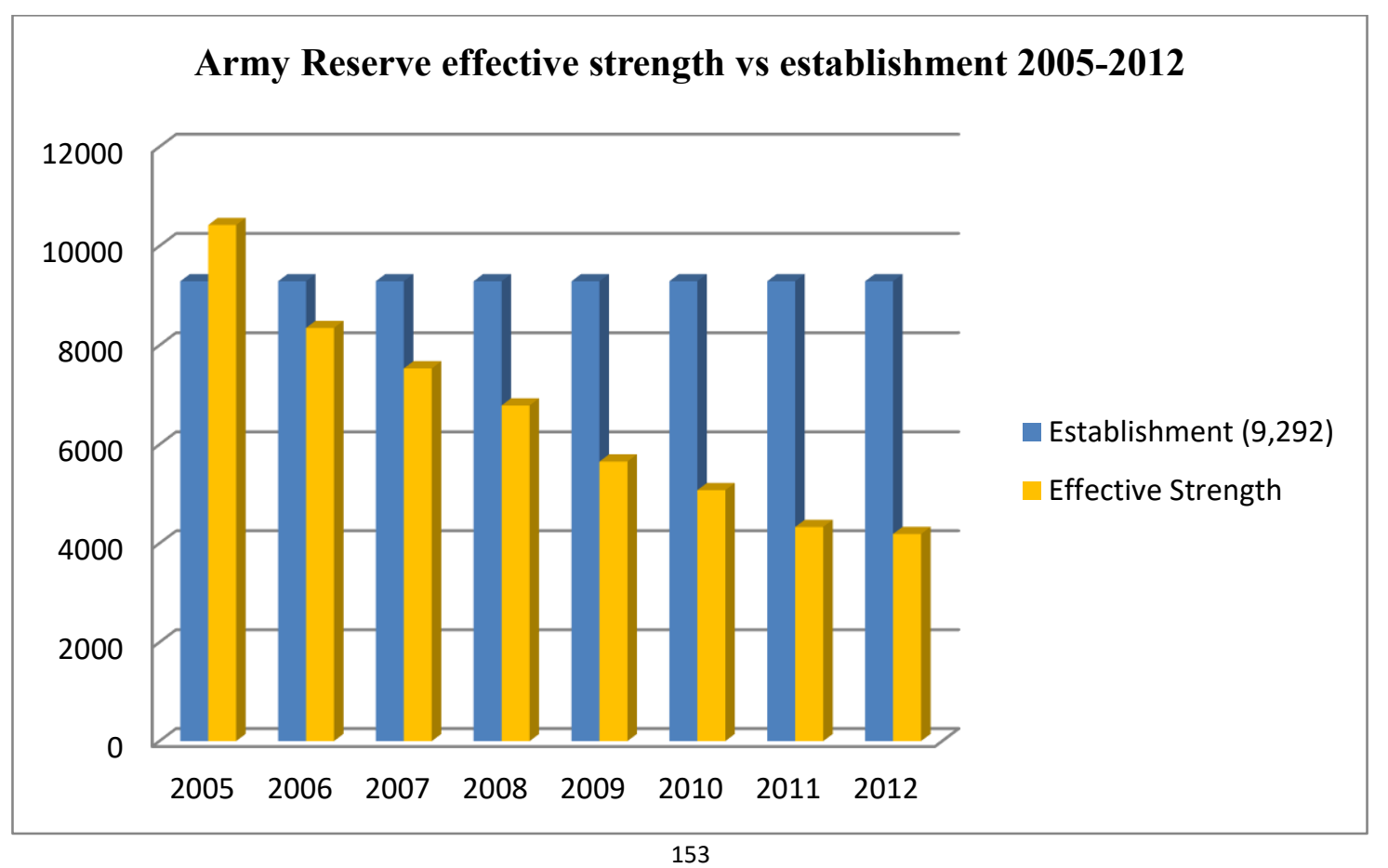

The graph shows a consistent downward trend from 2005 to 2012. However, the effective strength shown is not reliable in terms of establishing the number of reservists who could be utilised in the event of an emergency or other contingency. Personnel who attend paid full-time training periods are better trained than those who simply commit to the voluntary unpaid training hours. Therefore, the amount of personnel receiving pay is more indicative of the real strength of the force as shown in the next graph.

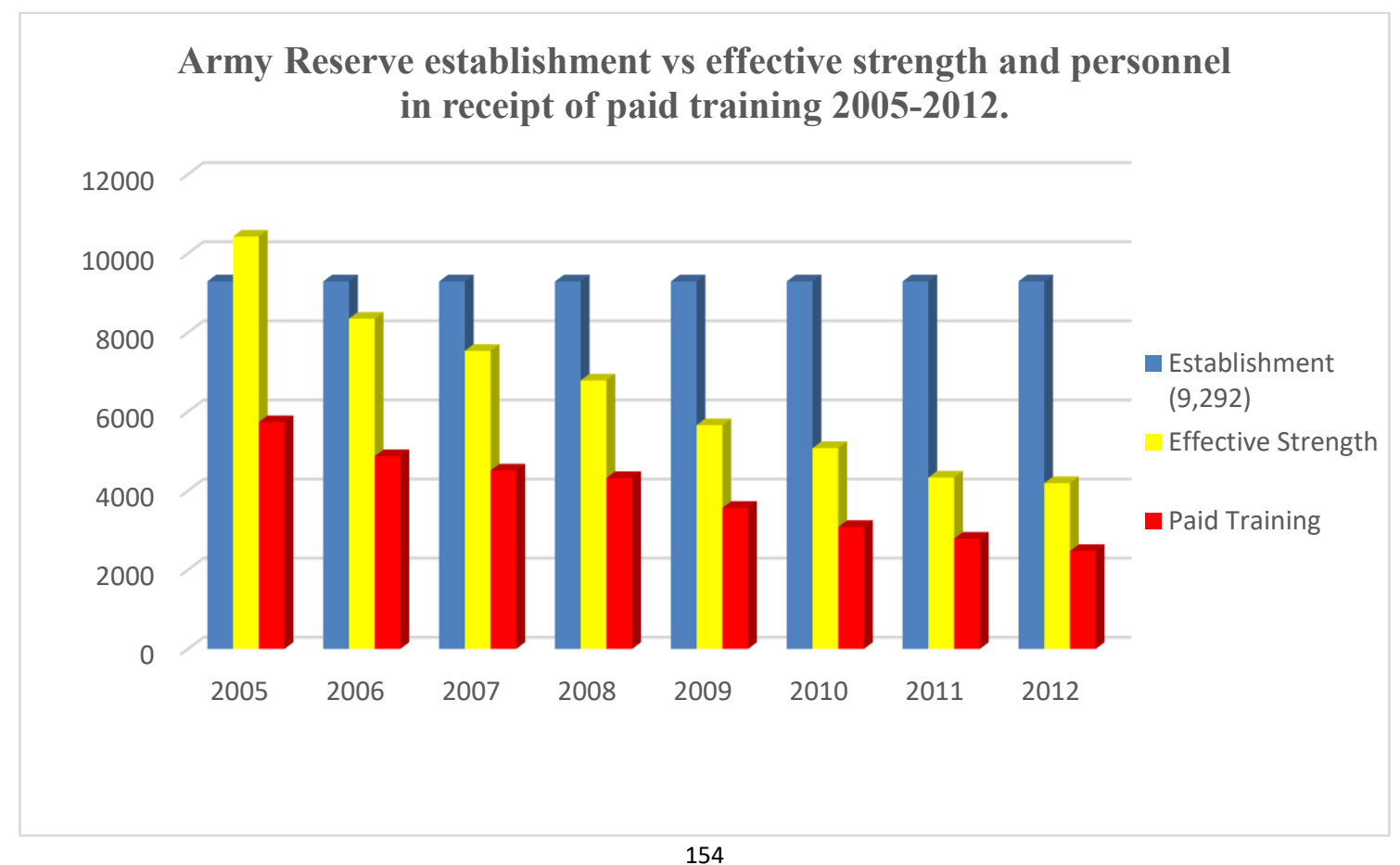


The figures of paid personnel show that, on average, only 59 percent of the effective strength of the Reserve received at least one days' pay between 2005 and 2012. Specifically, it also shows a continuous decline in personnel attending for paid training, with only 26 percent of the Reserve establishment attending paid training in 2012. This trend reflected the 2000 White Paper, which acknowledged that despite the effective strength of the FCA being 14,000 in that year, only 50 percent attended paid training. ${ }^{155}$ This shows that pattern is historical, yet remains unsolved, as the classification of an effective reservist has remained unchanged despite clear evidence that it artificially inflates any gauge of the strength of the Reserve. This data reflects the number of reservists who received at least one days' pay. To enhance the measure of qualitative strength a further variable must be included, those personnel who received a gratuity.

\begin{tabular}{|l|l|l|}
\hline \multicolumn{3}{|c|}{ Army Reserve Gratuity Payments 156} \\
\hline Rank & $\begin{array}{l}\text { Gratuity amount for 7 days } \\
\text { paid training and } \\
\text { completion of unpaid } \\
\text { training nights. }\end{array}$ & $\begin{array}{l}\text { Gratuity amount for 14 } \\
\text { days paid training and } \\
\text { completion of unpaid } \\
\text { training nights. }\end{array}$ \\
\hline Senior Officer & $€ 414$ & $€ 1,035$ \\
\hline Officers & $€ 306$ & $€ 765$ \\
\hline NCO's & $€ 252$ & $€ 630$ \\
\hline Privates & $€ 180$ & $€ 450$ \\
\hline
\end{tabular}

Defence Forces Regulation $R 5$ provided that a reservist who completed 48 voluntary hours commitment, fired their Annual Personal Weapon Test (APWT) and received at least seven days paid training received an annual financial gratuity. ${ }^{157}$ The gratuity incentivised attaining training benchmarks. The gratuity was the best metric for gauging the trained strength of the Reserve, as it measured reservists who not only just turned up to meet the minimum criteria for effective status, but who also met a qualitative standard. The gratuity reflected the true effective strength of the Army Reserve. 


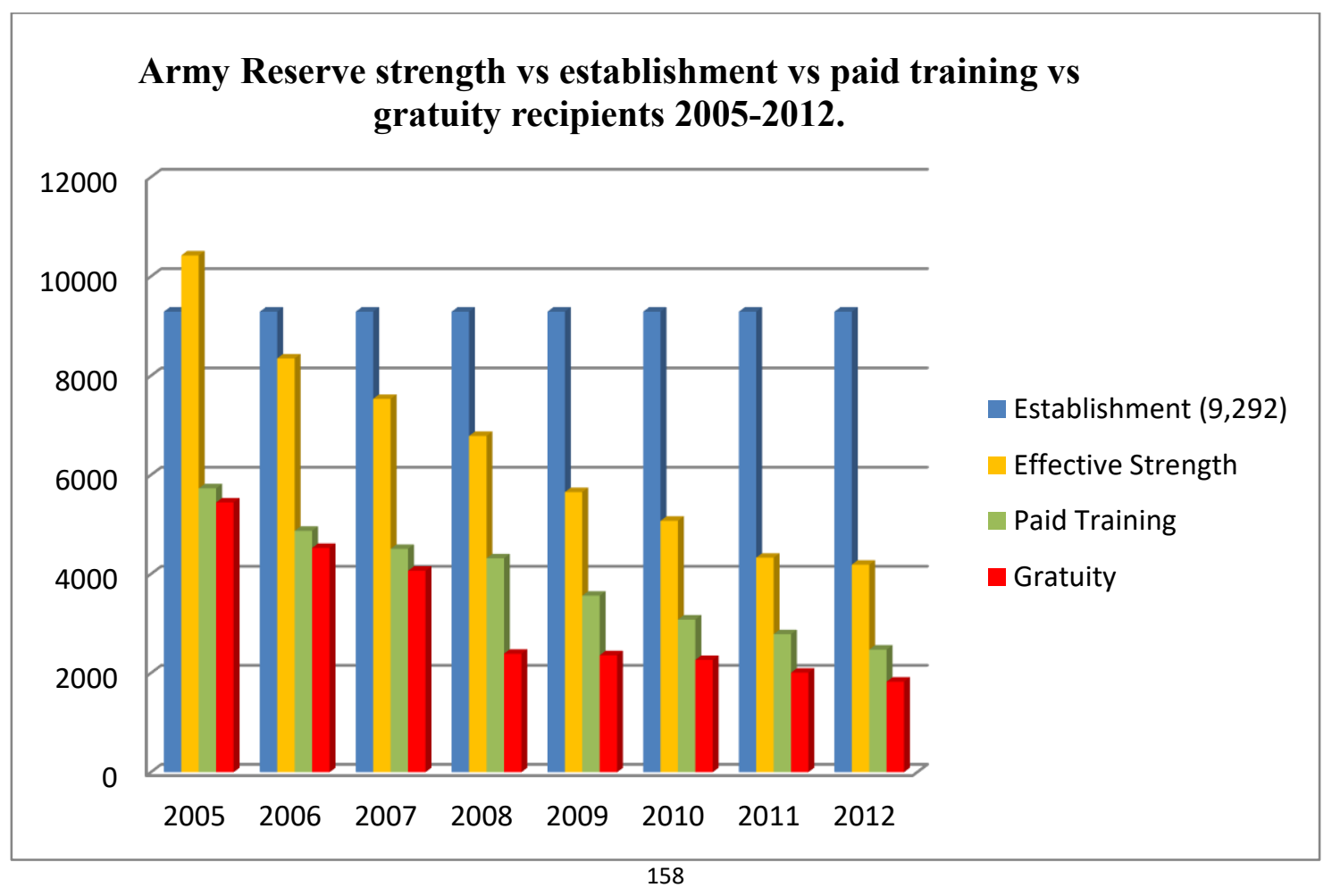

The graph clearly shows that the amount of personnel who received a gratuity was predominantly less than 50 percent of effective strength. The gratuity system was withdrawn in 2012, as a cost saving measure, so it is no longer a usable metric. While Defence Forces Regulation $R 5$ was seemingly immune to amendments regarding the definition of effective, it was swiftly amended to remove the gratuity payment in 2013. In the Single Force Concept, the same disparity in terms of effective strength and reliable strength still exists, and there is now no incentive to attain qualitative training benchmarks. The following graph outlines the effective strength, and numbers who received paid training from 2013 to 2015 in the Single Force Concept. The historical pattern endures. 


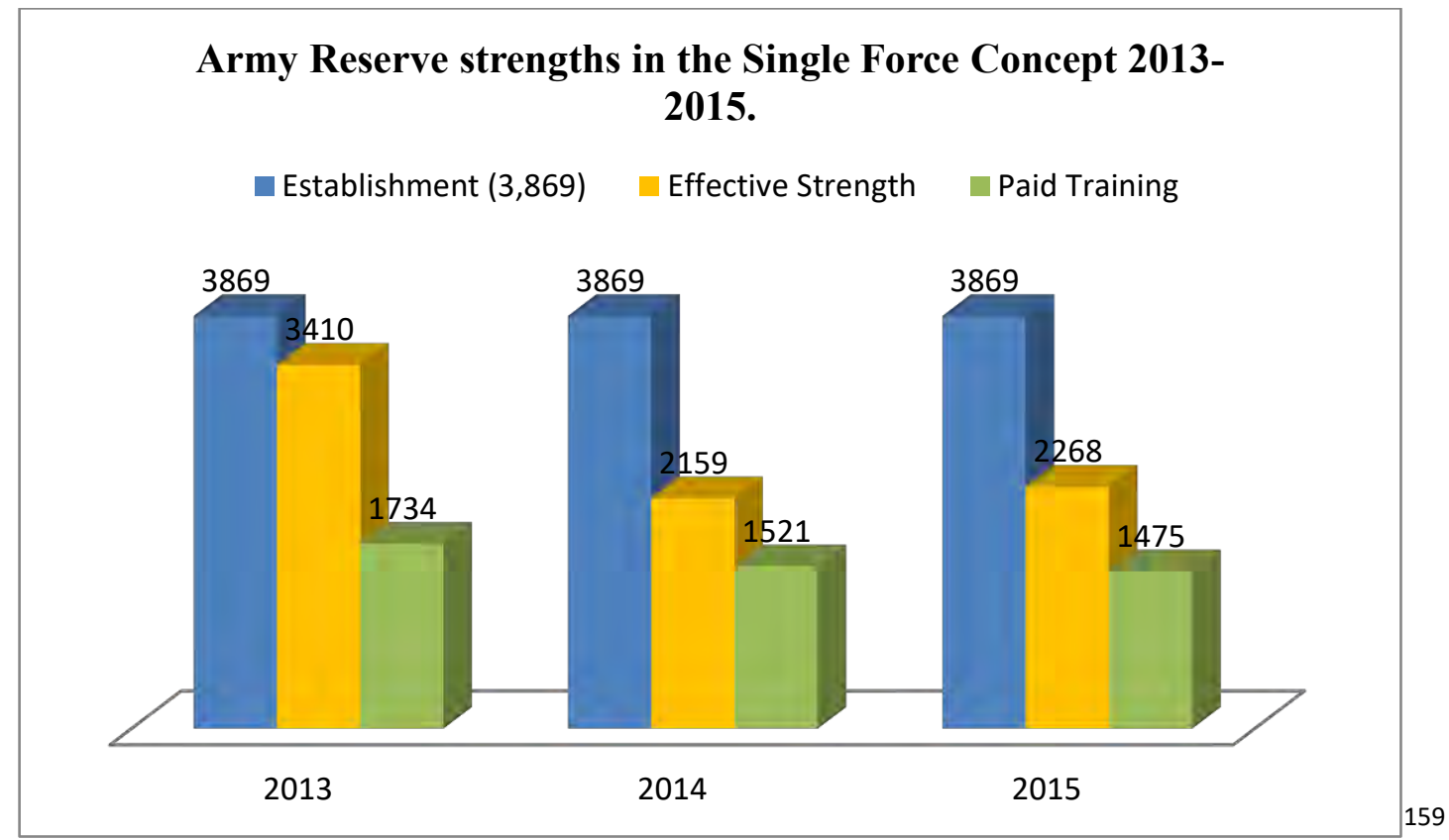

The order detailing the integration of the Reserve into the PDF in the Single Force Concept presented a new metric that could be used, Operational Readiness. ${ }^{160}$ Operational readiness in the PDF requires a minimum of 75 percent of a units' personnel meeting three criteria; completion of an APWT, completion of an annual medical and an annual fitness test. ${ }^{161}$ Administrative Order 01/2013 set out that, annually, each reservist must also complete these three benchmarks to make the Army Reserve "Operationally Ready." 162

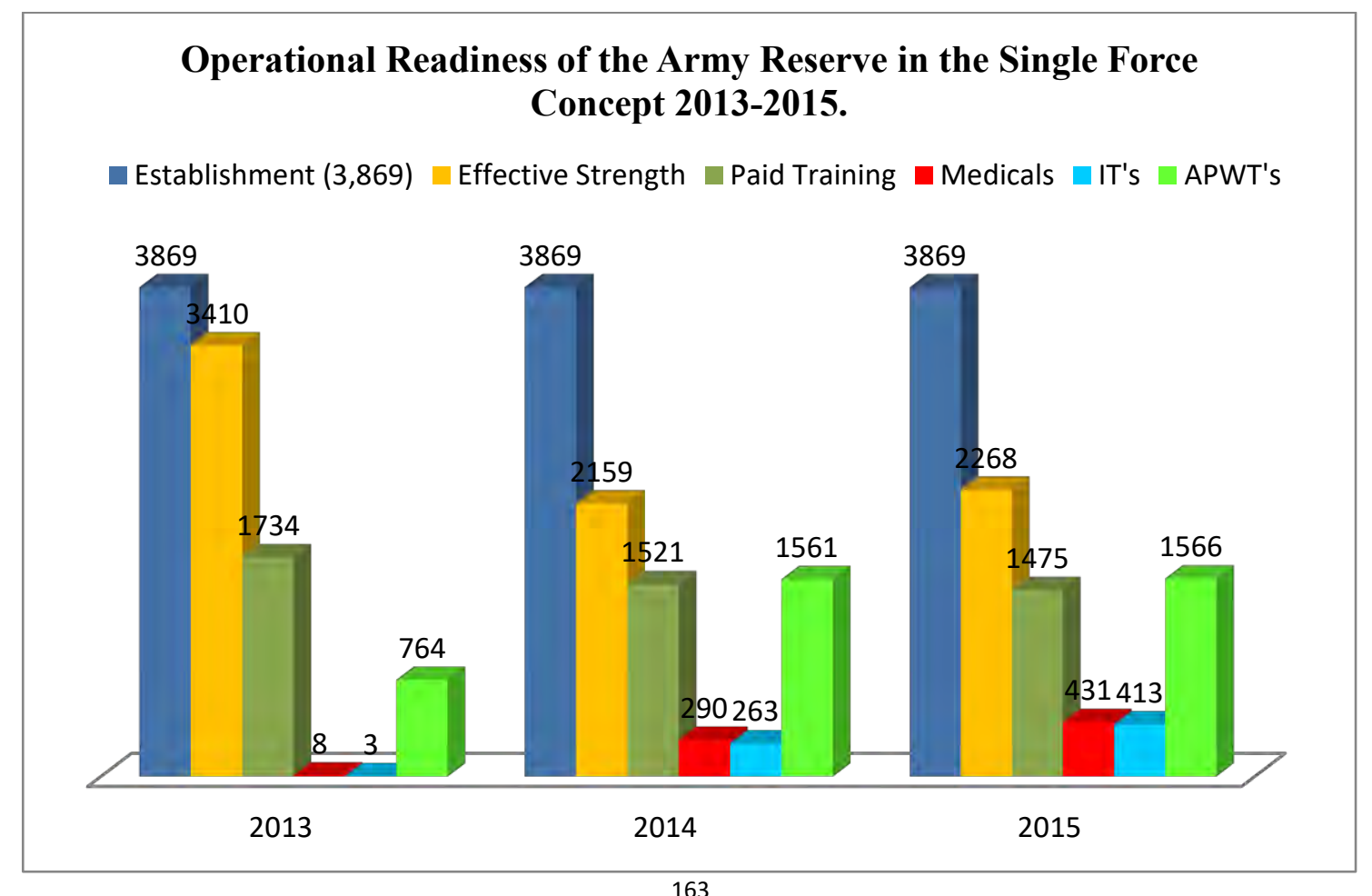

163 
These figures illustrate the attainment of the requirements to be operationally ready annually by reservists from 2013-2015. While most effective reservists fired their APWT, many did not complete a medical or fitness test. It is important to note that while Administrative Order 01/2013 stated that reservists should achieve these benchmarks, R5 was not amended to make them obligatory to remain effective in the Army Reserve. The graph does show an increasing trend in the numbers of personnel attaining these requirements but it also shows the majority of the Reserve cannot be classed as operationally ready. The low medical attainment can in part be attributed to the struggling medical infrastructure of the Defence Forces, discussed previously. The lack of fitness tests is unexplainable. Such tests are a prerequisite for reservists completing recruit training or career courses. ${ }^{164}$ But the fact that Administrative Order $01 / 2013$ did not make them mandatory, and the relatively low uptake implies there may be an aversion to adhering to physical fitness standards in the Army Reserve.

If the lowest common denominator is considered, in this case the fitness test, and it is assumed in the best-case scenario that those same individuals also completed their medical and APWT's the operational readiness figures for the Army Reserve from 2013-2015 would be 0.08, 12.18 and 18.2 percent respectively. While increasing annually, this is still substantially short of the 75 percent benchmark of the PDF. In terms of qualitative effectivity, the metric of operational readiness is most applicable when discussing the Army Reserve as a force to be utilised. Any response to an emergency would undoubtedly require fit, healthy personnel, qualified in the use of weaponry. This is not to suggest that most of the Reserve is unfit or unhealthy, as this cannot be definitively established. It is more likely that attainment of these requirements not being obligatory results in there being no motivation to achieve them. Similarly, whilst PDF unit commanders are under pressure to ensure that their units reach the threshold, reservists under their command are not included in this benchmark. ${ }^{165}$ Thus, there is no obligation on the reservist, nor motivation for unit commanders to compel their achievement. This is another reason why the definition of effective is a contradiction in terms. Quantitatively and qualitatively measuring the strength of the Army Reserve is thus, problematic.

\section{The Question of Sustainability.}

The 2015 White Paper stated that the key challenge going forward for the Reserve was personnel retention. ${ }^{166}$ This stems from the already highlighted decline in effective personnel. The VFM Review stated that from 2006-2009 twice as many personnel were leaving the force as opposed to joining. ${ }^{167}$ These figures are shown below, but they are incorrect. 


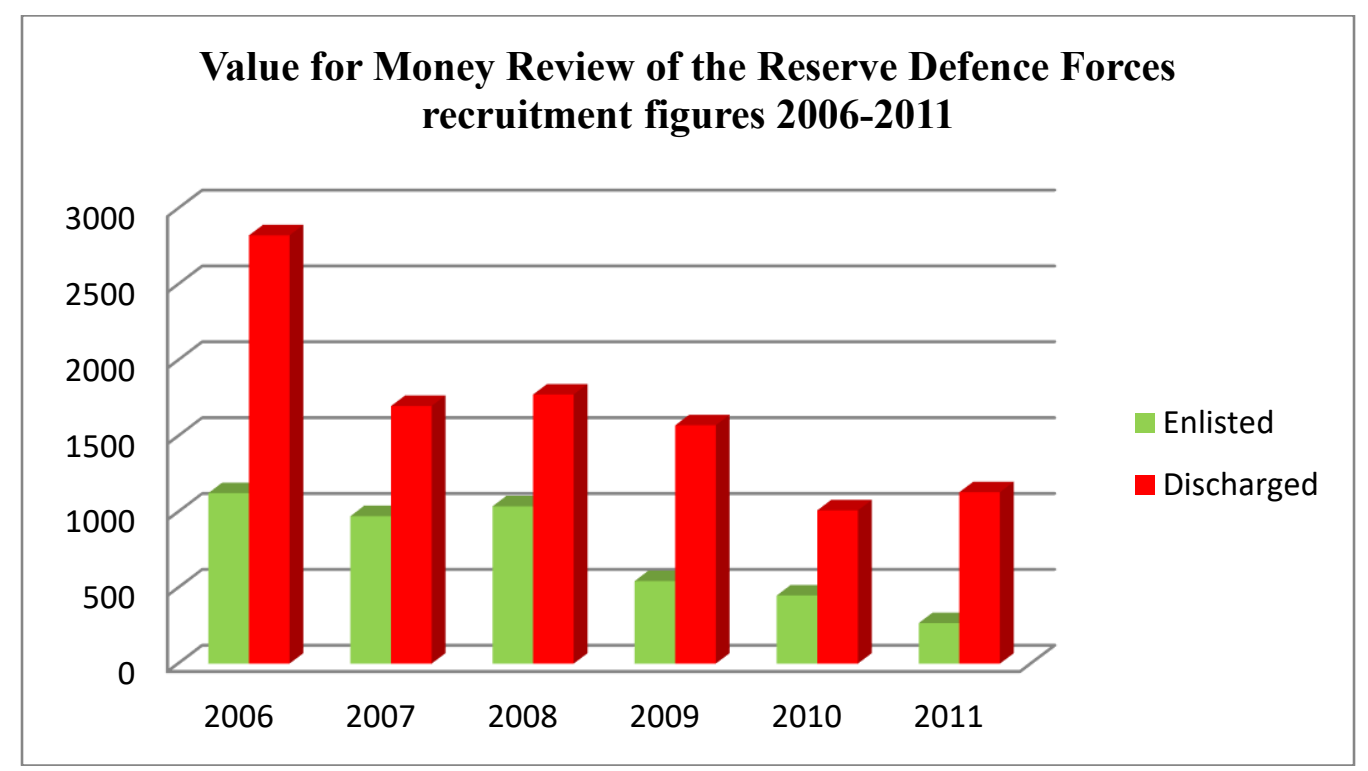

The most accurate recruitment and retention figures from the Defence Forces Personnel Management System (PMS) covering the same period are shown below, differing significantly from those of the VFM. When the FCA changed over to the Army Reserve in 2005 there were personnel who did not transfer over into the new organisation or chose not to continue their service. 4,762 personnel, to be precise. These personnel never joined any Army Reserve unit and were gradually discharged from 2006 to $2011 .{ }^{168}$ Thus, they were never members of the Army Reserve. Yet, for some reason, these 4,762 FCA personnel were included in the recruitment and retention figures in the VFM. Interestingly, many of these personnel were stationed in FCA locations that were not retained in the Army Reserve. This suggests that many may have been unwilling to travel significant distances, at their own cost, to remain in service. The figures provided in the following graph reflect Army Reserve enlistments, and Army Reserve discharges. 


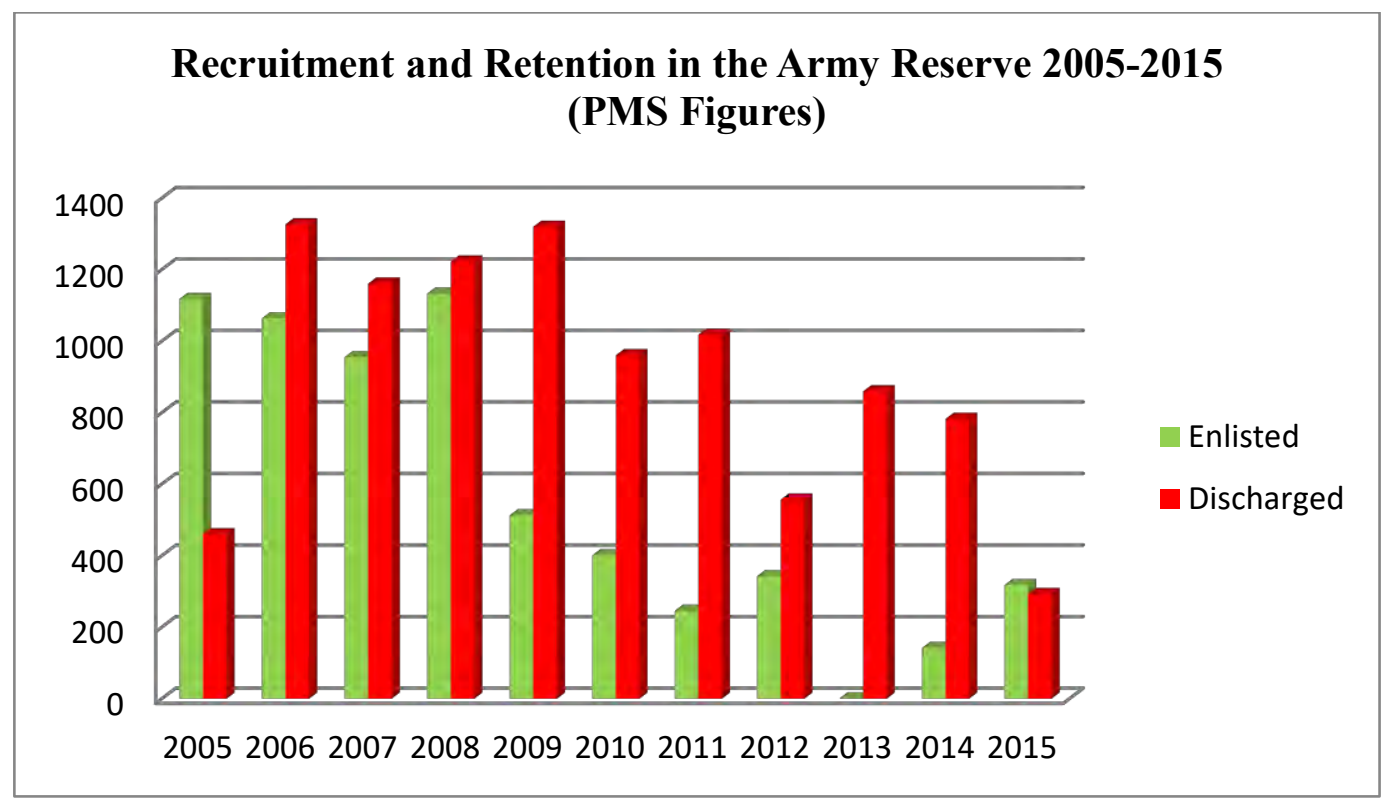

While the VFM was incorrect about the timeframe, its claim that the Army Reserve was losing more than twice the numbers of personnel joining was true, between 2009 and 2014, except for 2012. There was no recruitment in 2013 due to the reorganisation into the Single Force Concept. From 2006-2012, the duration of the twinned unit system of the Army Reserve, 6,002 personnel enlisted, whereas 8,046 were discharged. ${ }^{169}$ From 2013 to 2015, the first three years of the Single Force Concept, 2,037 personnel discharged, and only 461 enlisted. ${ }^{170}$ The VFM explained the high discharge rate as personnel leaving due to an inability to achieve effective status. ${ }^{171}$ This is semantics on the part of the VFM as no mention was made of the influence played by civilian employment or the unrealistic voluntary unpaid time commitment. Furthermore, if these figures really argued that being effective was difficult to achieve, why was the definition not subsequently changed? The net result, which the graph shows, is that the Reserve is over reliant on continuous recruitment in order to maintain its strength. Again, this is not a new issue. Between 1993 and 1998, the average effective strength of the FCA was 14,945 personnel. During the same period the FCA recruited 14,874 personnel, which equates to a 99.52 percent turnover. ${ }^{172}$ The over reliance is exemplified by the significant drop in strength when recruitment is suspended. In 1983, recruitment to the FCA was suspended due to public expenditure restrictions; the effective strength fell from 20,800 to 16,361, a drop of 22 percent in just one year. Similarly, in 2009, when public sector recruitment was halted due to the economic crash the numbers in the Army Reserve fell by 13 percent that year alone. ${ }^{173}$ In terms of sustainability, the graph also shows that the number of new recruits joining the Army Reserve has reduced in recent years. There are several reasons for this.

Prior to the 2009 recruitment freeze, reserve units, regardless of corps, could recruit independently without limitations. ${ }^{174}$ This resulted in active engagement by every unit to recruit. Post-2009 recruitment was limited severely due to the economic 
crisis. ${ }^{175}$ In the Single Force Concept the recruitment process is even more problematic. In a positive move, potential candidates are required to complete a medical, fitness test and interview in line with PDF recruitment competitions. ${ }^{176}$ Conversely, the recruiting process requires an individual to pass a security check with An Garda Siochana, taking up to six months to complete as PDF security checks take priority, which risks applicants losing interest in the process. ${ }^{177}$ Furthermore, recruitment is limited to certain periods of the year and coincides with PDF recruitment resulting in confusion for potential recruits in terms of whether they are joining the PDF or the Reserve, and competition between both organisations as they are essentially targeting the same candidates. ${ }^{178}$ Additionally, applicants must pay for a civilian medical examination at their own expense, only to subsequently submit for yet another medical examination carried out by the Defence Forces. ${ }^{179}$ The 2019 recruitment campaign exemplifies the problem. 1,186 individuals applied to join the Army Reserve. ${ }^{180}$ Of this number, just 97 were inducted. ${ }^{181} \mathrm{~A}$ conversion rate of just 8 percent. In 2015, it was suggested that it could take the Reserve until 2030 to reach full strength. ${ }^{182}$ With the results of the 2019 recruitment campaign, the Reserve will cease to exist long before 2030.

Another factor effecting declining enlistment is the greatly reduced geographical spread of the force. Figure 1 shows the geographical spread of the FCA prior to the reorganisation in 2005. FCA units were based in 22 PDF barracks (Red) and 69 non-barrack locations (Green) throughout the country.

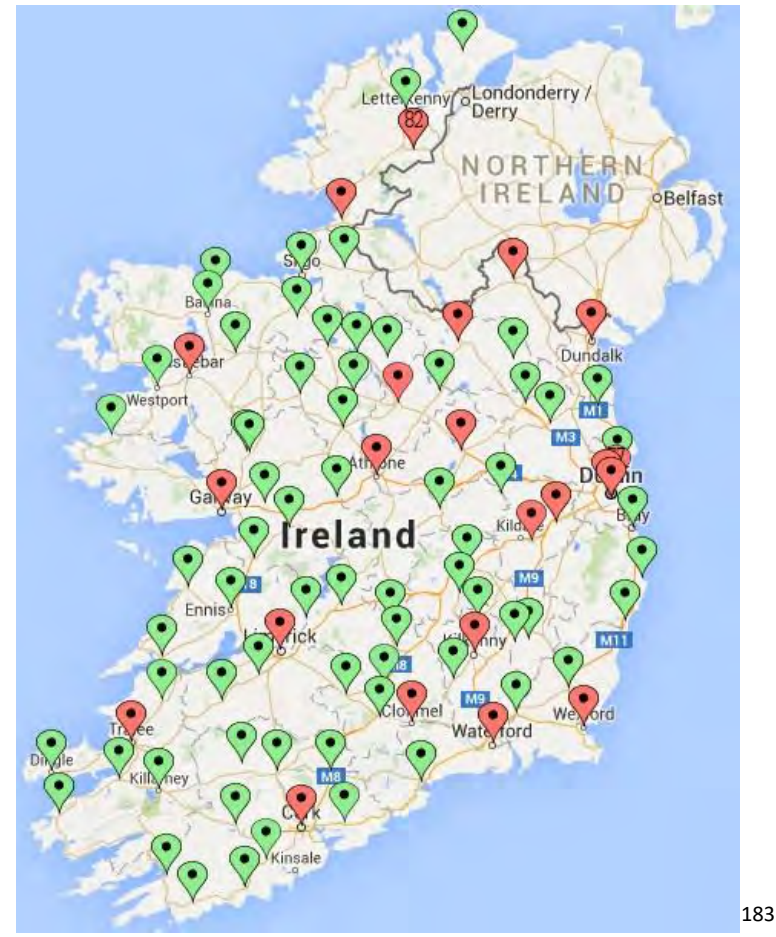

Figure 1: FCA Unit Distribution 1979-2005.

With the reorganisation into the Army Reserve in 2005 these 91 locations were reduced to 52 , reflecting the reduced organisational structure of the force, as shown in 
Figure 2. This reduction arguably contributed to the 4,762 FCA personnel who opted not to transfer into the Army Reserve in 2005.

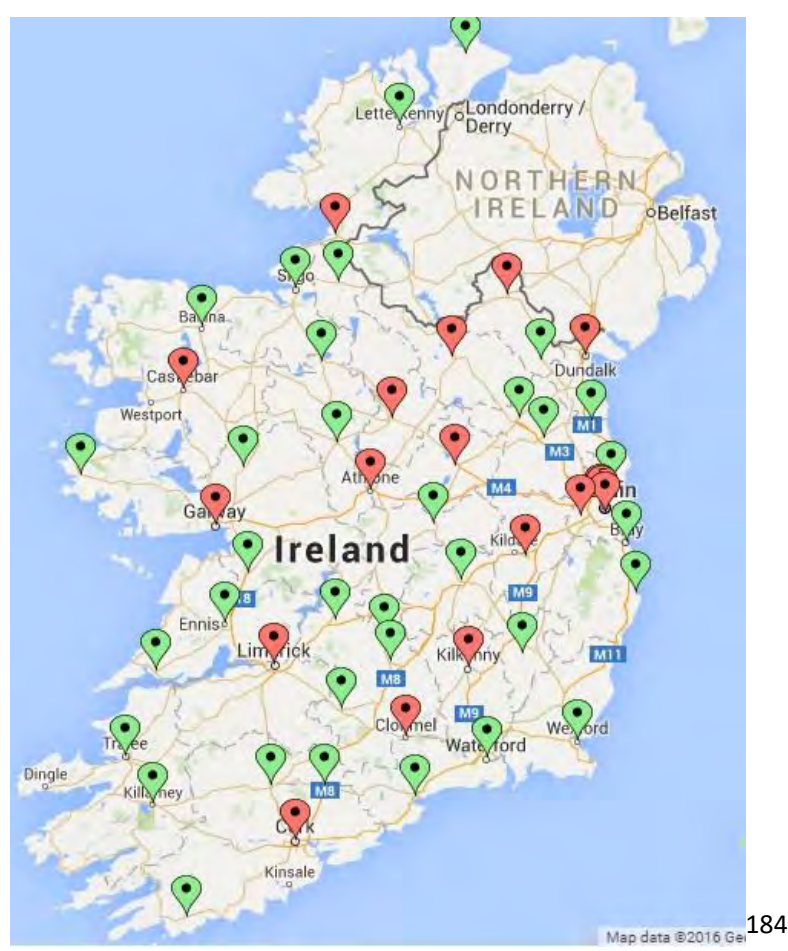

Figure 2: Army Reserve Unit Distribution 2005-2013.

Currently, in the Single Force Concept, the geographical spread stands at 25 locations countrywide (Figure 3 ). While this geographical contraction reflects the corresponding organisational contraction of the PDF, it hinders recruitment. The majority of rural Ireland does not have a Reserve presence. New entrants from such areas have to travel significant distances to attend reserve training, at their own expense. Also, with the majority of Reserve units based in PDF barracks it increases the competition between the two organisations in terms of recruiting locally. 


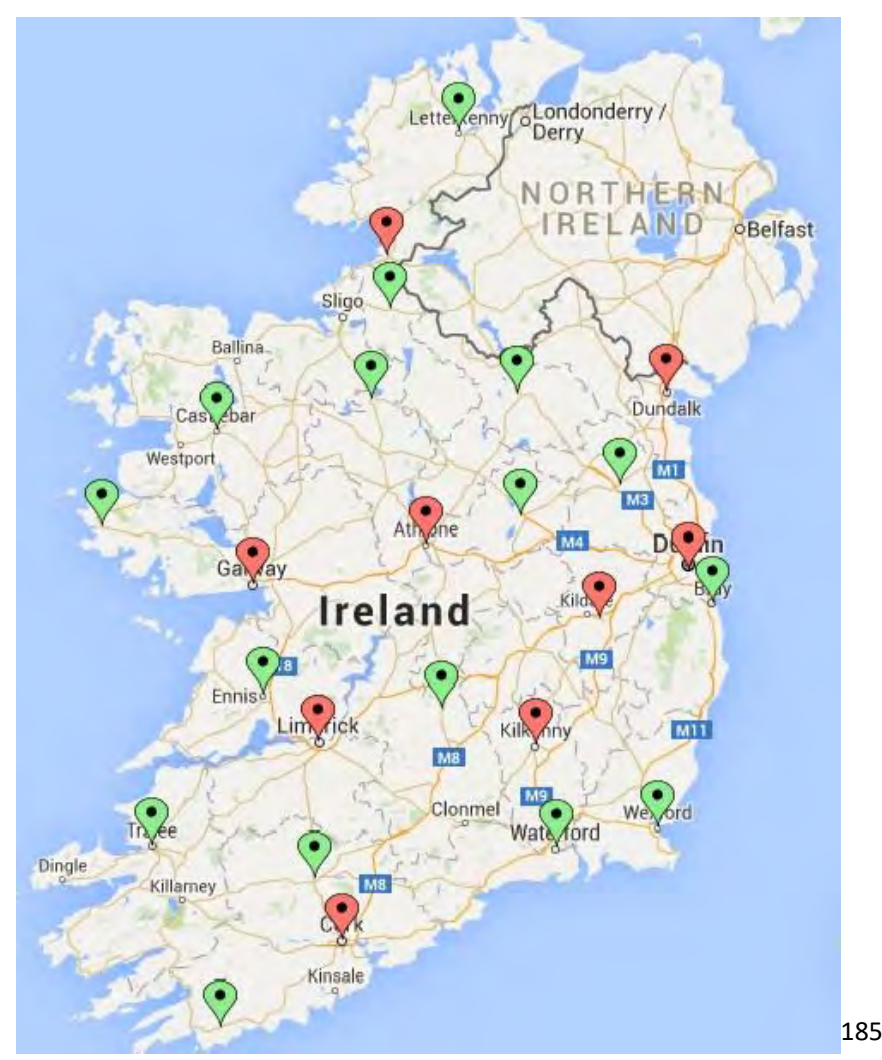

Figure 3: Single Force Concept Unit Distribution 2013-present.

In defence of the geographical contraction it is argued that, for the modern reservist, the quality of training one can receive in a rural outpost is not the same standard as could be achieved in a PDF barracks with access to weaponry. ${ }^{186}$ Though a valid argument in terms of integrating the Reserve with the PDF there are two problems. Firstly, the rural outposts are manned in the majority by reserve infantry companies, meaning that a sizeable portion of the force is unable to train regularly with weapons or equipment. Secondly, one key advantage of the geographical spread of the FCA, and pre-integration Army Reserve was that it created a defence link with rural Ireland where the population was aware of, and involved with, the Defence Forces. ${ }^{187}$ This link is now severed. In addition to the reduced geographical spread contributing to lower recruitment levels, the issue of significant numbers of personnel leaving the Army Reserve must also be considered.

There are critical factors implying why the effective strength of the Army Reserve has been in an almost continual decline. The historical retention issue suggests that, from the FCA to the Single Force Concept, the core issues influencing the effectiveness of the individual reservist have not been addressed. The legislation surrounding the force has not been amended in 66 years and Defence Forces regulations are shown to be out of phase with maintaining the effective strength of the Reserve. Yet, what is expected of reservists in terms of individual time commitment has increased significantly. In the Single Force Concept, PDF unit commanders are certainly asking more of their reservists than has been asked before. Correspondingly, 
we live in an age where, for many, civilian employment is also demanding more commitment beyond just the set working hours. Consequently, time commitments play a major role in the dwindling effective strength of the Reserve.

Another factor is the heavy reliance on recruitment to maintain the Army Reserve. The force is locked in a continuous cycle of training new personnel instead of focusing on individual continuous professional development. ${ }^{188}$ Essentially, reservists get, "bored." 189 This boredom stems from reservists having little opportunity to utilise their military training, meaningfully. ${ }^{190}$ Instead, they are football players permanently stuck on the bench, training with no output. Again, this highlights the wider issue of the role of the Army Reserve. Coupled with this increase in time commitment is a reduction in financial remuneration, with the withdrawal of the annual gratuity in 2012, and an increased emphasis on "unpaid voluntary service." ${ }^{191}$ Future Reserves 2020, the British Army Reserve initiative, argues that "if Defence routinely asks more than reservists or employers can reasonably give, then it is unlikely that Defence will have the reservists needed to deliver an assured contribution to national security." 192 The data infers that the Army Reserve has apparently asked more than reservists' can give. Between 2005 and 2015, 14,671 reservists were discharged. ${ }^{193}$ While the specific reasons reservists leave are hard to definitively quantify, this number speaks for itself. When this framework of reserve military service is superimposed on the current environment in Ireland, the lack of legislative support or clarity of purpose, it is perhaps unsurprising that Reserve strength has been in continual decline. Furthermore, the emphasis on voluntary unpaid service for reservists to be classed as effective while the Defence Forces is suffering an acute personnel shortage due to poor pay, will only cause reservists to question why they are giving up their time for free.

\section{The Problematic Force Structure.}

The Infantry Corps, as mentioned, makes up the bulk of the Army Reserve. When combined with the Cavalry and Artillery Corps, 89 percent of the force is combat oriented. This does not make sense, especially when overseas service, if available, is for specialist personnel only, and conventional military operations and large-scale ATCP operations are stated to be outside the capability of the Army Reserve. Thus, there is little or no practical utilisation of the skills of the Reserve's largest corps, and evidence shows it to be in continual decline. ${ }^{194}$ This is despite the Infantry Corps enjoying unlimited recruitment until 2009, and preferential recruitment from 2010 into the Single Force Concept. From 2013 to 2018 applicants to the Reserve could only choose their preferred geographic location. Consequently, almost all those applicants were assigned to combat units, as these were the units managing their recruit training. Recruitment data shows that in the Single Force Concept, between 2013 and 2015 there were 461 new recruits to the Army Reserve. They were assigned as follows: Engineering, Medical and CIS Corps (one recruit each), the Transport Corps (two recruits), the Cavalry Corps (eleven), the Artillery Corps (seventy-eight) and the 
Infantry Corps (366 recruits). This is despite the Infantry, Cavalry and Artillery Corps' discharging 1,748 personnel during the same period.

Only in the most recent 2019 recruitment competition could reserve applicants choose their preferred corps. In terms of discharges, the specialist corps retain personnel significantly better in comparison to the combat corps, as the chart below illustrates.

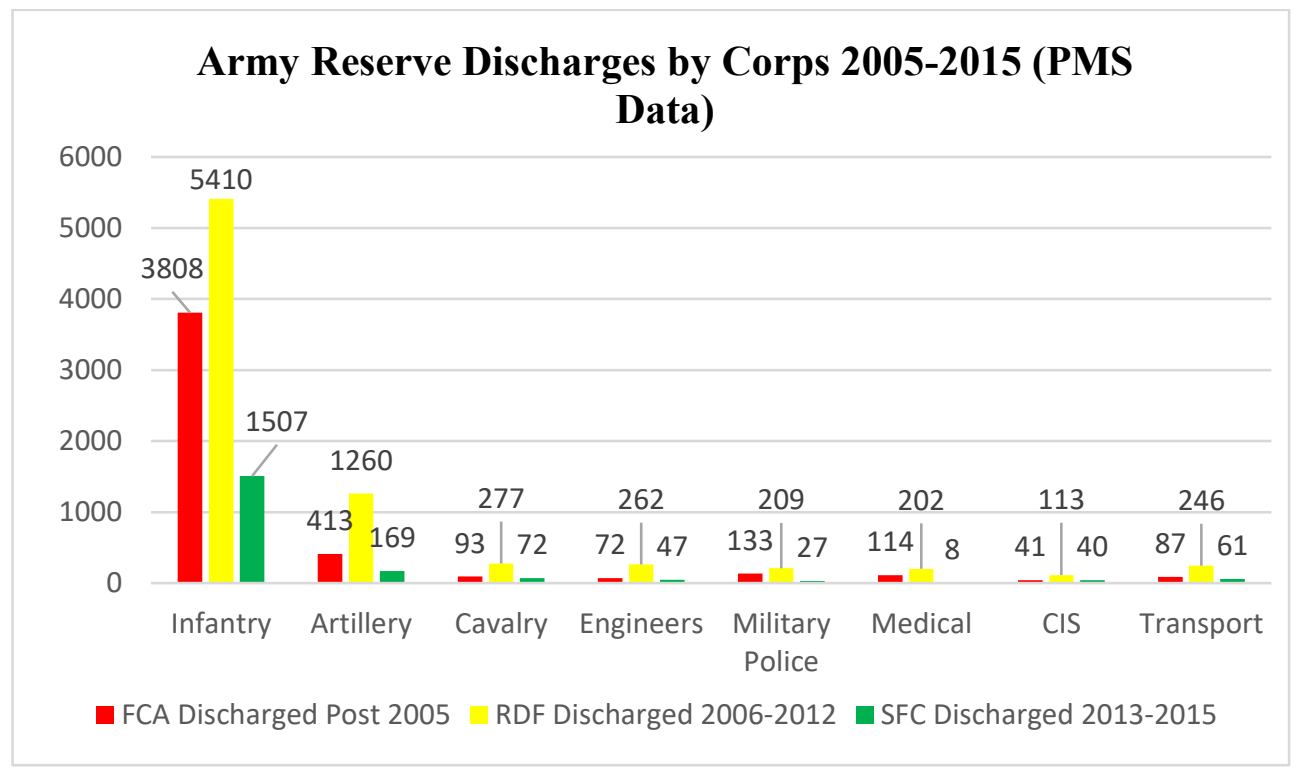

Reserve combat elements are indeed prudent, but with a shortage in the PDF of specialists such as radio technicians, vehicle mechanics, doctors, and cyber-security specialists and the Reserve combat elements suffering crippling losses in personnel, the question that comes to the fore is should this combat-focused force structure should be maintained? The answer is a definitive no. The fact that Medical and Engineering Corps reserve personnel are not capable of augmenting their PDF counterparts, with the required skills being civilian in nature, and attainment, supports the argument that the current recruiting system should change to specifically target skills that the PDF does not have, or skills qualifying reservists to fulfil specialised roles without retraining. ${ }^{195}$ To capitalise upon being able to recruit specialists that the Defence Force requires, in sufficient numbers, the force structure should be changed in favour of skills-focused, not combat-focused units. There should be a reduction in the number of reserve rifle companies, and in their place the personnel allocation should be put towards should CIS, medical, logistics and engineering battalions. This would allow the Defence Forces a bigger net to catch skilled individuals who want to contribute their expertise by providing more appointments for them to fill. To provide a working example of this suggestion, the Medical Corps is an ideal example, albeit, in reverse. 
A review of the Defence Force Medical Corps and infrastructure was completed in 2009. It concluded that the Medical Corps could only meet 40 percent of the needs of the Defence Forces, not including reserve requirements. The review suggested that the shortfall could be mitigated by relying on reserve medical units. ${ }^{196}$ In 2009, the Medical Corps had 226 reservists in three reserve medical companies. ${ }^{197}$ However, the Single Force Concept reduced this to just 32 personnel. The recommendations of the review were ignored, leaving the Defence Forces with just 32 reservists that have almost no utility. Currently, the pressure on the medical establishment at the point that reservists, for their annual medical, are relegated to attending a civilian doctor for a non-intensive medical assessment of their fitness for military service. The doctor is reimbursed by the Department of Defence for these services. ${ }^{198}$ This means the government is outsourcing, and paying for, medical examinations that are unsuited to assessing fitness for military service because the Defence Forces itself cannot cater to the organic needs of the force. The Defence Forces should forego a battalion's worth of reserve infantry, and strive to recruit the battalion's worth of civilian EMT's, doctors, nurses and others with medical qualifications.

\section{The Force Structure: An Argument for Change.}

The chart below shows the "effective" strength percentage of each reserve service corps, relative to its numerical establishment from 2006 to $2019 .{ }^{199} 2013$ is highlighted as this marked the launch of the Single Force Concept. The spike in percentage strength in 2013 reflects the amalgamation of several units into a smaller force structure. While each corps shows a decline, the rate of decline is significant. The Infantry Corps, where 1 percent equates to 59 personnel pre-2013, and 27 personnel after, shows a steep decline from 2006 onwards. The decline in the Cavalry and Artillery Corps is less pronounced but still evident. In contrast, the technical corps, despite limited recruitment post-2009, and almost no recruitment from 2013 to 2018, have a much slower rate of decline. And, as these units are significantly smaller compared to the combat arms, a 1 percent drop equates to less than one person on average.

\begin{tabular}{|l|l|l|l|l|l|l|l|l|l|l|l|}
\hline \multicolumn{7}{|c|}{ Army Reserve Effective Strength by Service Corps (\% of Establishment) } \\
\hline Corps & $\mathbf{2 0 0 6}$ & $\mathbf{2 0 0 7}$ & $\mathbf{2 0 0 8}$ & $\mathbf{2 0 0 9}$ & $\mathbf{2 0 1 0}$ & $\mathbf{2 0 1 1}$ & $\mathbf{2 0 1 2}$ & $\mathbf{2 0 1 3}$ & $\mathbf{2 0 1 4}$ & $\mathbf{2 0 1 5}$ & $\mathbf{2 0 1 9}$ \\
\hline Infantry & 92 & 81 & 74 & 59 & 53 & 44 & 43 & 81 & 56 & 65 & 43 \\
\hline Artillery & 84 & 82 & 78 & 71 & 65 & 56 & 58 & 84 & 50 & 61 & 42 \\
\hline Cavalry & 100 & 77 & 63 & 56 & 49 & 45 & 50 & 98 & 67 & 65 & 51 \\
\hline Military Police & 119 & 114 & 100 & 88 & 83 & 74 & 78 & 125 & 86 & 91 & 72 \\
\hline Medical & 69 & 65 & 56 & 54 & 47 & 42 & 49 & 162 & 106 & 106 & 62 \\
\hline Transport & 69 & 65 & 56 & 54 & 47 & 42 & 49 & 103 & 71 & 63 & 51 \\
\hline Engineers & 74 & 77 & 67 & 58 & 56 & 44 & 42 & 157 & 100 & 91 & 69 \\
\hline CIS & 69 & 72 & 65 & 54 & 55 & 57 & 60 & 75 & 52 & 52 & 40 \\
\hline
\end{tabular}


The chart shows that, even with preferential recruitment in the Single Force Concept, the Infantry Corps has declined by almost half since its implementation and the Artillery and Cavalry Corps are not much healthier. Arguably, this is because these corps are trained for conventional warfare but are only used in exercises without meaningful utilisation of their skills, thus the continuing rate of decline amongst their units. They get bored.

The more specialised corps' display more stable trends, with some units reaching above full strength at times. This suggests, that where reservists can bring and apply their own civilian professional skills in a military environment, exemplified by the reserve CIS personnel with the EU Battlegroups, they remain in service longer than their combat-focused colleagues. Their attrition rate is slower, but attrite they eventually do. Reservists in these corps still fall victim to the aforementioned factors that cause reservists to leave the organisation, it just seems to take a little longer. That these units hold onto personnel longer shows their potential. This should be capitalised upon. And there lies another problem. Some PDF unit commanders believe it optimistic expecting personnel, with too many outside pulls, to work for free with no legal framework. ${ }^{200}$ The Medical Corps does not have the capacity to meet the needs of the Defence Forces, yet reserve medical officers cannot be utilised to alleviate this as they would be unwilling to perform a military function for free that they are paid for in a civilian capacity. ${ }^{201}$ Others officers argue that reservists do not "join for the money," but instead want to get away from their civilian jobs to do something different. ${ }^{202}$ That specialist units maintain better proportional strength levels suggests that many reservists join specifically to use their skills, not get away from them. Some officers argue that the Defence Forces does not buy into the potential of the Army Reserve, failing to assess the broad skill-base reservists have. ${ }^{203}$ This is hard to dispute. The suggestion of a comprehensive survey of reservists' skills and professional qualifications was made in 2003. ${ }^{204}$ To date no comprehensive, force-wide survey has taken place. ${ }^{205}$ Consequently, the Defence Forces does not actually know who, what or how many skilled personnel the Army Reserve has to offer. The Medical Corps needs medically trained reservists, the Engineering Corps needs tradesmen and plant operators, the CIS Corps needs radio technicians and the Transport Corps needs qualified mechanics. All easy to identify with the right data. Instead, in the Single Force Concept a PDF unit commander must hope that a reservist with professional civilian skills and qualifications joins the unit that could benefit most from them. Due to the absence of a skills survey, this serendipitous coupling is probably a rare occurrence.

\section{International Comparators.}

Curiously, when one compares the Irish Army Reserve force structure to the land reserve components of Canada, New Zealand, Australia and the United States in terms of the ratio of combat units versus combat support units, the Irish Army Reserve has, proportionally, the most combat focused force structure of them all. The chart below sets out the numerical force structures in terms of units for the various land reserve components. When one compares the number of combat units versus combat support 
units the resulting ratio indicates the proportional focus of the force in question. In the cases of the United Kingdom and the United States, for every combat unit, there are 1.64 and 1.72 combat support units of equivalent sizes, respectively. This ratio shows that most units in the British Army Reserve, and the United States Army National Guard/Army Reserve, are not combat oriented. In the case of the Irish Army Reserve, however, for every combat unit, there is only 0.09 combat support units of equivalent size, as highlighted in the chart below.

\begin{tabular}{|l|c|c|c|c|c|c|}
\hline $\begin{array}{l}\text { Reserve } \\
\text { Forces }\end{array}$ & Ireland & $\begin{array}{l}\text { United } \\
\text { Kingdom }\end{array}$ & Canada & New Zealand & Australia & $\begin{array}{l}\text { United } \\
\text { States }{ }^{206}\end{array}$ \\
\hline Equivalence & Companies & Battalions & Battalions & Battalions & Battalions & Brigades \\
\hline Combat ${ }^{207}$ & 25 & 19 & 68 & 3.25 & 16 & 23 \\
\hline Artillery & 4 & 6 & 16.75 & 1 & 1 & 13 \\
\hline $\begin{array}{l}\text { Combat } \\
\text { Aviation }\end{array}$ & 0 & 1 & 0 & 0 & 0 & 10 \\
\hline $\begin{array}{l}\text { Special } \\
\text { Forces }\end{array}$ & 0 & 2 & 0 & 0 & 0 & 0 \\
\hline Logistics & 1 & 13 & 10 & 2 & 6 & 19 \\
\hline Medical & 0.25 & 17 & 1 & 1 & 0 & 10 \\
\hline $\begin{array}{l}\text { Military } \\
\text { Police }\end{array}$ & 0.5 & 1 & 0 & .25 & 0 & 9 \\
\hline Engineers & 0.5 & 7 & 10 & 0 & 3.5 & 12 \\
\hline Signals & 0.5 & 4 & 10 & 0 & 4.25 & 4 \\
\hline Intelligence & 0 & 4 & 1 & 0 & 0 & 6 \\
\hline MEB ${ }^{208}$ & 0 & 0 & 0 & 0 & 0 & 19 \\
\hline $\begin{array}{l}\text { Total Units } \\
\text { Combat/Css }\end{array}$ & $29 / 2.75$ & $28 / 46$ & $84.75 / 32$ & $4.25 / 3.25$ & $17 / 13.75$ & $46 / 79$ \\
\hline Ratio & $1: 0.09$ & $1: 1.64$ & $1: 0.38$ & $1: 0.76$ & $1: 0.81$ & $1: 1.72$ \\
\hline
\end{tabular}

What the chart shows is that in the United States and the United Kingdom reserve forces are structured to harness significant amounts of specialist skillsets in fields such as medical, military intelligence, engineering and logistics. This makes sense as it best allows these forces to benefit from the professional experience gained by civilian employment in specialist areas. In the case of Canada, Australia and New Zealand the reserve forces are more combat oriented proportionally, but the specialist fields are still represented by significant combat support units in their force structure. 
In all comparators, the structure of reserve forces does not mirror that of the regular army. Instead their structures reflect what the regular force needs in terms of skills to allow reserve forces to act as force multipliers. For instance, the Americans have more medical, engineering, military intelligence, and logistics units in the reserves than in the regular army. For the British Army, most of their medical establishment is in their Army Reserve, along with almost half of their intelligence and logistics units. Combat forces in regular armies are in a constant cycle of training. However, unless deployed, there is no need to constantly maintain significant numbers of regular logistics, transport or medical units as such units only really come into play in contingencies, or times of war. Therefore, many militaries focus their combat power in their regular forces, and their combat support elements in their reserve forces, to be used when required. Such reserve force structures allow regular standing armies to have more combat power, while leaving the bulk of specialist roles to the reserves. This is efficient as these specialists gain their experience in the civilian setting, in a constant cycle of training one might say, at a lower cost to the military, whilst allowing the regular army to focus training on what armies do best, the employment of combat power.

Given that other reserve forces deploy overseas for combat operations, the force structure of the Irish Army Reserve is difficult to explain. That is, unless one considers what the Single Force Concept did to the Army Reserve. Reservists were essentially superimposed upon, and inserted into, the force structure of the existing regular army, which, like many regular armies, is combat oriented. This goes some way to explaining the ratio of 1:0.09 in combat to combat support units. However, in the previous twinned unit system from 2005 to 2013, where the Army Reserve, almost unit for unit, mirrored the PDF force structure, the ratio was one combat unit for every 0.30 combat support unit. Again, this still makes the Army Reserve of 2005-2013 more combat oriented, proportionally, then the other five reserve forces examined. And again, this is because the Army Reserve during this period reflected the structure of the regular army. But what it also shows is that the Single Force Concept has reduced the capacity for the Defence Forces to harness civilian specialists in the Army Reserve, in line with international best-practice.

When one acknowledges the salary differences between members of the PDF, and civilian professionals, it is likely that skills that are in short supply in the PDF, or are particularly valuable militarily, can readily be found amongst the ranks of the Reserve, where reservists can enjoy a civilian income commensurate to their skills whilst also serving the Defence Forces. Harnessing these skills is best accomplished by not structuring the Reserve along the lines of the PDF. Reserve units should have been established reflecting what the PDF needed, to provide the desired capabilities. Other militaries have learned this lesson with beneficial results. Yet, the Single Force Concept is a leap backwards. The guiding principle behind designing the force structure of the Reserve in the Single Force Concept should not have been a mere repetition of days gone past, nor a reflection of the PDF. It should have been based on the skills and experiential capital the Reserve could provide to the Defence Forces, or what the 
Defence Forces needed. In military parlance, intelligence should drive decision-making. But without a skill survey of any kind, the data did not exist to influence the decisionmaking. In the information age, this data could have easily been obtained, it still can be.

For the reasons mentioned there is a well-grounded argument for changing the force structure of the Army Reserve. Given that there is suboptimal pay for reservists, and insufficient legal enablers, it is perhaps unsurprising that the 2013 reorganisation did not yield anything novel in terms of a revised force structure. Legislation is timeintensive to craft and incentivising skilled professionals to join the Reserve would have had a significant cost. The alternative was to opt for the familiar, which, as the data shows is neither working, nor sustainable.

\section{Financing the Reserve.}

The financial aspect surrounding the Reserve Defence Forces (the combined Army and Naval Service Reserve) was the basis for the 2012 VFM Review. It argued that the cost of the existing Reserve was too high. This largely influenced the downsizing of the force, the main reason the Single Force Concept exists today. However, this report either misrepresented, or misunderstood, the financial costs of maintaining the Reserve. The VFM attributed four main costs to the Reserve Defence Forces; the pay of PDF cadre training personnel, reservists' pay, transport, and ammunition and consumables. ${ }^{209}$ The graph below shows these costs from 2006-2011.

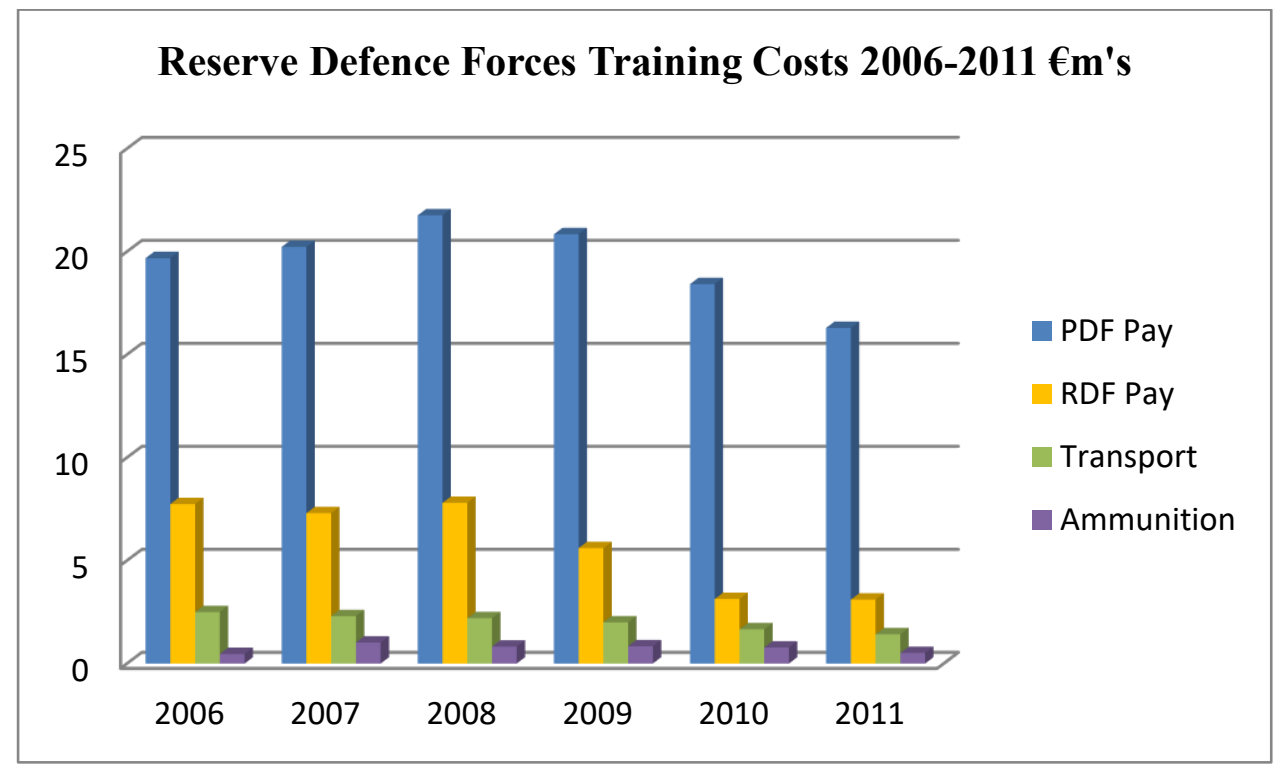

The biggest cost of the Reserve was PDF training personnel. On average the cost of the PDF cadre amounted to 82 percent of the cost of the Reserve from 2006-2009. ${ }^{210}$ The 
transport costs attributed to the training of the reserve was car and mileage allowances paid to PDF cadre personnel. ${ }^{211}$ Therefore, they are not actually training costs, they are incidental costs of the attached PDF personnel. In tangible terms the actual cost of the Reserve was pay, and ammunition consumption. The cost of weaponry was not a factor as there were enough weapons to arm the Reserve from existing stocks. ${ }^{212}$ In the Single Force Concept there has been no requirement to purchase additional weaponry for the now reduced force. The VFM sought to reduce the size of the Reserve in order to make financial savings, especially in terms of the cost of the cadre personnel. In the Single Force Concept the reserve is administered by the PDF staff of the units reservists are integrated into, thus negating the need for the majority of cadre staff. ${ }^{213}$ What is interesting is that in 2012, just prior to the Single Force Concept, the cost of PDF cadre pay was $€ 19$ million. ${ }^{214}$ Despite the VFM justifying the downsizing of the Reserve on the basis of reducing the cadre costs, the 2013 budget for PDF pay increased by $€ 18$ million. ${ }^{215}$ This is because the cadre personnel were, and always had been, serving members of the PDF who simply reverted back to PDF units when the Reserve units were integrated, thus increasing the PDF pay bill. Attributing their salaries to the Reserve was creative accountancy, nothing more.

The increase in PDF pay shows that no fiscal savings were made, contrary to the reasoning of the VFM, and the justification underpinning the 2013 reorganisation. The cost of the Reserve, in terms of pay, has been declining, corresponding with the dwindling effective strength of the force. Reserve pay cost just $€ 1.73$ million in 2015 . ${ }^{216}$ When these pay figures are compared to PDF pay, and indeed the yearly defence budget it becomes clear just how cost neutral the Army Reserve is, as shown in the graph below.

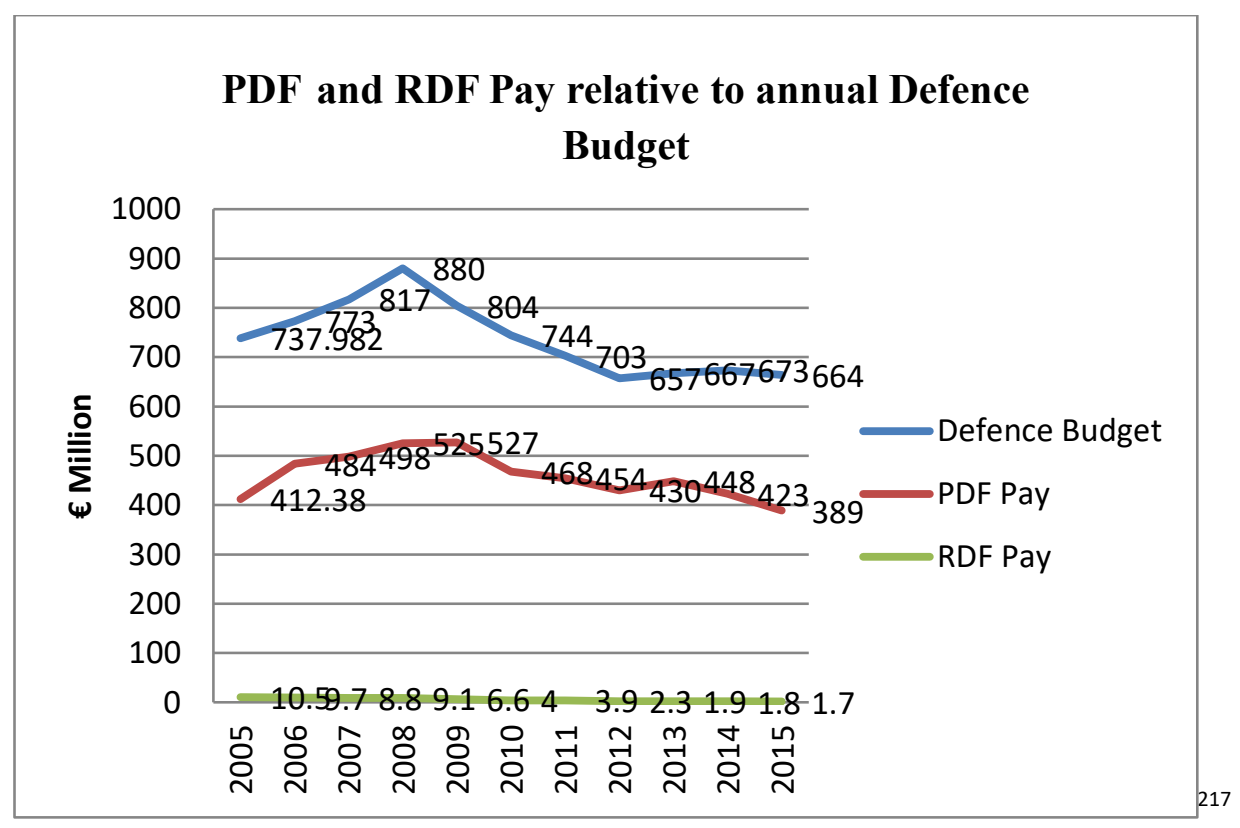

The level of financial investment in the Reserve has been described as "chickenfeed." ${ }^{218}$ In relation to the defence budget, this is hard to dispute. The VFM 
advocated the removal of the annual gratuity payment to reservists in order to use the savings to provide 40,000 paid training days a year for the Reserve. ${ }^{219}$ This was ostensibly to provide continuing amounts of sustainable paid training, starting with 41,500 paid training days in $2013 .{ }^{220}$ However, this guaranteed supply of paid training days was not upheld. In 2014, only 28,000 were budgeted, falling to 26,000 in $2015 .{ }^{221}$ The budget increased to allow for 30,000 in 2016 only due to the Easter Rising Centenary Commemorations. ${ }^{222}$ It was stated that the reallocation of gratuity funds would be enough to provide paid training for a force of $4,000 .{ }^{223}$ But the recruitment levels, discussed previously, make it clear that reaching 4,000 was never an attainable objective. Thus, government policy reduced the amount of remuneration to reservists in order to provide more paid training, which was subsequently reduced because the force could not meet the level of 4,000 , again due to government policy.

In 2009, when recruitment to the Reserve was suspended for economic reasons the Department of Defence handed back €23.4 million in unspent funds. ${ }^{224}$ Which, given the relatively low cost of the Reserve, would have negated the need to suspend recruitment to the Reserve, or the PDF during the economic crisis. The current Army Reserve is a product of economic strife. The same cannot be said of the wider Defence Forces. From 2006-2013 €864 million was spent on new equipment for the Defence Forces. ${ }^{225}$ More equipment was being procured than was being used. ${ }^{226}$ Thus, there was funds to allow even the most marginal investment in the Reserve, but it was evidently not a priority. In 2014, Reserve pay equated to only 75 percent of the annual cost of private cleaners to clean Defence Force buildings. ${ }^{227}$ Similarly, in 2015, Reserve pay almost matched that of the Defence Forces natural gas bill. 228 The 1999 Steering Group Report argued for greater financial investment and remuneration for the Reserve. ${ }^{229}$ Since that time the level of financial investment has plummeted. The gratuity made service for reservists cost neutral, as it offset the individuals travel costs and incentivised attendance at voluntary training and attainment of qualitative training benchmarks. ${ }^{230}$

\section{How much does the Army Reserve cost in the Single Force Concept?}

The following chart shows the actual cost of the Army Reserve, if at full strength of 3,869 , receiving 14, 28 or 42 days paid training relative to the 2015 defence budget. Incorporated into these figures are the cost of food rations, ${ }^{231}$ and a full issue of clothing, costing $€ 155.79$ per reservist. ${ }^{232}$ Webbing, helmets and body armour is not included as there is sufficient stock in the Defence Forces to equip the Reserve, so it is not an attributable cost. ${ }^{233}$ 


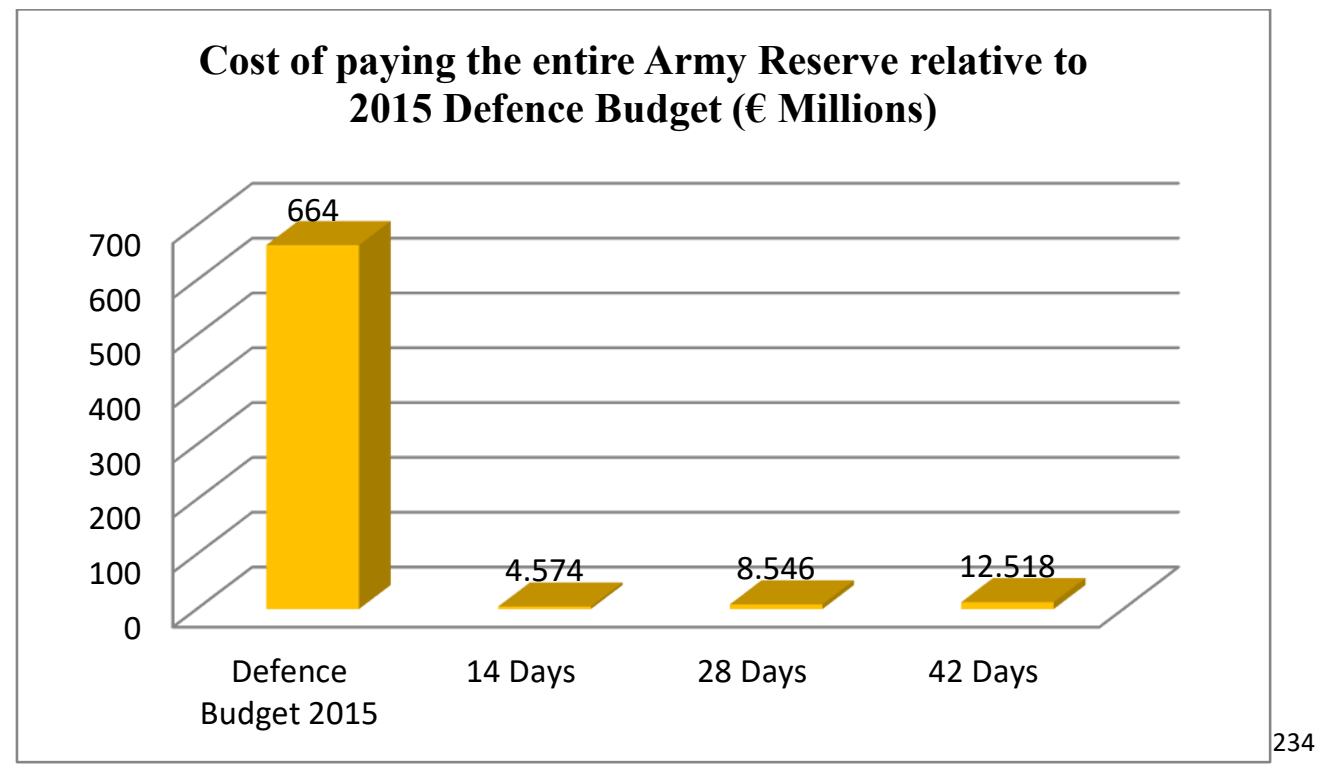

The cost of ammunition is not included as it is difficult to calculate and there is no cost of training as the Army Reserve in the main trains itself. Any PDF training personnel serve in the unit the reservists are integrated into, so not an attributable cost either. What the chart above shows is that paying the Reserve for the relevant periods of time would cost .68, 1.28 and 1.88 percent of the defence budget respectively; a negligible amount.

The relatively insignificant cost of the Reserve implies that the reintroduction of the gratuity would incur a negligible cost, so too would ending "voluntary unpaid training," thus improving commitment and effectiveness. That this has not happened suggests that the emphasis on "voluntary unpaid service" is a method of maintaining a Reserve for the lowest cost possible. An examination of Reserve levels of pay shows that the Single Force Concept does not conceptually extend to equal pay. The Defence Forces states that "members of the Army Reserve Forces are generally paid on the first point of the pay scale for the Permanent Defence Forces," dependent on rank. ${ }^{235}$ However, an examination of the comparative pay scales of the Army Reserve and the PDF shows that reservists are paid, on average, 18 percent less than the PDF first point of the pay scale, as detailed in the following table.

\begin{tabular}{|l|c|c|c|}
\hline \multicolumn{4}{|c|}{ Defence Forces Basic Pay (Weekly) } \\
\hline Rank & $\begin{array}{l}\text { Army Reserve (No } \\
\text { payscales, or MSA) }\end{array}$ & $\begin{array}{l}\text { PDF (First Point on } \\
\text { the Scale, excluding } \\
\text { MSA) }\end{array}$ & $\begin{array}{l}\text { Difference in PDF and } \\
\text { Reserve pay.\% }\end{array}$ \\
\hline Recruit & $€ 334$ & $€ 409$ & $-18 \%$ \\
\hline Private 2-Star & $€ 410$ & $€ 479$ & $-14 \%$ \\
\hline Private 3-Star & $€ 427$ & $€ 496$ & $-20 \%$ \\
\hline Corporal & $€ 512$ & $€ 641$ & $-20 \%$ \\
\hline Sergeant & $€ 561$ & $€ 702$ & $-20 \%$ \\
\hline $\begin{array}{l}\text { Quartermaster } \\
\text { Sergeant (CQMS) }\end{array}$ & $€ 650$ & $€ 809$ & $-20 \%$ \\
\hline
\end{tabular}




\begin{tabular}{|l|c|c|c|}
\hline $\begin{array}{l}\text { Company Sergeant } \\
\text { (CS) }\end{array}$ & $€ 662$ & $€ 824$ & $-20 \%$ \\
\hline Sergeant-Major (BSM) & $€ 739$ & $€ 918$ & $-20 \%$ \\
\hline Second Lieutenant & $€ 722$ & $€ 604$ & $+20 \%$ \\
\hline Lieutenant & $€ 722$ & $€ 701$ & $+2 \%$ \\
\hline Captain & $€ 739$ & $€ 919$ & $-19 \%$ \\
\hline Commandant & $€ 939$ & $€ 1,163$ & $-19 \%$ \\
\hline Lieutenant-Colonel & $€ 1,245$ & $€ 1,410$ & $-11 \%$ \\
\hline
\end{tabular}

It should be noted that, members of the PDF are entitled to a Military Service Allowance (MSA) in addition to basic pay, reservists are not entitled to this. Furthermore, PDF salaries increase with time served, yet Reserve pay remains constant as there are no pay scales for reservists. The disparity in pay originated during the recent economic crisis where public sector employees, including reservists, were forced to take a reduction in pay. PDF remuneration levels were subsequently restored, but this was not the case for the Reserve. The disparity in pay, which has lasted over a decade, was highlighted by the media as contributing to the decline in the numbers of reservists with headlines such as "Reserve Forces owed 'millions of euro'."237

Due to high taxation, a reserve private, when paid, receives just $€ 30$ per day after tax. ${ }^{238}$ With a greater emphasis on "voluntary unpaid training" it has been suggested that there is now no incentive to reserve service other than personnel enjoying it. ${ }^{239}$ Moreover it is argued that unpaid training is unfair, that financial incentive would improve effectiveness and commitment. ${ }^{240}$ This is exemplified by the trend of voluntary attendance going down as the economic situation in Ireland improves. ${ }^{241}$ This suggests that individuals are dedicating their time to pursuits that provides a financial return; their civilian careers. In 2019, Paul Kehoe, Minister of State with responsibility for Defence, argued that the Reserve strength was dwindling because "younger people have more opportunities now than they did 20 or 30 years ago." $242 \mathrm{His}$ assertion ignores the critical factor that many reservists may simply no longer see any opportunity, or benefit, to serving in the Army Reserve.

\section{The Army Reserve 2019: Six Years of the Single Force Concept.}

In January 2019, the "effective" strength of the Army Reserve was 1,620 personnel. ${ }^{243}$ Of this, 313 were recruits or 2 -stars, with another 626 being aged 45 or older. Six years in, most reservists are either inexperienced - relative to other reservists - or aging in military terms. The average age of a Captain or Lieutenant (junior officers) was 50 and 44 years old respectively. In terms of junior non-commissioned officers, the average age of a Sergeant was 49, and a Corporal, 39. ${ }^{244}$ This should be a cause for alarm. In July 2019, the effective strength was just 1,536, despite the 97 recruits from the April recruitment campaign. ${ }^{245}$ This is a record low numerically, proportionally and 
historically. With an establishment of 3,869, the Reserve, in July, stood at 39 percent strength. However, given the flawed definition of an effective reservist, the appreciable strength may be significantly lower in terms of active personnel, perhaps realistically amounting to circa 20-25 percent strength. As the chart below soberingly illustrates, the Army Reserve is now measured in sections instead of platoons, and platoons instead of companies.

\begin{tabular}{|c|c|c|c|}
\hline Unit $^{246}$ & $\begin{array}{c}\text { Reserve } \\
\text { Establishment }\end{array}$ & $\begin{array}{l}\text { Effective Strength } \\
\text { July } 2019 \text { (personnel) }\end{array}$ & $\begin{array}{c}\text { \% of } \\
\text { Establishment }\end{array}$ \\
\hline \multicolumn{4}{|c|}{ Combat Units } \\
\hline $1^{\text {st }}$ Infantry Battalion & 375 & 102 & $27 \%$ \\
\hline $3^{\text {rd }}$ Infantry Battalion & 415 & 160 & $39 \%$ \\
\hline $6^{\text {th }}$ Infantry Battalion & 375 & 131 & $35 \%$ \\
\hline $7^{\text {th }}$ Infantry Battalion & 375 & 214 & $57 \%$ \\
\hline $12^{\text {th }}$ Infantry Battalion & 446 & 176 & $39 \%$ \\
\hline $27^{\text {th }}$ Infantry Battalion & 375 & 133 & $35 \%$ \\
\hline $28^{\text {th }}$ Infantry Battalion & 375 & 115 & $31 \%$ \\
\hline $\begin{array}{l}1^{\text {st }} \text { Mechanised Infantry } \\
\text { Company }\end{array}$ & 68 & 33 & $48.5 \%$ \\
\hline \multicolumn{4}{|c|}{ Combat Support Units } \\
\hline 1 Brigade Cavalry Squadron & 61 & 22 & $36 \%$ \\
\hline 2 Brigade Cavalry Squadron & 61 & 27 & $44 \%$ \\
\hline $1^{\text {st }}$ Armoured Cavalry Squadron & 61 & 34 & $55 \%$ \\
\hline 1 Brigade Artillery Regiment & 188 & 47 & $25 \%$ \\
\hline 2 Brigade Artillery Regiment & 188 & 97 & $51.5 \%$ \\
\hline \multicolumn{4}{|c|}{ Combat Service Support Units } \\
\hline 1 Military Police Company & 29 & 1 & $3 \%$ \\
\hline 2 Military Police Company & 29 & 28 & $96 \%$ \\
\hline 1 Brigade Engineer Group & 34 & 15 & $44 \%$ \\
\hline 2 Brigade Engineer Group & 34 & 24 & $70.5 \%$ \\
\hline 1 Brigade CIS Company & 49 & 22 & $45 \%$ \\
\hline 2 Brigade CIS Company & 49 & 17 & $35 \%$ \\
\hline 1 Central Medical Unit (CMU) & 16 & 3 & $18.75 \%$ \\
\hline 2 Central Medical Unit (CMU) & 16 & 8 & $50 \%$ \\
\hline 1 Brigade Transport Company & 73 & 32 & $44 \%$ \\
\hline 2 Brigade Transport Company & 73 & 36 & $49 \%$ \\
\hline The Military College & 40 & 19 & $47.5 \%$ \\
\hline $\begin{array}{l}\text { Defence Forces Headquarters } \\
\text { (RSS) }\end{array}$ & 30 & 15 & $50 \%$ \\
\hline 1 Brigade Headquarters & 14 & 12 & $86 \%$ \\
\hline 2 Brigade Headquarters & 14 & 13 & $93 \%$ \\
\hline
\end{tabular}

As of July 2019, of twenty-four rifle companies, only seven had enough privates to field an infantry platoon; one company had just five privates on strength. One military 
police unit had an effective strength of just one soldier, while an artillery battery had only three gunners. In 2012, just prior to the Single Force Concept, the average unit effective strength of the Army Reserve was 46 percent. ${ }^{247}$ The above chart shows that it stood at 38 percent in July 2019. The Army Reserve is collapsing, slowly, but assuredly.

In December 2019, the Department of Defence published an update on the status of projects to be implemented as a result of the 2015 White Paper on Defence, the 2019 White Paper Update. In it, it was stated that the development of the Army Reserve in the Single Force Concept was still a priority, exemplified by the recreation of the Director of Reserve, a PDF staff position, and the creation of the Reserve Special Staff (RSS) in Defence Forces Headquarters, staffed by reservists to fill skill gaps in the PDF. ${ }^{248}$ Yet, the July data shows that the RSS, like almost every other unit, was at half strength. The 2015 White Paper created ten projects relating to the Army Reserve. Projects included exploring whether legislation needed reform (it does), further avenues to exploit voluntary unpaid service, a reserve skills survey and holding joint PDF/Reserve exercises. As of December 2019, nine of the projects had "not yet commenced," with another project, the creation of the RSS, on hold pending the completion of a skills survey. ${ }^{249}$ While it is not suggested that projects relating to the Army Reserve should take precedence over those dealing with the PDF, it is clear from the chart above that time for reforming the Army Reserve is fast running out. Once the force collapses, rebuilding it in the future will be exponentially harder then fixing it right now.

\section{Policy Recommendations.}

Change is needed, solutions are clear, though implementation will be complex. Fundamentally, legislative change is required to enable the Reserve to be usable. The optimistic attitude of expecting reservists to turn up without employment protection is a negligent view of security policy, at a minimum. The Army Reserve is trained for conventional military operations with almost no focus on ATCP training, despite the unlikelihood of a conventional military attack on Ireland; an internal security situation or weather-related emergency is much more probable. A realignment is required in the training of the Reserve to make it fit for purpose. Reserve personnel, even in small numbers, should be used in ATCP operations for experiential purposes moving forward and training syllabi should be pragmatic, reducing the dominance of warfare in favour of what will realistically be asked of the Army Reserve. The First Line Reserve should be disbanded. Instead, retiring PDF personnel should serve in the Reserve for a contractual period, thus imparting professional experience to the benefit of the Reserve and the Defence Forces as a whole. As this analysis has shown, the specialist corps have significant potential in terms of viability, and, in the case of the CIS Corps, in contributing significantly to the Defence Forces as a whole. These contributions could be multiplied if legislation and incentivisation is introduced. Nonetheless, a clear argument exists to change the force structure of the Reserve to allow the Defence 
Forces to benefit from civilian professional experience in specialist military roles. Rifle companies should give way to specialist battalions. Having the only realistic output of $89 \%$ of the force being the provision of ATCA is not the most efficient way to operate or maintain a reserve force.

Michael Mulqueen argued that Irish defence and security policy is inherently reactive instead of being proactive. ${ }^{250}$ Therefore, reforming the Army Reserve may only result when an emergency of sufficient magnitude is experienced. Luckily for Ireland, the Troubles in Northern Ireland was an evolving threat, allowing the Defence Forces the time to respond. Similarly, the flooding in $\mathbf{2 0 1 5}$ was a situation where the Reserve was able to provide sufficient personnel. Ireland, thus far, has gotten away with it. That many reservists committed voluntarily to these emergencies out of a sense of duty, and for little reward, has ironically been used to argue that reform, and worse still, rewarding such service, is unnecessary. These instances, instead of providing a glimpse of what if, has resulted in an expectation that voluntary supply will always meet the demand, should the occasion require it. The reality could prove to be a harsh lesson.

\section{Conclusion.}

Has the Single Force Concept resulted in a more viable, fit for purpose, Army Reserve? The answer, unfortunately, yet unsurprisingly, is no. In 1991, John P. Duggan stated that "even the most modest of emergency or contingency planning that required an available reserve could not be implemented." 25129 years later, this statement still rings true. In terms of viability, the Army Reserve is not usable due to lack of legislative supports. PDF unit commanders suggest that progress has been made in terms of interoperability, yet the personnel attrition rate shows that the current Reserve model is neither viable, nor sustainable. Is the Reserve fit for purpose? The ambiguity in the role coupled with the juxtaposed training makes it difficult to identify what the Army Reserve is "fit" for. The Single Force Concept reduced the potential meaningful contributions to the Defence Forces made by reservists in adopting an overwhelmingly combat focused force structure that champions unusable combat units and marginalises specialist skills, whilst the disparity in pay between reservists and members of the PDF has also remained unresolved. Skilled civilian professionals will not bolster the capabilities of the Defence Forces for free, yet 2013 heralded a new focus on voluntary unpaid training.

The Single Force Concept had the potential to fundamentally change the Army Reserve for the better. Yet, in almost every appreciable way, nothing changed; in some ways the situation worsened. Consequently, in the 41 years since the FCA emerged from its period of integration in 1979, almost no element of the conditions of service in the FCA or Army Reserve has changed. For those reservists currently serving in rifle companies in rural outposts, still under the command of a reserve company commander, their current service experience is no different from a member of the 
FCA, except now there is less remuneration but more time commitment. All that has changed, practically speaking, are the uniforms and the weapons. Thus, the Single Force Concept amounted to a rebranding, nothing more. As mentioned, the FCA was integrated into the PDF for twenty years (1959-1979), which ended in failure. Ignoring this precedent, the Single Force Concept has repeated the same mistakes by failing to enact any tangible improvements to support the operation of the Army Reserve. While the FCA had the critical mass to survive twenty years of integration, the current force size and crippling attrition rate means that six years in, the Army Reserve may not survive the Single Force Concept. The Single Force Concept has been a failure, not only because it did not bring any meaningful change, but because, conceptually, it ignored the overwhelming historical evidence that the Irish reserve model was categorically unsuited to anything approaching modern military best practice. It was conceptually ambitious to think that the Single Force Concept would result in anything other than the current situation. Conceptually ambitious, hardly novel, and ultimately failing. 


\section{Annex A: FCA Force Structure 1979-2005}
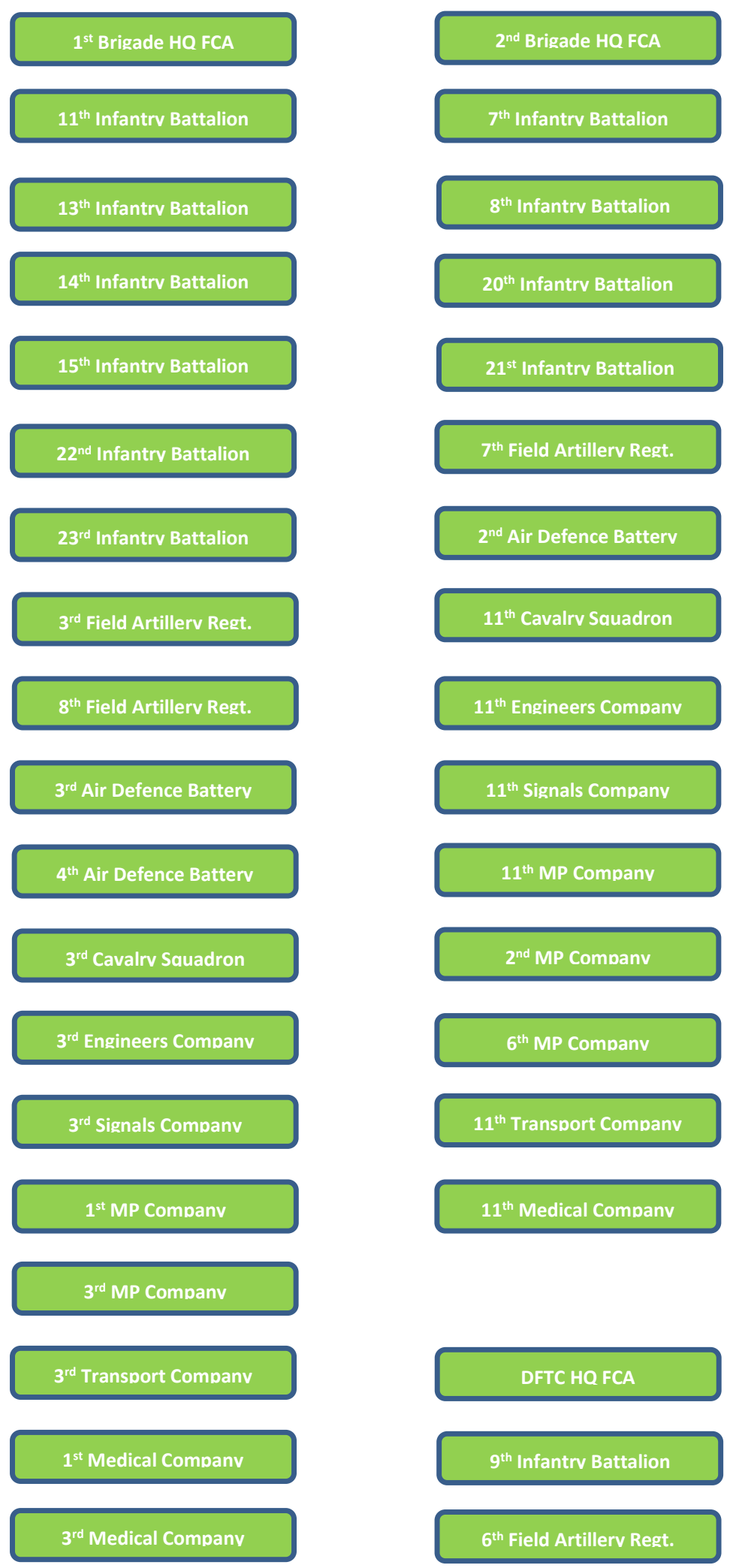

$21^{\text {st }}$ Infantrv Battalion

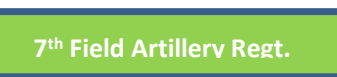

$2^{\text {nd }}$ Air Defence Battery

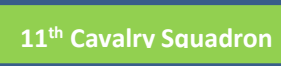

$11^{\text {th }}$ Engineers Companv

$11^{\text {th }}$ Signals Company

$11^{\text {th }}$ MP Company

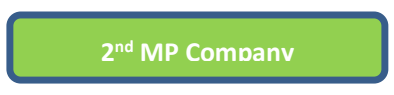

$6^{\text {th }}$ MP Company

$11^{\text {th }}$ Transport Company

$11^{\text {th }}$ Medical Companv 


\section{Annex B: Army Reserve and PDF Force Structure 2005-2012 (The Twinned Unit System) ${ }^{253}$}

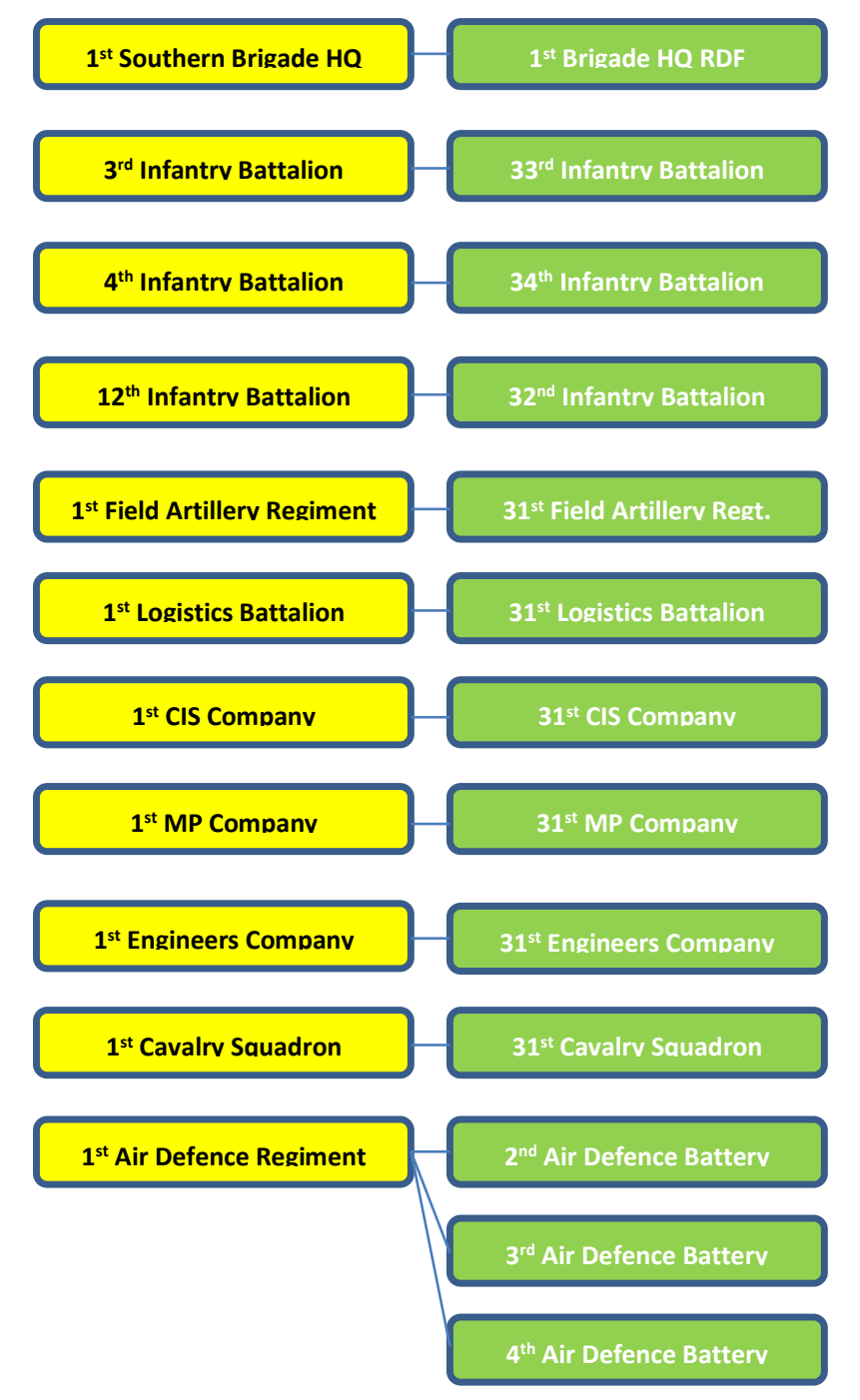

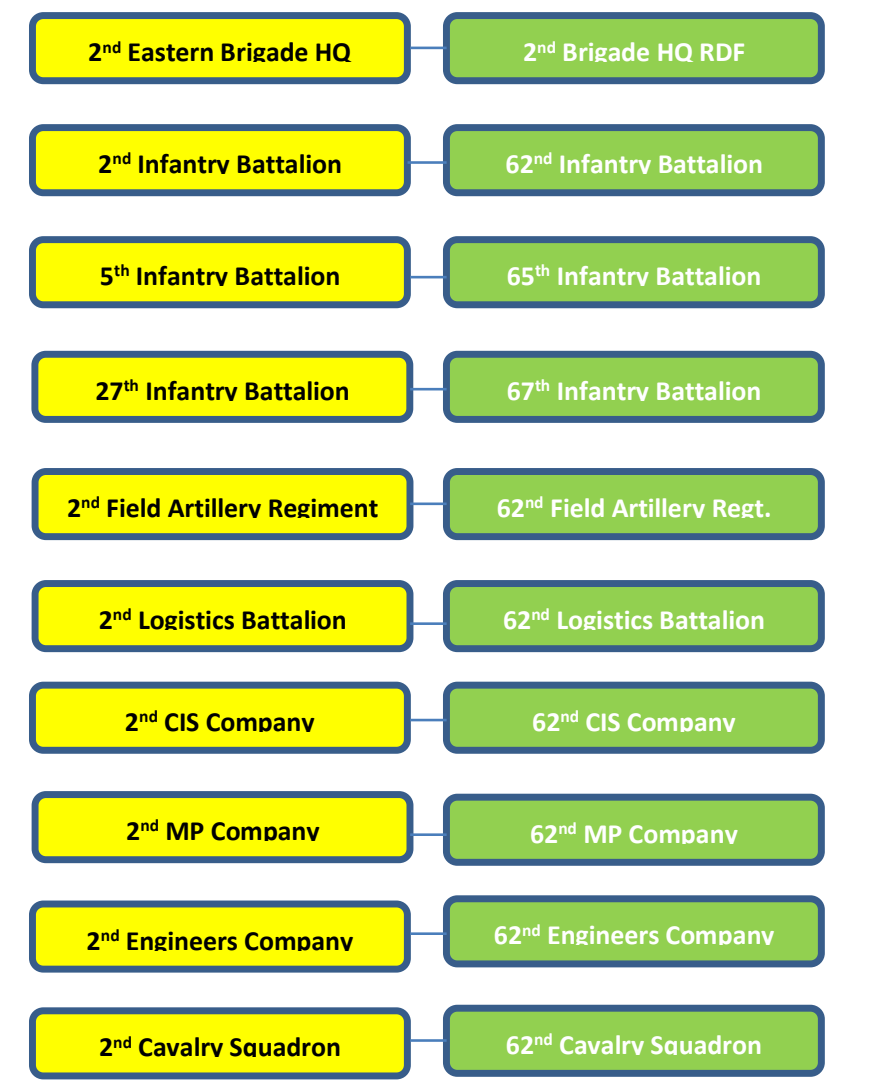

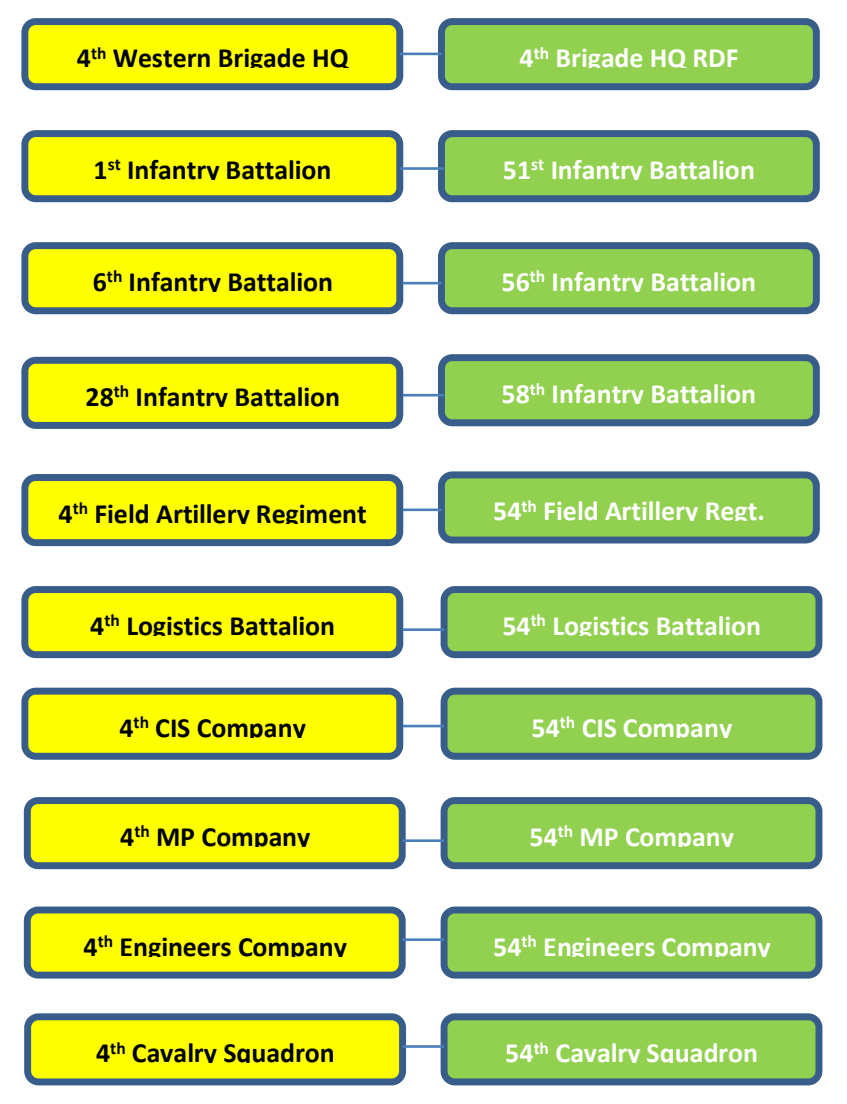

PDF Unit 


\section{Annex C: The Single Force Concept Force Structure 2013 - Present (PDF/Reserve Integration $^{254}$}
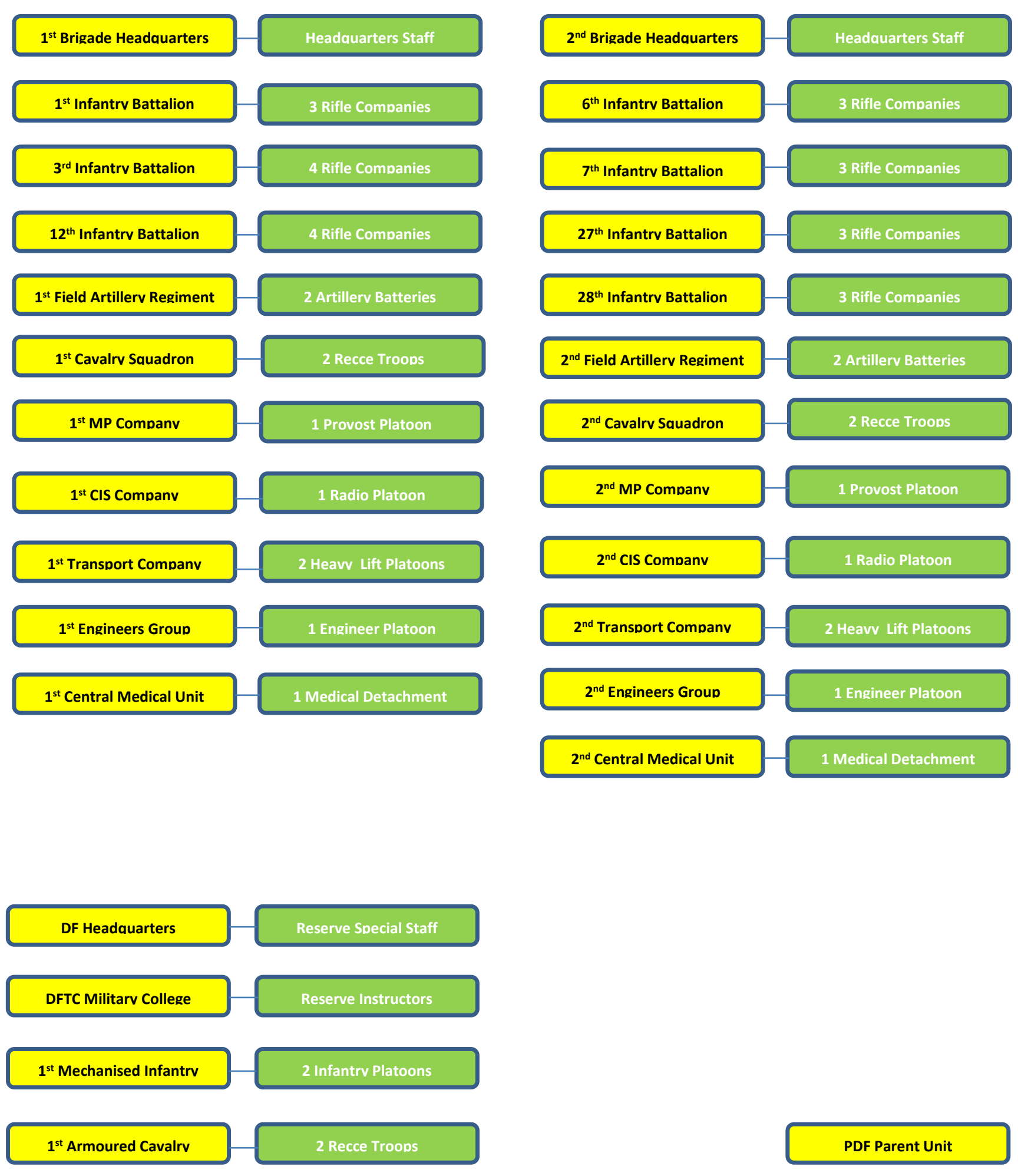

$2^{\text {nd }}$ Central Medical Unit

1 Medical Detachmen 


\section{Annex D: Individual Reserve Units Effective Strength 2006-2019 ${ }^{255}$}

The following series of charts display the effective strength of each reserve unit as a percentage of its authorised establishment from the launch of the Army Reserve in 2005 to July 2019 in the Single Force Concept. Excepting the infantry, each service corps is represented by a chart showing both pre and post Single Force Concept unit strengths. For the infantry, given the number of units, there are separate charts provided for 2006-2012 and for the Single Force Concept to present, respectively. Jumps in effective strength in 2013 are a consequence of the amalgamation of several understrength reserve units in the reduced force structure of the Single Force Concept. For comparative purposes, the personnel value of $1 \%$ strength for each service corps is provided beneath the corresponding charts. Where possible, the authorised numerical strength of each unit is provided in brackets on relevant charts. In the case of the $1^{\text {st }}$ Mechanized Infantry Company, the pronounced spike in effective strength is due to this units' much smaller size in relation to the other infantry units on the same chart.

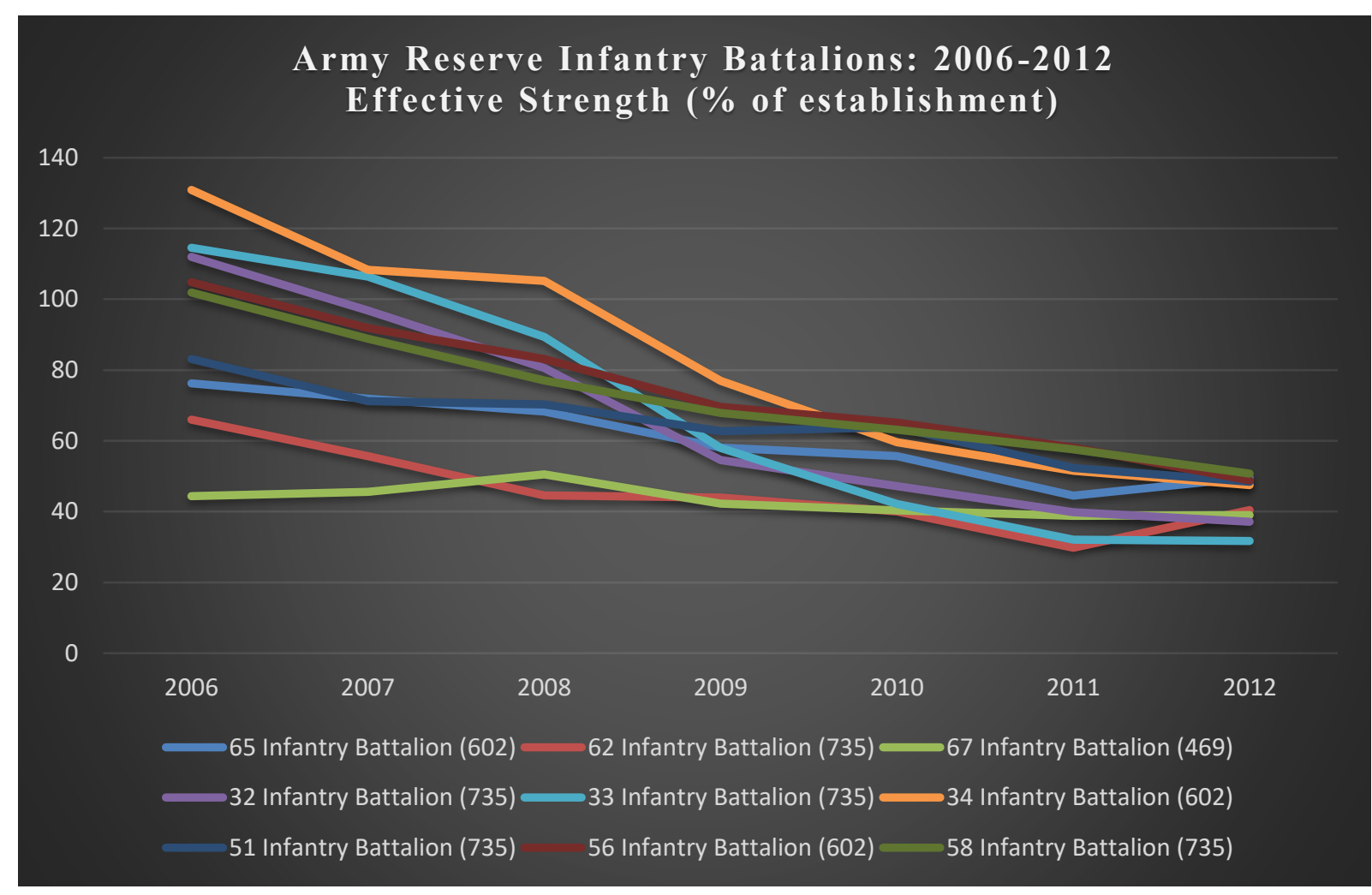

$1 \%$ represents 6.6 personnel. 
Army Reserve Infantry Components: The Single Force

Concept, 2013-2019

Effective Strength ( $\%$ of establishment)

120

100

80

60

40

20

0

2013

2014

2015

2019

1 Infantry Battalion (375)

6 Infantry Battalion (375)

3 Infantry Battalion (415)

12 Infantry Battalion (446)

28 Infantry Battalion (375)

7 Infantry Battalion (375)

27 Infantry Battalion (375)

1 Mechanised Infantry Company (68)

$1 \%$ represents on average 3.5 personnel.

Army Reserve Artillery Units \& Components:2006-2019 Effective Strength ( $\%$ of establishment)

\section{0}

100

80

60

40

20

0
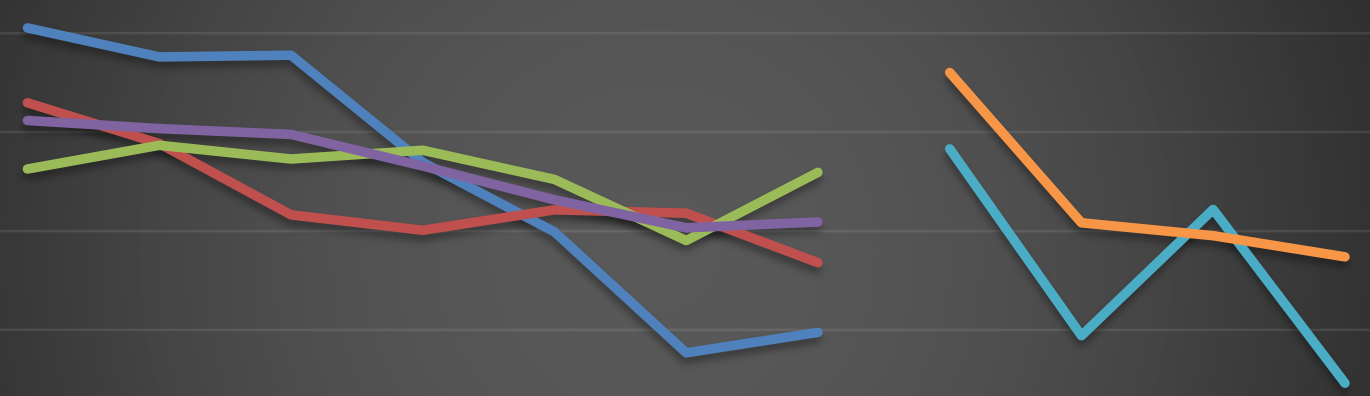

2006

$$
\begin{aligned}
& \begin{array}{llllllll}
2007 & 2008 & 2009 & 2010 & 2011 & 2012 & 2013 & 2014
\end{array} \\
& 54 \text { Artillery Regiment (291) }
\end{aligned}
$$

$1 \%$ represents on average 2.8 personnel from 2006-12 and 3.7 personnel from 2013 onwards. 
Army Reserve Cavalry Units \& Components:2006-2019 Effective Strength ( $\%$ of establishment)

160

140

120

100

80

60

40

20

0

2006

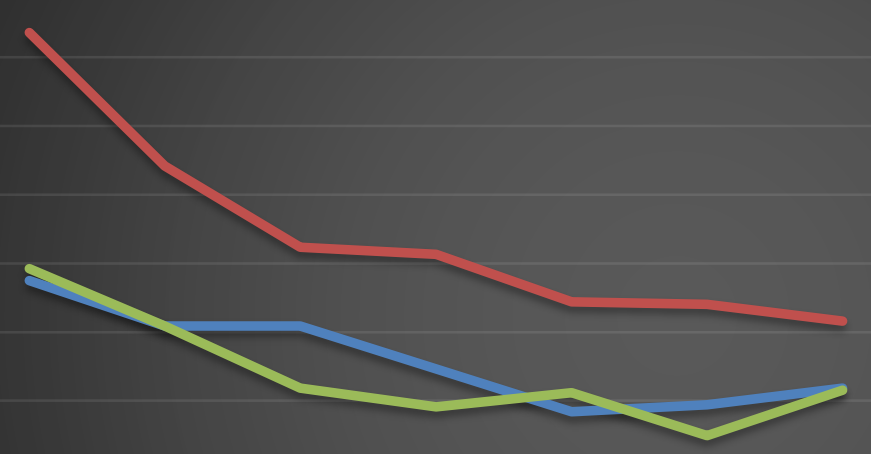

$$
\begin{array}{ccc}
2007 & 2008 & 2009 \\
& 31 \text { Cavalry Squadron (144) } \\
& 62 \text { Cavalry Squadron (144) } \\
& 2 \text { Cavalry Squadron (61) }
\end{array}
$$

$$
\begin{aligned}
& 2011 \quad 2012 \quad 2013 \quad 2014 \\
& 54 \text { Cavalry Squadron (144) } \\
& 1 \text { Cavalry Squadron (61) } \\
& 1 \text { Armoured Cavalry Squadron (61) }
\end{aligned}
$$

$1 \%$ represents 4.3 personnel from 2006-12 and 1.8 personnel from 2013 onwards.

\section{Army Reserve Engineer Units \& Components:2006-2019 Effective Strength ( $\%$ of establishment)}
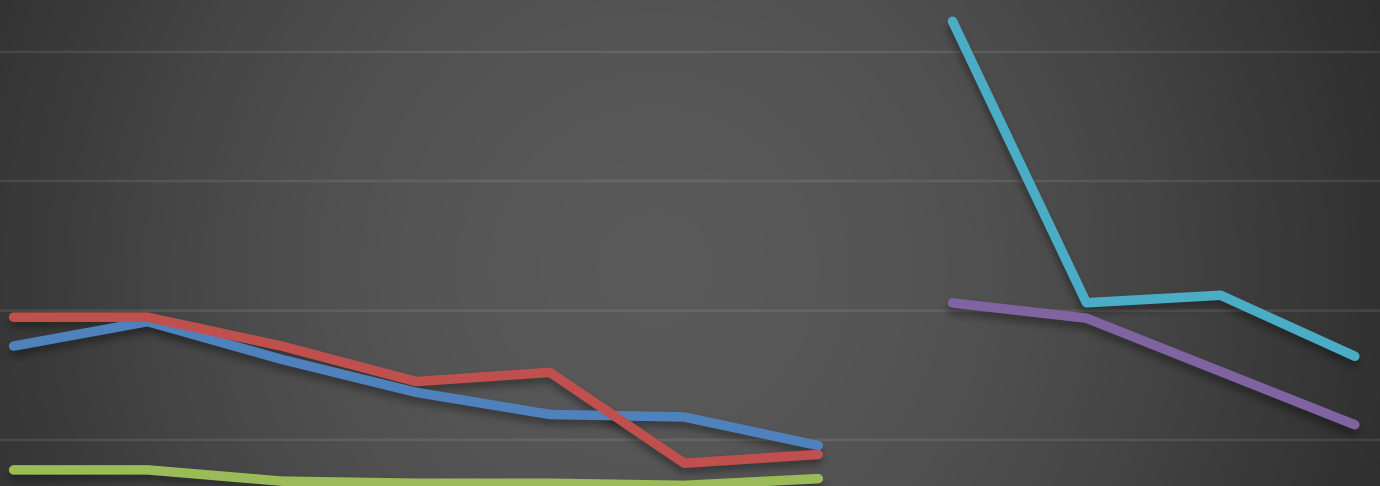

0

31 Engineers Company (117) 54 Engineers Company (117) $\leftrightharpoons 2$ Engineers Company (117)

1 Engineer Group (34) 2 Engineer Group (34)

$1 \%$ represents 1.1 personnel from 2006-12 and 0.6 personnel from 2013 onwards. 


\section{Army Reserve CIS Units \& Components:2006-2019 Effective Strength ( $\%$ of establishment)}

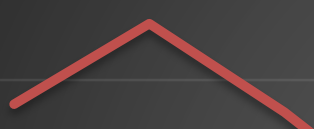

80
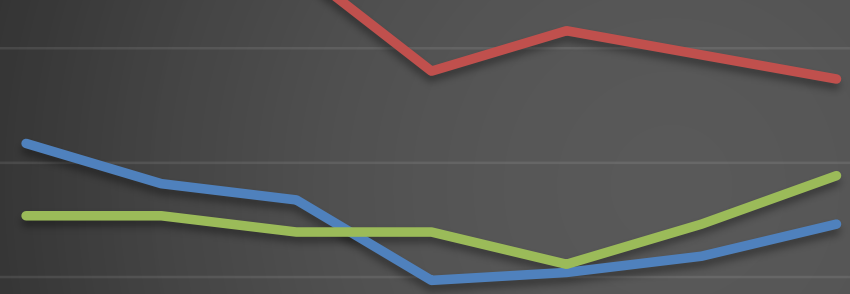

20

0

$\begin{array}{llllllllll}2006 & 2007 & 2008 & 2009 & 2010 & 2011 & 2012 & 2013 & 2014 & 2015\end{array}$

31 CIS Company (71) 54 CIS Company (71) 262 CIS Company (71)

1 CIS Company (49) 2 CIS Company (49)

1\% represents 0.7 personnel from 2006-12 and 0.9 personnel from 2013 onwards.

Army Reserve Military Police Units \& Components:20062019 Effective Strength

( $\%$ of establishment)

200

180

160

140

120

100

80

60

40

20

0

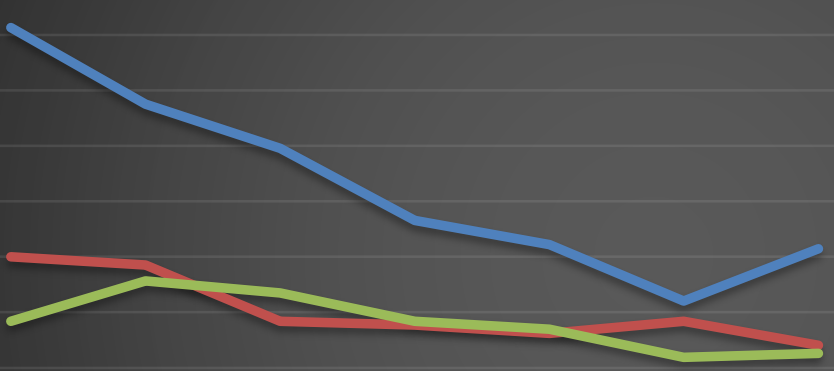

2006

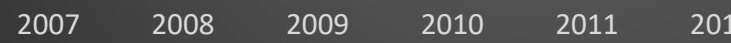

31 MP Company (69)—54 MP Company (69)

1 MP Company (29) 2 MP Company (29)

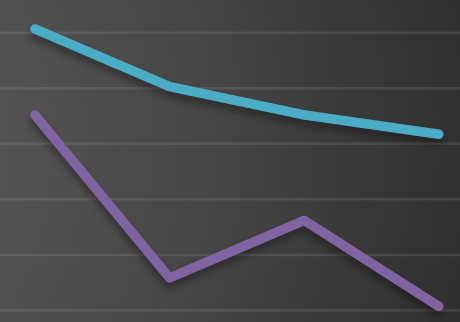

$2013 \quad 2014 \quad 2015$

2019

$1 \%$ represents 0.7 personnel from 2006-12 and 0.3 personnel from 2013 onwards. 
Army Reserve Transport Units \& Components:2010-2019

Effective Strength

(\% of establishment)

120

100

80

60

40

20

0

2010

2011

2012

2013

2014

2015

2019

31 Transport Company

1 Transport Company (73)

54 Transport Company

62 Transport Company

1\% represents 1.09 personnel from 2006-12 and 0.7 personnel from 2013 onwards. ${ }^{256}$

\section{Army Reserve Medical Units \& Components:2010-2019 \\ Effective Strength \\ ( $\%$ of establishment)}

250

200

150

100

50

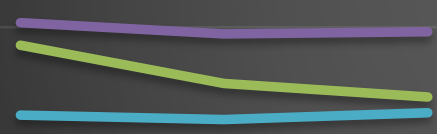

0

2010

2011

2012

2013

2014

2015

2019

$1 \mathrm{CMU}(16)$

31 Medical Company

62 Medical Company 54 Medical Company

$1 \%$ represents 0.78 personnel from $2006-12$ and 0.3 personnel from 2013 onwards. ${ }^{257}$ 


\section{REFERENCES}

${ }^{1}$ Certain issues confronting the Army Reserve in the Single Force Concept discussed in this article, such as legalities and the force structure, were also briefly addressed in Jonathan Carroll, "Relying on the Goodwill of the Individual, and Luck: The Problematic Nature of Utilising the Army Reserve Skills Base in the Single Force Concept" The Defence Forces Review 16 (December 2019): 30-41.

${ }^{2}$ Irish Defence Forces, Administrative Order 01/2013: Implementation of the Defence Forces

Reorganisation Plan Reserve Defence Forces. Defence Forces Administrative Document, 2013.

${ }^{3}$ John P. Duggan, A History of the Irish Army (Dublin: Gill \& MacMillan, 1991), 225.

${ }^{4}$ While the combined services of the Irish Air Corps, the Naval Service and the Army are collectively referred to as the Permanent Defence Forces, this article, for the sake of brevity and to avoid confusion, will hereafter use the term PDF to refer to the regular Irish Army, to avoid confusion by referring variously to both the Irish Army and Irish Army Reserve.

${ }^{5}$ Duggan, A History of the Irish Army, 225.

${ }^{6}$ Ibid, 238.

${ }^{7}$ Adrian J. English, Irish Army Orders of Battle, 1923-2004 (Takoma Park, MD: Tiger Lily Books, 2004), 49-50.

${ }^{8}$ Duggan, A History of the Irish Army, 281.

${ }^{9}$ English, Irish Army Orders of Battle, 54.

${ }^{10} \mathrm{Ibid}, 68$.

11 Terry O’Reilly, “The FCA 1946-2005,” History Ireland 19 (2011), 38.

12 The Defence Act 1954.

${ }^{13}$ Department of Defence, Report of the Steering Group on the Special Study of the Reserve Defence Force (Dublin: Department of Defence, 1999), 24; Dail Eireann 26 Jan.2005, parliamentary debates; official report, vol. dxcvi, 2005 [no.1] (Dublin, Stationary Office).

${ }^{14}$ Report of the Steering Group on the Special Study of the Reserve Defence Force, 1.

15 Ibid.

${ }^{16}$ Ibid, 2.

17 Ibid.

${ }^{18}$ Ibid, 5.

${ }^{19}$ Department of Defence, Defence Forces Annual Report 2004 (Dublin: Defence Forces Printing Press, 2004), 71.

${ }^{20}$ Department of Defence, “Speech by Mr. Willie O’Dea T.D., Minister for Defence at a ceremony to launch the New Reserve Defence Organisation, Sarsfield Barracks, Limerick, 1 October 2005," accessed 23 February, 2016,

https://www.gov.ie/en/publications/?term=FCA\&type=speeches\&organisation=department-of-defence.

${ }^{21}$ Irish Defence Forces, Admin Instruction 02/2006 Procedures for Enlistment into the Integrated

Reserve. Defence Forces Administrative Document, 2006; Commandant F (PDF), interviewed by author, February 2016; Captain P (PDF), interviewed by author, February 2016.

${ }^{22}$ Irish Defence Forces, Personnel Management System (PMS) Reports on Effective Strength on 31

December 2010-2015. Electronic Data, Supplied by the Defence Forces, January 2016.

${ }^{23}$ Irish Defence Forces, Administrative Order 01/2013.

${ }^{24}$ Lt. Col. B (PDF), interviewed by author, January 2016.

${ }^{25}$ The Defence Act 1954, s.87 and s.90.

${ }^{26}$ The Defence Act 1954, s.118 and s.243; Lt. Col. B (PDF), interviewed by author, January 2016.

${ }^{27}$ Report of the Steering Group on the Special Study of the Reserve Defence Force, 5.

${ }^{28}$ Department of Defence, Reserve Defence Forces Employers Information Booklet (Dublin: Department of Defence, 2016).

${ }^{29}$ Lt. Col. C (PDF), interviewed by author, January 2016.

${ }^{30}$ Main Political Party T.D. H, interviewed by author, April 2016.

${ }^{31}$ Main Political Party T.D. H, interviewed by author, April 2016.

${ }^{32}$ Reserve personnel from 1st, 6th and 12th Infantry Battalions, along with elements of 1st Brigade Transport Company were utilised in flood relief efforts in 2015. General Secretary RDFRA, interviewed by author, May 2016.

${ }^{33}$ Lt. Col. B (PDF), interviewed by author, January 2016. 
${ }^{34}$ Department of Defence, White Paper on Defence 2015 (Dublin: Department of Defence, 2015), 100; Report of the Steering Group on the Special Study of the Reserve Defence Force, 1.

35 The Defence (Amendment) Act 1960, the Defence (Amendment) Act 1993 and the Defence (Amendment) Act 2006 which legislate for the participation of Defence Forces personnel in UN peacekeeping missions, peace-enforcement missions and EU Battlegroups respectively all specifically state that such service is for members of the "Permanent Defence Forces," not reservists.

${ }^{36}$ Irish Defence Forces, TS RDF INF XX/2009 RDF overseas integration course syllabus of training (Dublin: Defence Forces Training and Education Directorate, 2009); Directorate of Reserve Forces, Letter seeking expressions of interest for overseas service. Letter. 2 Sep. 2008, supplied by RDFRA, January 2016; Reserve Defence Forces Representation Association, Press release pertaining to the cancellation of overseas service for the RDF. Letter. Undated, 2009, supplied by RDFRA, January 2016.

${ }^{37}$ Commandant D (PDF), interviewed by author, January 2016; Lt. Col. B (PDF), interviewed by author, January 2016.

${ }^{38}$ The United States Army reserve component is a combination of the Army National Guard, which focuses primarily on providing Brigade Combat Teams (BCT's) and some combat support units, and the United States Army Reserve which primarily focuses on Combat Service Support units.

${ }^{39}$ The relevant legislation is as follows, The Defence Act 1990 (New Zealand), The National Defence Act 1985 (Canada), The Reserve Forces Act (UK), The Defence Reserve (Protection) Act 2001 (Australia) and the Uniformed Services Employment and Reemployment Rights Act 1994 (United States, applying equally to the Army National Guard and the Army Reserve).

${ }^{40}$ All pieces of legislation noted above dictate custodial penalties relevant to that country's military or civil law.

${ }^{41}$ Ministry of Defence, Rates of Pay 2015 (London: Ministry of Defence, 2015). Ministry of Defence, Reserves in the Future Force 2020: Valuable and Valued (London: Ministry of Defence, 2011), 8.

${ }^{42}$ White Paper on Defence 2015, 95.

${ }^{43}$ Ibid, 96

44 Ibid, 30

${ }^{45}$ Department of Defence, Defence Forces Annual Report 2002 (Dublin: Defence Forces Printing Press, 2002), 5.

${ }^{46}$ Colonel N (PDF), interviewed by author, January 2016.

47 Ibid.

${ }^{48}$ Ibid.

49 The Potential NCO Course, the Standard NCO Course, the Senior NCO Course, the Potential Officer Course, the Young Officer Course, and the Standard Officer Course, all of which focus overwhelmingly on conventional military operations.

${ }^{50}$ White Paper on Defence 2015, 96; Irish Defence Forces, The Single Force Concept Discussion.

Meeting Minutes. Undated 2014, supplied by RDFRA, January 2016, 8.

${ }^{51}$ General Secretary RDFRA, interviewed by author, May 2016.

${ }^{52}$ Reserve personnel from $1^{\text {st }}, 6^{\text {th }}$ and $12^{\text {th }}$ Infantry Battalions along with elements of $1^{\text {st }}$ Brigade Transport Company were utilised in flood relief efforts; General Secretary RDFRA, interviewed by author, May 2016.

53 Ibid.

${ }^{54}$ Lt. Col. C (PDF), interviewed by author, January 2016.

${ }^{55}$ Report of the Steering Group on the Special Study of the Reserve Defence Force, 1.

${ }^{56}$ White Paper on Defence 2015, 59.

${ }^{57}$ Department of Defence, Value for Money Review of the Reserve Defence Forces (Dublin: Department of Defence, 2012), viii.

${ }^{58}$ Colonel N (PDF), interviewed by author, January 2016.

${ }^{59}$ Lt. Col. M (PDF), interviewed by author, April 2016.

${ }^{60}$ Ibid.

${ }^{61}$ Brian Hutton, "Ireland has 208 border crossings, officials from North and South agree," The Irish Times, accessed 27 October, 2019, https://www.irishtimes.com/news/ireland/irish-news/ireland-has-208border-crossings-officials-from-north-and-south-agree-1.3474246; The Belfast Telegraph, "Revealed: Number of border crossings between Northern Ireland and Republic," accessed 27 October, 2019, https://www.belfasttelegraph.co.uk/news/northern-ireland/revealed-number-of-border-crossings-betweennorthern-ireland-and-republic-36850570.html. 
${ }^{62}$ Joint Committee on Justice, Defence and Equality 4 Nov. 2015, committee debates; 2015 (Dublin, Stationary Office).

${ }^{63}$ English, Irish Army Orders of Battle, 57.

${ }^{64}$ This resulted in the formation of the $27^{\text {th }}, 28^{\text {th }}$ and $29^{\text {th }}$ PDF Infantry Battalions; Duggan, A history of the Irish Army, p.281.

${ }^{65}$ Lt. Col. C (PDF), interviewed by author, January 2016.

${ }^{66}$ Value for Money Review of the Reserve Defence Forces, 8.

${ }^{67}$ Irish Defence Forces, End of year personnel strength report 1970-2015.

${ }^{68}$ Ibid.

${ }^{69}$ Department of Defence, White Paper on Defence Update 2019 (Dublin: Department of Defence, 2019), 47.

${ }^{70}$ Joint Committee on Justice, Defence and Equality 24 Apr. 2013, committee debates; 2013 (Dublin, Stationary Office).

${ }^{71}$ Irish Defence Forces, Defence Force Regulation CS4: Numerical Establishment of the Defence Forces. Defence Forces Administrative Document, 2013.

${ }^{72}$ Defence Force Regulation CS4.

${ }^{73}$ Irish Defence Forces, TS RDF INF 16/2014 Reserve Defence Forces All-Arms Recruit Course (Dublin: Defence Forces Training and Education Directorate, 2014); Irish Defence Forces, TS RDF 23/2007 Reserve Defence Forces 2-3 Star Course (Dublin: Defence Forces Training and Education Directorate, 2007).

${ }^{74}$ It takes 29 full weeks to train a PDF recruit up to 3-Star Private. Conversely, for a reservist to reach the same rank the Recruit and 3 Star courses are two full time weeks in length with several weekends respectively; Irish Defence Forces, TS RDF INF 16/2014 Reserve Defence Forces All-Arms Recruit Course; Irish Defence Forces, TS RDF 23/2007 Reserve Defence Forces 2-3 Star Course; Value for Money Review of the Reserve Defence Forces, 52.

${ }^{75}$ Value for Money Review of the Reserve Defence Forces, 52.

${ }^{76}$ Lt. Col. C (PDF), interviewed by author, January 2016.

${ }^{77}$ Ibid.

${ }^{78}$ Ibid.

${ }^{79}$ Ibid.

${ }^{80}$ Ibid.

${ }^{81}$ Ibid.

${ }^{82}$ Commandant K (PDF), interviewed by author, March 2016.

${ }^{83}$ Ibid.

${ }^{84}$ Colonel N (PDF), interviewed by author, January 2016; Commandant K (PDF), interviewed by author, March 2016; Commandant F (PDF), interviewed by author, February 2016; Lt. Col. M (PDF), interviewed by author, April 2016.

${ }^{85}$ Commandant F (PDF), interviewed by author, February 2016.

${ }^{86}$ Courses such as the $105 \mathrm{~mm}$ Light Gun Course and the Artillery Gun Detachment Commanders Course mean that reserve and regular personnel are both equally qualified and interoperable in an artillery role due to its tangible metric of skills. Commandant K (PDF), interviewed by author, March 2016.

${ }^{87}$ Commandant K (PDF), interviewed by author, March 2016; Commandant F (PDF), interviewed by author, February 2016.

${ }^{88}$ Lt. Col. M (PDF), interviewed by author, April 2016. Anecdotally, prior to the 2013 reorganisation, the commanding officer of $1^{\text {st }}$ Air Defence Regiment, an integrated unit made up of one regular battery and three reserve batteries, claimed that No.4 Battery (Reserve) was the most proficient battery in the Regiment; Commandant K (PDF), interviewed by author, March 2016.

${ }^{89}$ Commandant K (PDF), interviewed by author, March 2016.

90 Ibid.

${ }^{91}$ Defence Force Regulation CS4.

${ }^{92}$ Commandant D (PDF), interviewed by author, January 2016.

${ }^{93}$ Ibid.

${ }^{94}$ Ibid.

${ }^{95}$ The Introduction to Basic Reconnaissance Techniques Course is the base level cavalry course for reserve personnel. The Combat Tracking Course and vehicle gunnery courses are currently under review to establish modularised equivalents that reserve personnel can complete. Irish Defence Forces, TS RDF 
76/2010 Introduction to basic reconnaissance techniques course (Dublin, 2010); Commandant D (PDF), interviewed by author, January 2016.

96 Ibid.

${ }^{97}$ This is a departure from the independent reserve cavalry squadrons from 2005 to 2013 which had their own Panhard AML 60/90 armoured cars with reservists qualified to drive and act as gunners;

Commandant D (PDF), interviewed by author, January 2016.

${ }^{98}$ Ibid.

${ }^{99}$ Ibid.

${ }^{100}$ Irish Defence Forces, TI 03/2011 Defence Forces Driver Training Policy (Dublin: Defence Forces Training and Education Directorate, 2011).

${ }^{101}$ Commandant D (PDF), interviewed by author, January 2016.

102 Commandant G (AR), interviewed by author, January 2016.

${ }^{103}$ Commandant D (PDF), interviewed by author, January 2016.

${ }^{104}$ Commandant G (AR), interviewed by author, January 2016.

${ }^{105}$ Commandant E (PDF), interviewed by author, January 2016.

106 Ibid.

107 Ibid.

108 Ibid.

109 This is interesting as the PDF Military Probationer Course, the entry level course for Military Police personnel, is six months long, compared to the equivalent reserve course lasting just two weeks and several weekends. Obviously while the key tenets of military law enforcement are imparted there would still be a disparity in experience and practical application of military law enforcement; Commandant $\mathrm{E}$ (PDF), interviewed by author, January 2016.

${ }^{110}$ Commandant A (PDF), interviewed by author, January 2016.

111 Ibid.

112 Ibid.

113 Ibid.

114 Ibid.

${ }^{115}$ Colonel N (PDF), interviewed by author, January 2016.

${ }^{116}$ The reserve CIS contingent amounts to 98 personnel at full strength in two radio platoons. Defence Force Regulation CS4.

117 The issue of harnessing reservists professional skills in the Defence Forces is also discussed in Jonathan Carroll, "Relying on the goodwill of the individual, and luck: The problematic nature of utilising the Army Reserve skills base in the Single Force Concept" The Defence Forces Review 16 (December 2019): 30-41.

${ }^{118}$ Commandant A (PDF), interviewed by author, January 2016; Commandant Q (AR), interviewed by author, December 2019.

${ }^{119}$ Sean Murphy, "The Role of Reservists in Developing and Enhancing Technological Solutions through the Application of their knowledge and skills gained in the Private /Commercial/Voluntary/Public Sectors. " Unpublished submission to The Defence Forces Review 16, (December, 2019), supplied by author.

${ }^{120}$ Sean Murphy, "The Role of Reservists in Developing and Enhancing Technological Solutions through the Application of their knowledge and skills gained in the Private /Commercial/Voluntary/Public Sectors," unpublished submission to The Defence Forces Review 2019, supplied by author.

${ }^{121}$ Commandant Q (AR), interviewed by author, December 2019.

${ }^{122}$ Defence Force Regulation CS4.

${ }^{123}$ Lt. Col. J (PDF), interviewed by author, January 2016.

${ }^{124}$ Ibid.

125 Ibid.

126 Ibid.

${ }^{127}$ Lt. Col. J (PDF), interviewed by author, January 2016.

${ }^{128}$ Captain P (PDF), interviewed by author, February 2016.

${ }^{129}$ Ibid.

${ }^{130}$ Ibid.

${ }^{131}$ Ibid.

132 Ibid.

${ }^{133}$ Ibid. 


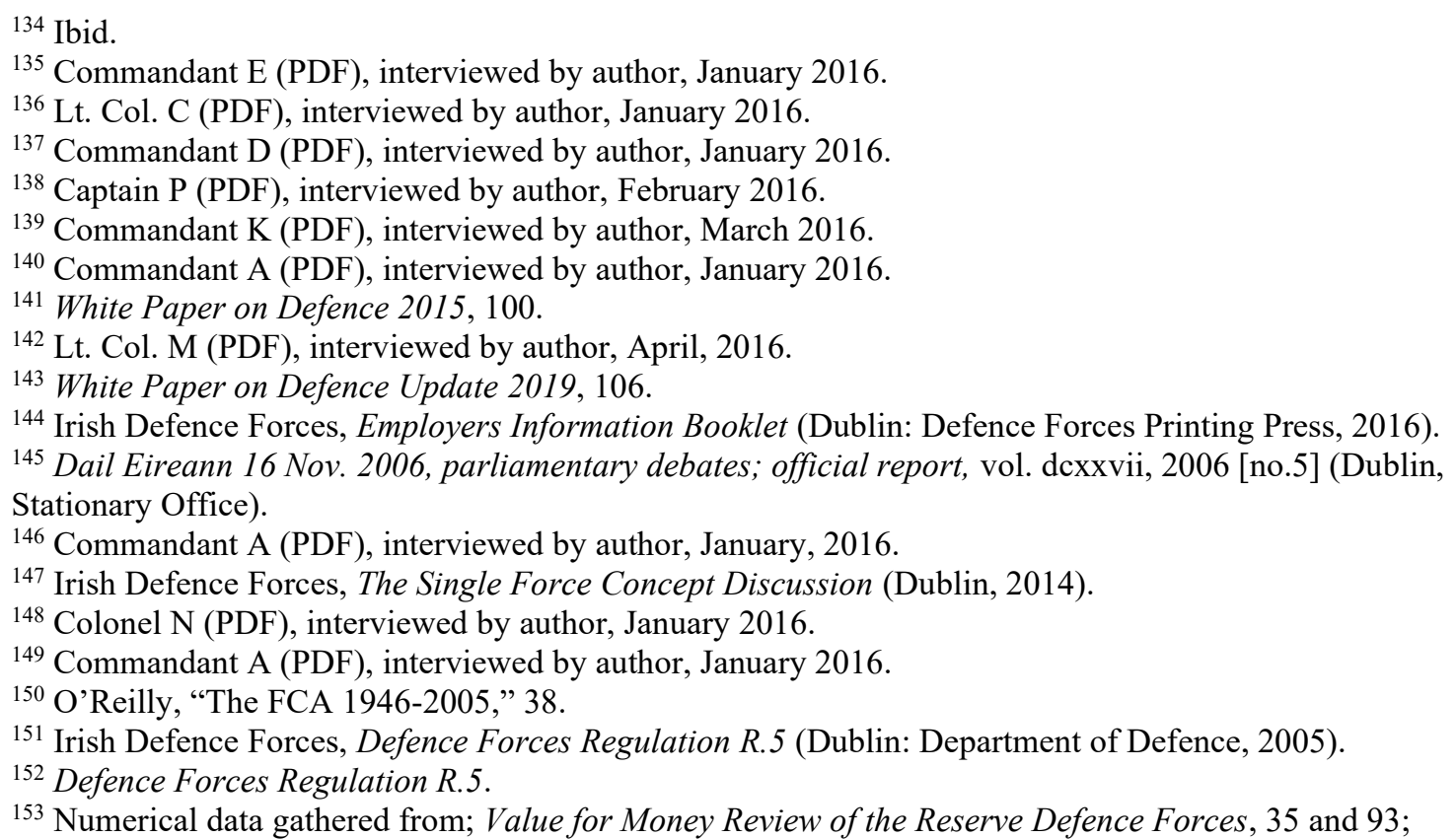

${ }^{153}$ Numerical data gathered from; Value for Money Review of the Reserve Defence Forces, 35 and 93; Department of Defence, Defence Forces Annual Report 2012 (Dublin: Defence Forces Printing Press, 2012), 13; Department of Defence, Defence Forces Annual Report 2014 (Dublin: Defence Forces Printing Press, 2014), 19; Irish Defence Forces, Personnel Management System (PMS) Reports on Effective Strength on 31 December 2010-2015. Electronic Data, Supplied by the Defence Forces, January 2016.

${ }_{154}$ Numerical data gathered from; Value for Money Review of the Reserve Defence Forces, 43; Defence Forces Annual Report 2012, 23; Department of Defence, Defence Forces Annual Report 2013 (Dublin: Defence Forces Printing Press, 2013), p.26; Dail Eireann 13 Oct. 2009, parliamentary debates; official report, vol. dcxci, 2009 [no.3] (Dublin, Stationary Office); General Secretary RDFRA, interviewed by author, May 2016.

${ }^{155}$ Department of Defence, White Paper on Defence (Dublin: Department of Defence, 2000), 52.

156 Value for Money Review of the Reserve Defence Forces, 96.

157 Defence Forces Regulation R.5.

${ }_{158}$ Numerical data gathered from; Value for Money Review of the Reserve Defence Forces, 47; Dail Eireann 13 Oct. 2009, parliamentary debates; official report, vol. dcxci, 2009 [no.3] (Dublin, Stationary Office); Dail Eireann 17 Dec. 2009, parliamentary debates; official report, vol. dcxcviii, 2009 [no.5] (Dublin, Stationary Office); Dail Eireann 7 May 2013, parliamentary debates; official report, unrevised, 2013 (Dublin, Stationary Office).

${ }^{159}$ Numerical data gathered from; Defence Forces Annual Report 2013, 26; Defence Forces Annual Report 2014, 19; Personnel Management System (PMS) Reports on Effective Strength on 31 December 2010-2015; General Secretary RDFRA, interviewed by author, May 2016; Commandant F (PDF), interviewed by author, February 2016.

${ }^{160}$ Administrative Order 01/2013.

${ }^{161}$ Commandant E (PDF), interviewed by author, January 2016.

162 Administrative Order 01/2013.

${ }^{163}$ Numerical data gathered from: Irish Defence Forces, Personnel Management System Reports on Annual Medical Attainment 2013-2015. Electronic Data, Supplied by the Defence Forces, January 2016; Irish Defence Forces, Personnel Management System Reports on Annual APWT Attainment 2013-2015. Electronic Data, Supplied by the Defence Forces, January 2016.; Irish Defence Forces, Personnel Management System Reports on Annual IT Attainment 2013-2015. Electronic Data, Supplied by the Defence Forces, January 2016.

${ }^{164}$ Commandant F (PDF), interviewed by author, February 2016.

${ }^{165}$ Commandant A (PDF), interviewed by author, January 2016.

${ }^{166}$ White Paper on Defence 2015, 99.

167 Value for Money Review of the Reserve Defence Forces, v.

${ }^{168}$ Irish Defence Forces, Personnel Management System Reports on Annual Discharges 2005-2015.

Electronic Data, Supplied by the Defence Forces, January 2016. 
${ }^{169}$ Personnel Management System Reports on Annual Discharges 2005-2015; Irish Defence Forces, Personnel Management System Reports on Annual Enlistments 2005-2015. Electronic Data, Supplied by the Defence Forces, January 2016.

170 Personnel Management System Reports on Annual Discharges 2005-2015; Personnel Management System Reports on Annual Enlistments 2005-2015.

${ }^{171}$ Value for Money Review of the Reserve Defence Forces, 40.

172 Report of the Steering Group on the Special Study of the Reserve Defence Force, 24; Dail Eireann 2 Mar. 1999, parliamentary debates; official report, vol. di, 1999 [no.3] (Dublin, Stationary Office).

${ }^{173}$ Report of the Steering Group on the Special Study of the Reserve Defence Force, 18 and 24;

Department of Defence, Defence Forces Annual Report 2009 (Dublin: Defence Forces Printing Press, 2009), 16

${ }^{174}$ Commandant G (AR), interviewed by author, January 2016.

175 Value for Money Review of the Reserve Defence Forces, 40.

${ }^{176}$ General Secretary RDFRA, interviewed by author, May 2016.

177 Ibid.

178 Ibid.

${ }^{179}$ Ibid.

${ }^{180}$ Ibid.

${ }^{181}$ Houses of the Oireachtas, "Defence Forces Reserve Strength, Dáil Éireann Debate, Thursday 5

December 2019, accessed 6 December, 2019, https:/www.oireachtas.ie/en/debates/question/2019-12$05 / 49 /$.

182 Joint Committee on Justice, Defence and Equality 4 Nov. 2015, committee debates; 2015 (Dublin, Stationary Office).

${ }^{183}$ Dail Eireann 26 Feb. 1981, parliamentary debates; official report, vol. cccxxvii, 2009 [no.3] (Dublin, Stationary Office).

${ }^{184}$ Dail Eireann 26 Nov. 2009, parliamentary debates; official report, vol. dexcvi, 2009 [no.2] (Dublin, Stationary Office).

185 Administrative Order 01/2013.

${ }^{186}$ Lt. Col. C (PDF), interviewed by author, January 2016.

${ }^{187}$ Colonel N (PDF), interviewed by author, January 2016.

${ }^{188}$ Commandant F (PDF), interviewed by author, February 2016.

189 Commandant L (PDF), interviewed by author, March 2016.

190 Joint Committee on Justice, Defence and Equality 24 Apr. 2013, committee debates; 2013 (Dublin, Stationary Office).

${ }^{191}$ White Paper on Defence 2015, 97.

${ }^{192}$ Ministry of Defence, Reserves in the Future Force 2020 (London: Ministry of Defence, 2013), 28.

193 Personnel Management System Reports on Annual Discharges 2005-2015.

${ }^{194}$ Personnel Management System Data records that in the 2005-2015 period the reserve infantry component recruited 4,346 new recruits but discharged 10,725 personnel.

195 Captain P (PDF), interviewed by author, February 2016.

${ }^{196}$ PA Consulting Group, Defence Forces Medical Services Review (Dublin: PA Consulting Group, 2009), 40-46 and 97; Commandant G (AR), interviewed by author, January 2016.

197 The $62^{\text {nd }}, 54^{\text {th }}$ and $31^{\text {st }}$ Reserve Logistics Support Battalions headquartered in Dublin, Galway and Cork had a medical company within each battalion.

${ }^{198}$ General Secretary RDFRA, interviewed by author, June 2019.

${ }^{199}$ Numerical gathered from: Value for Money Review of the Reserve Defence Forces, 93; Personnel Management System (PMS) Reports on Effective Strength on 31 December 2010-2015; General Secretary RDFRA, interviewed by author, May 2016. Also, prior to the Single Force Concept, Medical and Transport units were grouped together into Logistics Support Battalions. Separate data on these specific companies during this time period are unavailable, as such the figures for both from 2006 to 2012 reflect the battalion effective strength instead of the separate companies.

${ }^{200}$ Commandant F (PDF), interviewed by author, March 2016.

${ }^{201}$ Lt. Col. J (PDF), interviewed by author, January 2016.

${ }^{202}$ Lt. Col. C (PDF), interviewed by author, January 2016; Commandant E (PDF), interviewed by author, January 2016.

${ }^{203}$ Commandant K (PDF), interviewed by author, March 2016. 
${ }^{204}$ Department of Defence, Department of Defence and Defence Forces Strategy Statement 2003-2005 (Dublin: Department of Defence, 2003), 10.

${ }^{205}$ General Secretary RDFRA, interviewed by author, June 2019.

206 The United States Army reserves are a combination of the Army National Guard, which focuses primarily on providing combat units in the form of Brigade Combat Teams with some Combat Service Support units and the United States Army Reserve which primarily focuses on Combat Service Support. In this table the figures provided are a combination of both forces. Interestingly the National Guard and Army Reserve contain the majority of the US Army’s medical, engineering, logistics and military intelligence units in terms of brigade equivalents.

${ }^{207}$ For the purposes of this table "Combat" units encompass infantry, cavalry and armoured units.

208 The Maneuver Enhancement Brigade (MEB) is a uniquely American formation designed as a Combat Service Support Brigade encompassing various supporting units such as Civil Affairs and Military Police. ${ }^{209}$ Value for Money Review of the Reserve Defence Forces, 29 and 33.

${ }^{210}$ Joint Committee on Justice, Defence and Equality 24 Apr. 2013, committee debates; 2013 (Dublin, Stationary Office).

${ }^{211}$ Dail Eireann 19 Oct. 2010, parliamentary debates; official report, vol. dccxix, 2010 [no.1] (Dublin, Stationary Office).

212 Defence Forces Annual Report 2002, 57; Defence Forces Annual Report 2005, 22.

${ }^{213}$ Administrative Order 01/2013.

${ }^{214}$ Dail Eireann 17 May 2012, parliamentary debates; official report, vol. dccxlv, 2012 [no.5] (Dublin, Stationary Office).

${ }^{215}$ Defence Forces Annual Report 2013, 55.

${ }^{216}$ Department of Public Expenditure, "Public expenditure databank," accessed 29 February 2016, http://databank.per.gov.ie/Expenditure.aspx?rep=GrossVA.

${ }^{217}$ Numerical data gathered from: Defence Forces Annual Report 2005, 65; Defence Forces Annual Report 2006, 86; Defence Forces Annual Report 2007, 72; Defence Forces Annual Report 2008, 61; Defence Forces Annual Report 2009, 63; Defence Forces Annual Report 2010, 53; Defence Forces Annual Report 2011, 49; Defence Forces Annual Report 2012, 48; Defence Forces Annual Report 2013, 55; Defence Forces Annual Report 2014, 51; Department of Public Expenditure, "Public expenditure databank," accessed 29 February 2016, http://databank.per.gov.ie/Expenditure.aspx?rep=GrossVA.

${ }^{218}$ Commandant F (PDF), interviewed by author, March 2016.

${ }^{219}$ Value for Money Review of the Reserve Defence Forces, 86.

${ }^{220}$ Dail Eireann 7 May 2013, parliamentary debates; official report, unrevised, 2013 (Dublin, Stationary Office).

${ }^{221}$ General Secretary RDFRA, interviewed by author, May 2016.

222 Ibid.

${ }^{223}$ Value for Money Review of the Reserve Defence Forces, 86.

${ }^{224}$ Dail Eireann 25 May 2010, parliamentary debates; official report, vol. dccx, 2010 [no.1] (Dublin, Stationary Office).

${ }^{225}$ Department of Defence, Review of inventory management in the Defence Forces (Dublin: Department of Defence, 2013), 8.

226 Ibid, 4.

227 Department of Defence, Purchase orders $€ 20,000$ or above for Department of Defence and the Defence Forces (2014).

228 Ibid.

${ }^{229}$ Report of the Steering Group on the Special Study of the Reserve Defence Force, 1.

${ }^{230}$ Joint Committee on Justice, Defence and Equality 4 Nov. 2015, committee debates; 2015 (Dublin, Stationary Office).

${ }^{231}$ A daily food ration is $€ 4.20$ per soldier per day; General Secretary RDFRA, interviewed by author, May 2016.

232 Irish Defence Forces, "itemised clothing prices."

${ }^{233}$ In 2013 there were sufficient stocks of webbing, body armour and helmets for the entire Defence Forces valued at $€ 5.1$ million, $€ 1.05$ million and $€ 779,000$ respectively; Review of Inventory Management in the Defence Forces, p.80.

234 "Reserve Defence Forces, Rates of Pay," Irish Defence Forces, accessed January 12, 2016, http://www.military.ie/careers/reserve/join-the-reserve/rates-of-pay/; Irish Defence Forces, "itemised clothing prices." 
235 “Reserve Defence Forces, Rates of Pay,” Irish Defence Forces, accessed December 17, 2019, https://www.military.ie/en/careers/reserve-defence-forces/rates-of-pay/.

236 "Reserve Defence Forces, Rates of Pay," Irish Defence Forces, accessed December 17, 2019, https://www.military.ie/en/careers/reserve-defence-forces/rates-of-pay/; "Rates of Pay for Enlisted Personnel of the Permanent Defence Force, Rate W.E.F. 01 September 2019” Irish Defence Forces, Last Modified October 15, 2019, accessed December 17, 2019, https:/www.gov.ie/en/collection/65e6ecroutinely-published-information/; "Rates of Pay and Allowances for Officers of the Permanent Defence Force, With Effect From 1st September 2019” Irish Defence Forces, Last Modified October 15, 2019 , accessed December 17, 2019, https://www.gov.ie/en/collection/65e6ec-routinely-published-information/. ${ }^{237}$ Sean O'Riordan, "Reserve Forces owed 'millions of euro'," The Irish Examiner, accessed December 17, 2019, https:/www.irishexaminer.com/breakingnews/ireland/reserve-forces-owed-millions-of-euro934365.html.

${ }^{238}$ Commandant G (AR), interviewed by author, January 2016.

${ }^{239}$ Commandant A (PDF), interviewed by author, January 2016

${ }^{240}$ Commandant K (PDF), interviewed by author, March 2016.

${ }^{241}$ Commandant A (PDF), interviewed by author, January 2016.

${ }^{242}$ White Paper on Defence Update 2019, 98.

${ }^{243}$ General Secretary RDFRA, interviewed by author, June 14, 2019.

244 Ibid.

${ }^{245}$ General Secretary RDFRA, interviewed by author, December 6, 2019.

${ }^{246}$ Raw data supplied by General Secretary RDFRA, interviewed by author, December 6, 2019. Statistical analysis completed by author.

247 Personnel Management System (PMS) Reports on Effective Strength on 31 December 2010-2015.

248 White Paper on Defence Update 2019, 47 and 55.

${ }^{249}$ Ibid, 106-107.

${ }^{250}$ Michael Mulqueen, Re-evaluating Irish National Security Policy: Affordable Threats? (Manchester: Manchester University Press, 2009), 97.

${ }^{251}$ Duggan, A History of the Irish Army, 292.

252 Defence Forces Annual Report 2002, 71.

${ }^{253}$ Defence Forces Annual Report 2004, 63.

${ }^{254}$ Administrative Order 01/2013.

${ }^{255}$ Value for Money Review of the Reserve Defence Forces, 93; Personnel Management System (PMS) Reports on Effective Strength on 31 December 2010-2015.

${ }^{256}$ Prior to the Single Force Concept, the data on the Medical and Transport Companies was collated as total figures for the Logistics Support Battalions, as such specific data on these companies is only available from 2010 onwards. 